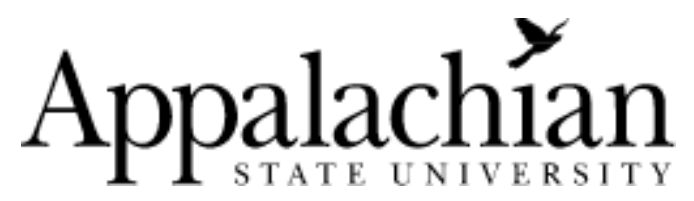

Department of Economics Working Paper

Number 11-10 | September 2011

Three New Empirical Tests of the

Pollution Haven Hypothesis When

Environmental Regulation is Endogenous

Daniel L. Millimet

Southern Methodist University \& IZA

Jayjit Roy

Appalachian State University 


\title{
Three New Empirical Tests of the Pollution Haven Hypothesis When Environmental Regulation is Endogenous
}

\author{
Daniel L. Millimet* \\ Southern Methodist University \& IZA \\ Jayjit Roy \\ Appalachian State University
}

August 4, 2011

\begin{abstract}
The validity of existing empirical tests of the Pollution Haven Hypothesis (PHH) is constantly under scrutiny due to two shortcomings. First, the issues of unobserved heterogeneity and measurement error in environmental regulation are typically ignored due to the lack of a credible, traditional instrumental variable. Second, while the recent literature has emphasized the importance of geographic spillovers in determining the location choice of foreign investment, such spatial effects have yet to be adequately incorporated into empirical tests of the PHH. As a result, the impact of environmental regulations on trade patterns and the location decisions of multinational enterprises remains unclear. In this paper, we circumvent the lack of a traditional instrument within a model incorporating geographic spillovers utilizing three novel identification strategies. Using state-level panel data on inbound U.S. FDI, relative abatement costs, and other determinants of FDI, we consistently find (i) evidence of environmental regulation being endogenous, (ii) a negative impact of own environmental regulation on inbound FDI in pollution-intensive sectors, particularly when measured by employment, and (iii) larger effects of environmental regulation once endogeneity is addressed. Neighboring environmental regulation is not found to be an important determinant of FDI.
\end{abstract}

JEL: C31, F21, Q52

Keywords: Foreign Direct Investment, Environmental Regulation, Spillovers, Instrumental Variables, Control Function, Heteroskedasticity

${ }^{*}$ The authors are grateful to Arik Levinson for providing the data, and comments from Arik Levinson, Arthur Lewbel, Frank Vella, Per Fredriksson and seminar participants at SMU and Tulane University, and conference participants at Texas Camp Econometrics XVI, the 2010 Southern Economic Association Meetings, and the 2011 Western Economic Association Meetings. Corresponding author: Daniel Millimet, Department of Economics, Box 0496, Southern Methodist University, Dallas, TX 75275-0496. Tel: (214) 768-3269. Fax: (214) 768-1821. E-mail: millimet@smu.edu. 


\section{Introduction}

The precise relationship between environmental policy, the location of production, and subsequent trade flows remains an open and hot-button issue. Of particular concern is the so-called Pollution Haven Hypothesis $(\mathrm{PHH})$, whereby a reduction in trade barriers enables polluting multinational enterprises (MNEs) to outsource (at least some) production activities to areas with less stringent environmental regulation, thereby altering both the spatial distribution of economic activity and subsequent trade patterns through the creation of havens for polluting firms. Kellenberg (2009, p. 242) states that "the empirical validity of pollution haven effects continues to be one of the most contentious issues in the debate regarding international trade, foreign investment, and the environment." Brunnermeier and Levinson (2004, p. 6) characterize the debate as "particularly heated."

Proper examination of this relationship is crucial for several reasons. First, understanding determinants of trade patterns and the spatial distribution of MNE activity is imperative in the current economic climate. In particular, given the dramatic rise in foreign direct investment (FDI) relative to trade volumes over the past two decades, understanding the behavior of MNEs is critical. For example, global FDI inflows rose from less than $\$ 600$ billion in 2003 to roughly $\$ 2.1$ trillion in 2007 in nominal terms (UNCTAD 2010). Aggregate inbound FDI stocks rose from $\$ 2.1$ trillion in 1990 to nearly $\$ 18$ trillion in 2009 in nominal terms (UNCTAD 2010). Moreover, the U.S. is the largest recipient of global FDI flows, receiving $\$ 316$ billion in FDI inflows in 2008, roughly $\$ 100$ billion more than the next two largest hosts combined (Belgium and China).

Second, if countries are able to attract (or deter) FDI by manipulating environmental regulations, then international coordination may be necessary to avoid Pareto-inefficient levels of regulation due to transboundary pollutions or other spillovers (e.g., Levinson 1997, 2003). Third, if countries are able to influence the location of MNE activity and ultimately trade patterns through environmental regulation, then bringing environmental policies under the purview of trade agreements may be necessary to realize the intended effects of such agreements. Fourth, and related to this prior point, existing institutional structures such as the World Trade Organization (WTO) may be used to impede countries from choosing their desired environmental policies if such policies can be shown to impact trade flows between members. Finally, a detailed analysis of the PHH has broader implications for the general study of capital competition (e.g., Wilson 1999).

Despite the high stakes, the existing literature has been unable to convincingly assess the empirical validity of the PHH for three reasons. First, environmental regulation is complex and multidimensional, making any empirical measure fraught with measurement error. Shadbegian and Wolverton (2010, p. 13) 
state: "Measuring the level of environmental stringency in any meaningful way is quite difficult, whether at the national, state, or local level." The difficulty arises from the fact that different regulations typically cover different pollutants, regulations may exist at multiple levels (e.g., federal and local), and monitoring and enforcement are imperfect. Along these lines, Levinson (2008, p. 1) states: "The problem is not merely one of collecting the appropriate data; merely conceiving of data that would represent [environmental stringency] is difficult." Xing and Kolstad (2002, p. 3) refer to the measurement of environmental regulation as "no easy task" due to its "complexity." Moreover, depending on the empirical measure employed, the measurement error need not be classical and any bias may be accentuated by the reliance on fixed effects methods in the recent literature.

Second, even if an accurate measure of environmental regulation is available, it may be endogenous for other reasons (e.g., Levinson 2008; Levinson and Taylor 2008). For example, it may be correlated with unobserved determinants of location choice such as tax breaks or other firm-specific treatments, the provision of other public goods in addition to environmental quality (e.g., infrastructure), agglomeration, the stringency of other regulations such as occupational safety standards, corruption, local political activism, political institutions, etc. (see Arauzo-Carod et al. (2010) for a review). In addition, reverse causation may be an issue. For instance, anticipation of low FDI inflows may drive reductions in environmental stringency. Or, an increase in FDI may increase the efficacy of industrial lobby groups (e.g., Cole et al. 2006; Cole and Fredriksson 2009). Conversely, as Keller and Levinson (2002, p. 695) state: "Those states that do not attract a lot of polluting manufacturing probably do not enact stringent regulations - there simply is less need to worry about industrial pollution in states with less industrial activity, and those states that do attract polluting manufacturing may respond by enacting more stringent regulation." Levinson (2010, p. 63) summarizes these arguments succinctly: "International trade has environmental consequences, and environmental policy can have international trade consequences."

Third, existing studies of the PHH inadequately incorporate geographic spillovers. Recent theoretical models emphasize that the extent of MNE activity in one location depends not just on attributes of that location, but also on the attributes of other potential hosts. Moreover, the predicted direction of the crosseffects is not always in the opposite direction of the own-effects, a restriction that is implicit in discrete choice models (e.g., Yeaple 2003; Ekholm et al. 2003; Grossman et al. 2003; Baltagi et al. 2007, 2008; Blonigen et al. 2007, 2008; Arauzo-Carod et al. 2010). Failure to account for geographic spillovers in empirical analyses of PHH may lead to biased inference. This may be particularly problematic in the context of empirical analyses of inbound U.S. FDI since state-level environmental regulations have been shown to be strongly related to the regulatory stringency of neighboring states (Fredriksson and Millimet 2002). 
While these shortcomings, particularly the first and second, are well known, convincing solutions have proven elusive due to the difficulty of finding valid exclusion restrictions. In this paper, we simultaneously address these three shortcomings while examining the spatial distribution of inbound U.S. manufacturing FDI across the 48 contiguous states. Geographic spillovers are incorporated in an unrestricted manner by including a spatially lagged counterpart for each state-level attribute. Measurement error, unobserved heterogeneity, and reverse causation concerns are then addressed utilizing three novel identification strategies designed to circumvent the need to identify valid exclusion restrictions in the usual sense. As each does so under a different set of assumptions, utilizing all three strategies enables us to assess the robustness of the results to the identifying assumptions.

The first method generates instruments utilizing a differencing strategy based on Pitt and Rosenzweig (1990). The key identifying assumptions are that the marginal effects of certain covariates are identical across pollution-intensive and non-pollution-intensive sectors, and these covariates are significantly related to environmental stringency. The second and third methods are based on identification strategies that utilize higher moments of the data. Klein and Vella's (2009, 2010) and Lewbel's (2010) approaches each exploit conditional second moments to circumvent the need for traditional instruments. Identification is achieved in the Klein and Vella $(2009,2010)$ approach by assuming that while the errors are heteroskedastic, the conditional correlation between the errors is constant. In the Lewbel (2010) approach, identification is achieved through the presence of covariates related to the conditional variance of the first-stage errors, but not the conditional covariance between first- and second-stage errors.

In addition to the application, we also undertake a small-scale Monte Carlo study. While the performance of the estimators considered here have been evaluated previously using simulated data, to our knowledge these evaluations have been confined to the case of a single endogenous regressor. Here, we verify that each method extends to the case of multiple endogenous variables (as in our application). We also undertake a so-called empirical Monte Carlo design based on Huber et al. (2010) that simulates placebo values of the endogenous variables within the real data from our analysis.

The results are striking. In terms of the estimation approaches, we indeed verify that all three identification strategies perform well in settings with two endogenous variables. In addition, the performances of the Klein and Vella (2009) and Lewbel (2010) approaches are comparable to the performance of a traditional instrumental variable (IV) estimator when strong, valid exclusion restrictions are available.

In terms of the application, using state-level panel data, we consistently find (i) evidence of environmental regulation being endogenous when examining the behavior of pollution-intensive industries, (ii) a negative impact of own environmental stringency on inbound FDI in pollution-intensive sectors, particularly when measured by employment, and (iii) significantly larger effects of environmental regulation once 
endogeneity is addressed. Neighboring environmental regulation is not an important determinant of FDI (although the estimates are relatively imprecise in the analysis and the empirical Monte Carlo study). However, spillovers from other attributes are present (although not the focus of this study), indicating the importance of incorporating spatial effects more generally in models of FDI determination. Thus, while not homogeneous (as in Henderson and Millimet (2007) and Ederington et al. (2005)), environmental regulation is a significant determinant of location choice by some MNEs at least at the regional level. As such, policymakers should be concerned about the incentives for localities to set regulation at Pareto-inefficient levels and governments to influence trade patterns in highly pollution-intensive industries through the strategic manipulation of environmental policy.

The remainder of the paper is organized as follows. Section 2 presents a brief literature review, concentrating on prior studies attempting to address endogeneity concerns. Section 3 describes the empirical methods, the data, and the results. Finally, Section 4 concludes.

\section{Literature Review}

The literature assessing the empirical validity of the PHH has yet to reach a consensus due to the numerous complexities confronted by researchers. ${ }^{1}$ Levinson (2008) effectively separates the literature into first and second generation studies. The first generation encompasses cross-sectional studies treating environmental regulation as exogenous. These studies typically found no statistically meaningful evidence in support of the PHH (and sometimes found counter-intuitive effects). The second generation predominantly encompasses panel data studies designed to remove unobserved heterogeneity invariant along some dimension (most often time, but occasionally across sectors differentiated by pollution intensity). Panel approaches, however, require environmental regulation to be strictly exogenous conditional on the (typically time invariant) unobserved heterogeneity (and other covariates). A few studies within this second generation have attempted to relax this assumption and utilize traditional IV approaches. These second generation studies typically find economically and statistically significant evidence in support of the PHH.

As mentioned, it is unlikely that existing panel studies are sufficient to yield unbiased estimates of the impact of environmental regulation on the location of economic activity and/or subsequent trade patterns. The omission of third-country effects, the omission of variables that vary over time or differentially affect pollution-intensive and non-pollution-intensive sectors such as tax breaks and agglomeration effects, measurement error in proxies for environmental regulation, and dependence between current environmental regulation and past (or current) shocks to economic activity point strongly to violations of strict exogeneity

\footnotetext{
${ }^{1}$ See Jaffe et al. (1995), Copeland and Taylor (2004), and Brunnermeier and Levinson (2004) for reviews of the literature.
} 
(e.g., Henderson 1997; List et al. 2003; Cole and Fredriksson 2009).

Recognizing this, several studies test the PHH utilizing traditional exclusion restrictions. These studies are summarized in Table 1. At the risk of over-simplifying the literature, the instruments used generally fall within three categories. The first set includes lagged environmental regulation or lags of other covariates (Cole and Elliott 2005; Jug and Mirza 2005; Ederington and Minier 2003). For such variables to represent valid instruments, the error term should not be serially correlated, which may be particularly unrealistic if measurement error is serially correlated or agglomeration effects are not accurately modeled. Both are distinct possibilities. Serial correlation in measurement error is likely due to the use of the same imperfect proxy over time. Agglomeration effects are not likely to be modeled perfectly given their complex nature due to multiple origins (e.g., domestic versus foreign and within and across industries) and non-linearities (Arauzo-Carod et al. 2010).

The second set includes instruments based on the geographic dispersion of industries (Levinson and Taylor 2008; Cole et al. 2005; Ederington et al. 2004; List et al. 2003). Specifically, the level of pollution emitted by other industries in the locations where a given industry tends to locate is used to generate instruments. For such variables to be valid instruments, the geographic distribution of industries must be exogenous. However, as with the first set of instruments, these instruments are likely to be correlated with the error term if agglomeration effects are not accurately modeled. In fact, the instruments fail the Sargan overidentification test at the $p<0.01$ confidence level in Levinson and Taylor (2008). Similar instruments do fare better in Cole et al. (2005).

The final set of instruments include a variety of contemporaneous, location-specific attributes that are hypothesized to impact environmental regulation but not directly impact firm location decisions or trade patterns. Examples range from economic variables such as attributes of the agricultural sector, per capita income, and public expenditures to demographic variables such as urbanization, infant mortality, population density, and schooling to political economy variables such as corruption, and proxies for industry lobby bargaining power. Kellenberg (2009) also utilizes some spatially lagged covariates as exclusion restrictions. Needless to say, one can plausibly argue in each case that such variables may also directly impact firm location or trade patterns, or be correlated with the error term due to non-classical measurement error or omitted geographic spillovers, agglomeration effects, or other sources of heterogeneity. Brunnermeier and Levinson (2004, p. 37), reviewing the literature at the time, state that "as is always true of instrumental variable analyses, the instruments are open to critique." That said, Kellenberg (2009) is noteworthy as the instruments fare well in terms of the usual specification tests.

Despite the suspect validity of the identification strategies employed in these prior studies, rigorous specification testing is noticeably absent in many. A few discuss the strength of the first-stage relationship 
and/or conduct Hausman-type tests for endogeneity, but most neglect to test or even discuss why the proposed instruments should be exogenous or excluded from the second-stage equation for location choice or trade patterns; Levinson and Taylor (2008) and Kellenberg (2009) are notable exceptions. Nonetheless, these studies nearly universally obtain a more detrimental effect of environmental regulation on the behavior of pollution intensive sectors once endogeneity is (attempted to be) addressed. Given this background, we now turn to our analysis.

\section{Empirical Analysis}

\subsection{Structural Model}

To fix ideas, a typical model used to assess determinants of (continuous) measures of FDI stocks or flows with panel data is a standard two-way fixed effects specification:

$$
\ln \left(F D I_{i t}\right)=\eta_{i}+\lambda_{t}+\sum_{k} \beta_{k} x_{i k t}+\varphi_{i t}
$$

where $F D I$ is some measure of MNE activity in location $i$ and time $t, x_{k}, k=1, \ldots, K$, are time-varying observable attributes of location $i, \eta_{i}$ and $\lambda_{t}$ are location and period fixed effects, respectively, and $\varphi_{i t}$ is the error term. A proxy for environmental regulation is one element in $x$. As is well known, consistent estimates of the parameters in (1) requires $x$ to be strictly exogenous.

As discussed previously, the model in (1) is potentially flawed due to the exclusion of geographic spillovers. The omission of spillovers is one reason why the strict exogeneity assumption may fail in practice. Thus, we begin by augmenting (1) to include spatially lagged counterparts for each covariate:

$$
\ln \left(F D I_{i t}\right)=\eta_{i}+\lambda_{t}+\sum_{k}\left[\beta_{k} x_{i k t}+\delta_{k} \sum_{j \in \Omega} \omega_{i j t} x_{j k t}\right]+\varepsilon_{i t}
$$

where $\varepsilon_{i t} \equiv \varphi_{i t}-\sum_{k} \delta_{k} \sum_{j \in \Omega} \omega_{i j t} x_{j k t}, \omega$ is the weight given by location $i$ to neighbor $j$ in period $t, \Omega$ includes the set of neighbors of location $i$, and $\varepsilon_{i t}$ is the new error term. Even if all elements in the regressors in the augmented model are strictly exogenous, estimation of (2) is nonstandard given the introduction of the weights, $\omega$. To proceed, the weights must be chosen a priori.

As is well known in these types of models, the choice of the weights is ad hoc; thus, the spatially lagged variables are potentially measured with error. Prior to discussing the weighting schemes utilized, two comments are warranted. First, if the weights are mis-specified, this would likely attenuate the estimates of $\delta_{k}$ to zero, as we are essentially looking for evidence of spillovers in the wrong place. Thus, the estimates should be interpreted as lower bounds (in absolute value). However, if we find evidence of geographic 
spillovers, then this is not particularly problematic. Second, as discussed below, since we are treating own and neighboring environmental regulation as endogenous, we are able to recover consistent estimates (under the assumptions of the estimators utilized) of neighboring environmental regulation as long as the signal-noise ratio is not negligible.

That said, we utilize three straightforward weighting schemes. First, we assign a weight of zero to non-contiguous neighbors and equal weights to all contiguous neighbors. In other words, $\sum_{j} \omega_{i j t} x_{j k t}$ simplifies to the mean of $x_{j k t}$ in neighboring states. Second, following Fredriksson and Millimet (2002), we adopt two regional breakdowns for the 48 mainland U.S. states (see Appendix A). The use of regional weights is also motivated by the evidence in Glick and Woodward (1987) that foreign-owned affiliates in manufacturing tend to serve regional markets. For each regional breakdown, $\sum_{j} \omega_{i j t} x_{j k t}$ simplifies to the mean of $x_{j k t}$ in all other neighbors within the same region (again, giving each regional neighbor equal weight). The two regional classifications come from the U.S. Bureau of Economic Analysis (BEA) and Crone (1998/1999). The BEA regional classification system was introduced in the 1950s and has never been amended. While this classification system is widely used by economists in studying regional economic activity, Crone (1998/1999) devised an alternative regional breakdown for U.S. states using cluster analysis to group states according to similarities in economic activity. We refer to these weighting schemes as BEA and Crone regional weights, respectively.

Even with specification of the weights, estimation of (2) is complicated by the fact that own and neighboring environmental regulation are likely correlated with the error term, $\varepsilon$, due to measurement error, spatial error correlation, unobserved heterogeneity, and/or reverse causation. Thus, traditional fixed effects estimates are not likely to yield consistent estimates of $\beta$ and $\delta$. Before discussing our approach to identification, we briefly discuss the structure of the data as this will make the empirical approaches easier to document. We then present each estimation method along with its results.

\subsection{Data}

The data come directly from Keller and Levinson (2002); thus, we provide only limited details. Summary statistics are provided in the Appendix. The data cover the 48 contiguous U.S. states from 1977 - 1994, omitting 1987 due to missing data on abatement costs. The measures of FDI include the value of gross property, plant, and equipment (PP\&E) of foreign-owned affiliates for all manufacturers, as well as just for the chemical sector (1992 - 1994 omitted), and employment at foreign-owned affiliates for all manufacturers, as well as just for the chemical sector $\left(1992-1994\right.$ omitted). ${ }^{2}$ The chemical sector (SIC 28) is

\footnotetext{
${ }^{2}$ For each dependent variable, the sample represents an unbalanced panel where the number of observations for total manufacturing PP\&E (employment) are 811 (814); for chemical sector PP\&E (employment), the sample size is 563 (621).
} 
analyzed in isolation given that FDI in these industries is most likely to be responsive to spatial variation in environmental stringency given the pollution-intensive nature of production (Ederington et al. 2005).

Consistent with figures reported elsewhere, inbound FDI stocks increased tremendously over the sample period. Aggregate manufacturing PP\&E increased over tenfold from 1977 to 1994, from roughly $\$ 20$ million to nearly $\$ 300$ million (in 1982 US\$). An increase of similar proportion occurred in the chemical sector from 1977 to 1991, from roughly $\$ 10$ million to $\$ 90$ million. Employment grew at a slower, but still substantial, rate, increasing from roughly 675,000 to almost 2.3 million in aggregate manufacturing; 190,000 to 500,000 in the chemical sector.

In the theoretical model of inbound FDI presented in Blonigen et al. (2008), determinants of FDI include trade costs, cost and demand shifters, and parent country attributes. Here, total road mileage and state effects capture time-varying and time invariant (e.g., distance to ports) differences in trade costs across states. Population and market proximity (a distance-weighted average of all other states' gross state products) reflect market size and demand shocks. Relative abatement costs (RAC), unemployment rate, unionization rate, average production-worker wages across the state, land prices, energy prices, and tax effort (actual tax revenues divided by those that would be collected by a model tax code, as calculated by the Advisory Commission on Intergovernmental Relations) capture variation in production costs and resource availability. RAC is the proxy for environmental regulation. This measure is attributable to Levinson (2001) and represents the ratio of actual state-level abatement costs to predicted state-level abatement costs, where the predicted value is based on the industrial composition of the state. Consequently, higher values indicate relatively more stringent environmental protection. The index varies over time and across states. Finally, since FDI is aggregated across all countries outside the U.S., time effects capture parent country attributes. All variables are expressed in logarithmic form with the exception of the unemployment and unionization rates. In addition, we form the spatially lagged variables first and then take logs, again with the exception of spatially lagged unemployment and unionization rates.

Prior to continuing, it is important to note that the Spearman rank correlation between RAC and total manufacturing FDI as measured by PP\&E is positive $(\rho=0.11, p=0.003)$; the correlation is even stronger when only considering the chemical sector $(\rho=0.13 ; p=0.001)$. Neither correlation is statistically significant using employment to measure FDI. Moreover, as shown in Keller and Levinson (2002), total manufacturing FDI as measured by employment (and PP\&E) increased by more over the sample period in the 20 states experiencing the largest increase in RAC than in the 20 states experiencing the largest decline in RAC. In addition, Table A1 in the Appendix shows that mean total manufacturing FDI as measured by PP\&E is higher when RAC exceeds one (indicating more stringent environmental regulation), as well as for the chemical and non-chemical sectors considered separately. However, mean total manufacturing 
employment, as well as in the chemical and non-chemical sectors, is lower in states with RAC greater than one. In any event, finding statistical evidence consistent with the PHH, particularly using data on PP\&E, would appear to require the existence of significant selection (on either observed or unobserved variables) into more stringent RAC.

\subsection{Estimation}

\subsubsection{Pitt \& Rosenzweig (1990) Approach}

Model The first identification strategy used to address the potential endogeneity of own and spatially lagged environmental regulation is based on the approach put forth in Pitt and Rosenzweig (1990). Pitt and Rosenzweig (1990) are concerned with the impact of an endogenous household-level variable on children differentiated by gender. Lacking a traditional exclusion restriction, the solution proposed entails examining the differential effect of the endogenous variable on sons versus daughters and generating exclusion restrictions by assuming that some exogenous household-level covariates have identical effects on boys and girls. In our application, we apply this logic to assess the differential effect of own and spatially lagged environmental regulation on two types of FDI: FDI in pollution-intensive and non-pollution-intensive sectors. Valid exclusion restrictions are generated by assuming that some exogenous state-level covariates have equal effects on FDI across these two sectors.

Formally, we re-write the structural model in $(2)$ separately for pollution-intensive $(P)$ manufacturing sectors and non-pollution-intensive $(N P)$ manufacturing sectors:

$$
\begin{array}{r}
\ln \left(F D I_{i t}^{p}\right)=\eta_{i}^{p}+\lambda_{t}^{p}+\sum_{k=1}^{K_{1}}\left[\beta_{1 k}^{p} x_{1 i k t}+\delta_{1 k}^{p} \sum_{j \in \Omega} \omega_{i j t} x_{1 j k t}\right] \\
+\sum_{k=1}^{K_{2}}\left[\beta_{2 k} x_{2 i k t}+\delta_{2 k} \sum_{j \in \Omega} \omega_{i j t} x_{2 j k t}\right]+\varepsilon_{i t}^{p} \\
\ln \left(F D I_{i t}^{n p}\right)=\eta_{i}^{n p}+\lambda_{t}^{n p}+\sum_{k=1}^{K_{1}}\left[\beta_{1 k}^{n p} x_{1 i k t}+\delta_{1 k}^{n p} \sum_{j \in \Omega} \omega_{i j t} x_{1 j k t}\right] \\
+\sum_{k=1}^{K_{2}}\left[\beta_{2 k} x_{2 i k t}+\delta_{2 k} \sum_{j \in \Omega} \omega_{i j t} x_{2 j k t}\right]+\varepsilon_{i t}^{n p}
\end{array}
$$

where $K_{1}+K_{2}=K$. Thus, $x_{1}$ includes a subset of $x$ for which the marginal effects on FDI are allowed to differ depending on the pollution intensity of the industry. The marginal effects of covariates included in $x_{2}$ are assumed to be constant across sectors (and thus lack a $p$ or $n p$ superscript). In the analysis, we take the chemical sector as the pollution-intensive sector and all other manufacturing sectors as the (relatively) non-pollution-intensive sector (e.g., Xing and Kolstad 2002; Wagner and Timmins 2009). While there are 
certainly other data partitions one may try (conditional on data availability), results based on treating only the chemical sector as pollution-intensive should yield evidence of the PHH if it exists.

Subtracting (4) from (3) in each time period yields

$$
\begin{aligned}
\Delta \ln \left(F D I_{i t}\right) & =\Delta \eta_{i}+\Delta \lambda_{t}+\sum_{k=1}^{K_{1}}\left[\Delta \beta_{1 k} x_{1 i k t}+\Delta \delta_{1 k} \sum_{j \in \Omega} \omega_{i j t} x_{1 j k t}\right]+\Delta \varepsilon_{i t} \\
& \equiv \widetilde{\eta}_{i}+\widetilde{\lambda}_{t}+\sum_{k=1}^{K_{1}}\left[\Delta \beta_{1 k} x_{1 i k t}+\Delta \delta_{1 k} \sum_{j \in \Omega} \omega_{i j t} x_{1 j k t}\right]+\Delta \varepsilon_{i t} .
\end{aligned}
$$

In (5) $x_{2 i k t}$ and $\sum_{j \in \Omega} \omega_{i j t} x_{2 j k t}, k=1, \ldots, K_{2}$, are available as exclusion restrictions. ${ }^{3}$

This identification strategy relies on choosing a set of exogenous controls, $x_{2}$, and imposing the restrictions that $\beta_{2}^{p}=\beta_{2}^{n p}=\beta_{2}$. If the restrictions imposed lead to an overidentified model (i.e., there are at least two variables in $x_{2}$ ), then the usual overidentification test constitutes a test of the restrictions imposed. To see this, note that if $\beta_{2 k}$ or $\delta_{2 k}$ does in fact differ across sectors differentiated by pollution intensity, then the error term in (5) will contain terms such as $\Delta \beta_{2 k} x_{2 i k t}$ or $\Delta \delta_{2 k} \sum_{j=1}^{48} \omega_{i j t} x_{2 j k t}$ and the resulting instruments will be correlated with the error.

While this approach aids in the generation of instruments for environmental regulation, it does so at a cost (even if the restrictions are valid). Specifically, the approach only provides consistent estimates of $\Delta \beta_{1}$ and $\Delta \delta_{1}$, not the individual, structural parameters from (4) and (3). Thus, ignoring the case where $\beta_{1}^{n p}$ and $\delta_{1}^{n p}$ equal zero, this approach only identifies the differential effects of the (own and spatially lagged) covariates in $x_{1}$ on inbound FDI in pollution-intensive relative to non-pollution-intensive sectors. While one might be tempted to assume that the parameters in $\beta_{1}^{n p}$ and $\delta_{1}^{n p}$ corresponding to own and spatially lagged environmental regulation are zero, this is unlikely to be the case. On the one hand, our definition of the non-pollution-intensive sector still includes some polluting industries since it aggregates all manufacturing sectors except the chemical sector. On the other hand, when treating environmental regulation as exogenous and ignoring geographic spillovers, Henderson and Millimet (2007) obtain some positive and statistically meaningful nonparametric regression estimates of the association between environmental regulation and inbound U.S. FDI. Similarly, Mulatu et al. (2010) obtain a statistically insignificant, but positive effect of environmental stringency on production shares in the least pollution-intensive sectors. Thus, the magnitudes and even the signs of $\beta_{1}^{n p}$ and $\delta_{1}^{n p}$ are unknown.

\footnotetext{
${ }^{3}$ Note, this approach is similar to the strategy employed in Wagner and Timmins (2009). However, in that study, the authors assume that environmental regulation is exogenous in their analog to the differenced equation given by (5). Thus, their identification strategy requires no location-specific unobservables be correlated with environmental regulation, but differentially associated with investment across sectors by pollution intensity. As shown below, this assumption is rejected in our data.
} 
Results The results are presented in Panels A (PP\&E) and B (employment) in Table 2. The specifications estimated correspond to (5) except that the differenced state fixed effects, $\widetilde{\eta}_{i}$, are replaced with region dummies. Thus, we are assuming that time invariant attributes that differentially affect sectors according to their pollution intensity are constant within regions. Estimation is performed using ordinary least squares (OLS) and limited information maximum likelihood (LIML) which has been shown to perform relatively well in small samples with weaker instruments (e.g., Stock et al. 2002; Flores-Lagunes 2007). The variables in $x_{2}$ include market proximity, population, and tax effort as such variables should be equally relevant to all manufacturing industries. Four specifications are estimated. Specification 1 omits all geographic spillovers. Specifications 2-4 include such spillovers, where Specification 2 uses the contiguous weighting scheme and Specifications 3 and 4 use the BEA and Crone regional weighting schemes, respectively. Finally, note that we only display the point estimates for own and neighboring environmental regulation to conserve space. Full estimation results are available upon request.

Turning to the results, four findings emerge. First, the OLS estimates are negative and statistically significant, as well as significantly larger in magnitude than the estimates reported in Keller and Levinson (2002). This difference follows from a change in the definition of the dependent variable, as well as the fact that the model in (5) eliminates time-varying unobservables that are correlated with both FDI and environmental regulation, but affect FDI equally across sectors (e.g., local macroeconomic shocks or political corruption). In addition, the OLS estimates are fairly stable across the four specifications; neighboring environmental regulation is statistically significant only in Specification 2.

Second, the identification strategy works well as determined by the usual IV specification tests, particularly when using employment to measure FDI. Specifically, we reject the null that the model is underidentified at the $p<0.01$ confidence level in every case using Kleibergen and Paap's (2006) rk statistic, and the Kleibergen and Paap (2006) F-statistic is reasonably large. In addition, we fail to reject the validity of the instruments using Hansen's overidentification test in all cases when using employment to measure FDI, and in Specifications 2 and 3 in Panel A at the $p<0.05$ confidence level. Thus, the Pitt and Rosenzweig (1990) approach fares well in the current application. Third, in both panels, we reject exogeneity of own environmental regulation in Specification 1 and own and neighboring environmental regulation in Specifications 2-4. Thus, strict exogeneity of own and spatially lagged environmental regulation is overwhelmingly rejected.

Finally, the LIML estimates are statistically significant at the $p<0.01$ confidence level using either the traditional approach or the Anderson and Rubin (1949) test robust to weak instruments. Moreover, the point estimates are considerably larger in magnitude than the OLS estimates in absolute value; however, the standard errors are also roughly four to five times larger. Neighboring environmental regulation is 
rarely statistically significant although the estimates are very imprecise.

While the point estimates for own environmental regulation are economically large, and we will return to the issue of precision later, it helps to put the magnitude in context since the dependent variable is now the log difference in pollution-intensive and non-pollution-intensive FDI. For example, consider the results in Panel B, Specification 1. Ohio in 1991 had 17,600 (104,900) workers in foreign-owned affiliates in the chemical sector (all other manufacturing sectors); thus, relative employment in the chemical sector was $16.8 \%$. The value of its RAC index was 0.86 , making it a fairly lax state according to the index. The ceteris paribus effect of Ohio increasing its RAC at the time to match California (1.00) would have been a decline in relative employment in the chemical sector to $10.8 \%$. In contrast, the OLS estimate implies a decline to only $15.4 \%$. What is not known is how much of this change is due to a relative decline in employment in the pollution-intensive sector and how much is due to a relative increase in employment in the non-pollution-intensive sector. As stated previously, Henderson and Millimet (2007) find heterogeneous, and often positive, associations between own environmental regulation and total manufacturing FDI when treating regulation as exogenous.

Before turning to the next identification strategy, we attempt a (partial) falsification test of the Pitt and Rosenzweig (1990) approach in the current context. Specifically, we exclude the food and kindred products industry (SIC 20) from our original definition of the non-pollution-intensive sector (all manufacturing except the chemical industry) and treat this as our pollution-intensive sector. Our new definition of the non-pollution-intensive sector is all manufacturing industries except the chemical sector and the food and kindred products sector. Thus, we are attempting to compare two relatively non-pollution-intensive sectors by (incorrectly) treating the food and kindred products sector as pollution-intensive. As a result, if the identification strategy is valid and food and kindred products really is no more pollution-intensive than the average (non-chemical) manufacturing industry, we would expect to find statistically insignificant effects of own and neighboring environmental regulation.

The results are presented in Table $3{ }^{4}$ Of the eight models estimated using LIML, the instruments pass the overidentification test in five. In these five models, only one of eight coefficient estimates related to own or neighboring environmental regulation is statistically significant at even the $p<0.10$ confidence level. This is only marginally greater than is to be expected by chance. Thus, we interpret this as evidence in favor of the identification strategy.

\footnotetext{
${ }^{4}$ Note, the number of observations differs from Table 2 due missing data on FDI in the food and kindred products sector.
} 


\subsubsection{Lewbel (2010) Approach}

Model The next two identification strategies used to address the potential endogeneity of own and neighboring environmental regulation exploit the conditional second moments of the endogenous variables. Lewbel (2010) complements earlier work by Vella and Verbeek (1997), Lewbel (1997), Rigobon (2003), and Ebbes et al. (2004) and, as in the Pitt and Rosenzweig (1990) approach, generates instruments that are valid under certain assumptions.

To proceed, we re-write the FDI equation given in (2) together with the first-stage specifications for own and neighboring environmental regulation to make matters explicit. The system of equations is

$$
\begin{aligned}
\ln \left(F D I_{i t}\right) & =X_{i t} \Pi+\beta \ln \left(R A C_{i t}\right)+\delta \ln \left(\sum_{j \in \Omega} \omega_{i j t} R A C_{j t}\right)+\varepsilon_{i t} \\
\ln \left(R A C_{i t}\right) & =X_{i t} \Pi_{1}+\zeta_{1 i t} \\
\ln \left(\sum_{j \in \Omega} \omega_{i j t} R A C_{j t}\right) & =X_{i t} \Pi_{2}+\zeta_{2 i t},
\end{aligned}
$$

where $R A C$ is the measure of relative abatement costs, $X$ includes all the other regressors from $x$ in $(2)$ except $R A C$ (i.e., including the spatial terms and the state and time fixed effects), and $\zeta_{1}$ and $\zeta_{2}$ are the error terms in the first-stage equations assumed to be correlated with $\varepsilon$. As stated, the model is not identified since there are no exclusion restrictions in (7) and (8). However, Lewbel (2010) shows that if $\zeta_{1}$ and $\zeta_{2}$ are heteroskedastic and at least a subset of the elements of $X$ are correlated with the error variances but not with the error covariances, then the model is identified.

Formally, the Lewbel (2010) approach entails choosing $z_{r} \subseteq X$ such that

$$
\begin{aligned}
\mathbb{E}\left[z_{r}^{\prime} \zeta_{r}^{2}\right] & \neq 0 \\
\mathbb{E}\left[z_{r}^{\prime} \varepsilon \zeta_{r}\right] & =0
\end{aligned}
$$

for $r=1,2$. If these assumptions are satisfied, then $\widetilde{z}_{r} \equiv\left(z_{r}-\bar{z}\right) \zeta_{r}, r=1,2$, are valid instruments. If the errors contain a common (homoskedastic) factor, along with heteroskedastic idiosyncratic components (where the heteroskedasticity of $\zeta_{r}$ depends on $z_{r}$ ), then these assumptions will be satisfied. Formally, if we can re-write the errors in $(6)-(8)$ as

$$
\begin{aligned}
\varepsilon_{i t} & \equiv \kappa_{i t}+\widetilde{\varepsilon}_{i t} \\
\zeta_{\text {rit }} & \equiv \kappa_{i t}+\widetilde{\zeta}_{\text {rit }}, \quad r=1,2,
\end{aligned}
$$

where $\kappa$ is homoskedastic, $\widetilde{\zeta}_{r}, \quad r=1,2$, is heteroskedastic (with variance depending on $z_{r}$ ), and $\widetilde{\zeta}_{r}$, $r=1,2$, and $\widetilde{\varepsilon}$ are independent of each other and $\kappa$, then (9) and (10) are satisfied. This data-generating 
process (DGP) is plausible if $\kappa$ represents homoskedastic measurement error in environmental stringency, or a composite index of unobserved variables impacting both environmental stringency and FDI (such as those discussed previously) is drawn from an identical distribution across observations. However, the idiosyncratic shocks to environmental stringency may be drawn from different distributions.

In the analysis, we use the Breusch-Pagan test for heteroskedasticity to identify variables significantly related to the first-stage error variances. We include land prices, total road mileage, and market proximity in $z_{1}$; the spatially-lagged counterparts are included in $z_{2}$. The instruments, $\widetilde{z}_{r}$, are then created by replacing $\zeta_{r}$ with its estimate obtained from (consistent) OLS estimates of the first-stage. See Appendix B for further estimation details.

Prior to continuing, it is interesting to note - with further examination - that land prices and total road mileage are associated with a lower variance of $\zeta_{1}$; neighboring land prices and total road mileage (market proximity) are associated with a lower (higher) variance of $\zeta_{2}$. In Keller and Levinson (2002), land prices and total road mileage are negatively associated with FDI inflows, whereas market proximity is positively related. Thus, the pattern of heteroskedasticity is consistent with the notion that states with less favorable attributes for attracting FDI minimize the volatility in another attribute, environmental stringency, that may adversely impact inbound FDI.

Results The results are presented in Tables 4 and 5, where the different panels and specifications are identical to Tables 2 and 3. Table 4 contains the results for the chemical sector only; Table 5 assesses total manufacturing. In the tables, the OLS estimates are presented for comparison, where the Specification 1 results are identical to Keller and Levinson (2002). The estimates obtained using the Lewbel (2010) approach are given under the column labelled 'IV'.

As with the Pitt and Rosenzweig (1990) approach, four salient findings emerge. First, the OLS estimates are negative and statistically significant in the vast majority of cases. The main exception is when examining FDI as measured by employment in total manufacturing (Panel B, Table 5). In addition, the OLS estimates are fairly stable across the four specifications; neighboring environmental regulation is statistically significant only in Specifications 2 and 3 when assessing employment in the chemical sector (Panel B, Table 4). Inclusion of the spatial effects has little effect on the estimated marginal effect of own environmental regulation.

Second, as with the Pitt and Rosenzweig (1990) approach, the Lewbel (2010) identification strategy works well as determined by the usual IV specification tests when geographic spillovers are omitted (Specification 1) as well as in the majority of cases when spatial effects are included (particularly when using 
the two regional weighting schemes in Specifications 3 and 4). ${ }^{5}$ Specifically, we reject the null that the model is underidentified at the $p<0.01$ confidence level in every case using Anderson's (1951) canonical correlation test, and the Cragg and Donald (1993) F-statistic is reasonably large. In addition, we fail to reject the validity of the instruments using Anderson and Rubin's (1950) overidentification test in all cases but one at the $p<0.10$ confidence level for Specifications 1, 3, and 4. In addition, Specification 2 fares well in terms of these tests when examining total manufacturing. Thus, the Lewbel (2010) approach performs well.

Third, when focusing on the cases that pass the specification tests, we reject exogeneity of own (and neighboring) environmental regulation in the majority of cases for the chemical sector. There is much less support for endogeneity when examining total manufacturing. Thus, there is only strong evidence of endogeneity when focusing on the most pollution-intensive sectors.

Finally, turning to the point estimates in the cases that pass the specification tests for the chemical sector (Table 4), the LIML estimates are statistically significant at at least the $p<0.10$ confidence level using either the traditional approach or the Anderson and Rubin (1949) test robust to weak instruments; often statistically significant at the $p<0.01$ confidence level. Moreover, as with the Pitt and Rosenzweig (1990) approach, the point estimates are larger in absolute value compared to OLS; however, the standard errors are also roughly two to three times larger. Neighboring environmental regulation is statistically significant in Specification 3, but not Specification 4. Thus, choice of weighting scheme does matter in meaningful ways.

To put the magnitude of the effects in context, we return to the previous thought experiment. Using the results in Panel B, Specification 4, if Ohio in 1991 had raised the value of its RAC index from 0.86 to match California (1.00), then employment in foreign-owned affiliates in the chemical sector would have been expected to decline from 17,600 to roughly 15,100 . In contrast, the OLS estimate implies a decline to only about 16,500 .

In terms of the total manufacturing results (Table 5), we often fail to reject exogeneity as noted previously. Moreover, adding the spatial effects has little influence on the estimates from Keller and Levinson (2002); Kellenberg (2009) obtains a similar finding. One noteworthy finding, however, occurs in Specification 3 when examining employment (Panel B). Here, we do reject exogeneity and the IV point estimate indicates a positive and statistically significant effect of own environmental regulation. While we are cautious about putting too much stock in any one estimate given the number of specifications estimated, this is consistent with the heterogeneous effects documented elsewhere in the prior literature

\footnotetext{
${ }^{5}$ Note, for computational reasons, we follow Keller and Levinson (2002) and do not present robust standard errors here; in several specifications, the robust estimate of the covariance matrix was not of full rank.
} 
(e.g., Henderson and Millimet 2007). In particular, this result and the prior results for the chemical sector only highlight the fact that the impact of environmental regulation (as well as its statistical properties) depends on the pollution intensity of the industry, consistent with existing studies (e.g., Ederington et al. 2005; Jug and Mirza 2005; Mulatu et al. 2010).

\subsubsection{Klein \& Vella (2009) Approach}

Model The final identification strategy is based on the parametric implementation of the estimator proposed in Klein and Vella $(2009,2010)$ and expanded upon in Farré et al. (2010). To proceed, consider the system of equations given in (6) - (8). In addition to being mean zero, the following assumptions are made concerning the errors:

$$
\begin{aligned}
& \varepsilon_{i t}=S_{\varepsilon}\left(z_{i t}\right) \varepsilon_{i t}^{*} \\
& \zeta_{r i t}=S_{r}\left(z_{i t}\right) \zeta_{r i t}^{*}, \quad r=1,2 \\
& S_{\varepsilon}\left(z_{i t}\right) / S_{r}\left(z_{i t}\right), \quad r=1,2, \text { varies across } i \\
& \mathbb{E}\left[\varepsilon_{i t}^{*} \zeta_{r i t}^{*}\right]=\rho_{r}, \quad r=1,2
\end{aligned}
$$

where $\varepsilon_{i t}^{*}$ and $\zeta_{r i t}^{*}$ are homoskedastic errors and $z \subseteq X$. Thus, at least some of the errors are required to be heteroskedastic in such a way that the ratio $S_{\varepsilon}\left(z_{i t}\right) / S_{r}\left(z_{i t}\right), r=1,2$, varies across observations. However, the conditional correlation, $\rho_{r}, r=1,2$, between the underlying homoskedastic portion of the errors must be fixed. Note, while the three heteroskedasticity terms $-S_{\varepsilon}\left(z_{i t}\right)$ and $S_{r}\left(z_{i t}\right), r=1,2$ - are written as a function of the same set of covariates, $z$, this need not be the case. There are no restrictions on which variables may enter each of these terms.

Klein and Vella (2010) give some examples of DGPs satisfying these assumptions. One such case arises if there exists a common factor, as in the Lewbel (2010) approach. However, here the common factor enters multiplicatively and may itself be heteroskedastic. Specifically, if we can write the errors as

$$
\begin{aligned}
& \varepsilon_{i t}=S_{\varepsilon}\left(z_{i t}\right) \kappa_{i t} \widetilde{\varepsilon}_{i t} \\
& \zeta_{r i t}=S_{r}\left(z_{i t}\right) \kappa_{i t} \widetilde{\zeta}_{r i t}, \quad r=1,2
\end{aligned}
$$

where $\widetilde{\varepsilon}$ and $\widetilde{\zeta}_{r}$ are mean-zero, independent of $X$ and $\kappa$, and have a constant correlation given by $\rho_{r}$, then (11) - (14) are satisfied.

Reverting back to (14), it is worth considering what this identification condition implies. One possible interpretation includes viewing $\varepsilon_{i t}^{*}$ and $\zeta_{r i t}^{*}, r=1,2$, as correlated measures of agglomeration. Agglomeration may affect environmental stringency due to the scale effect of pollution-generating activity. However, 
the impact may depend on state-level attributes, $z_{i t}$. For instance, states with attributes that are not conducive to attracting FDI may limit the impact of agglomeration on environmental stringency. Similarly, own agglomeration may impact FDI through economies of scale, but the effect may depend on state-level attributes as well. Neighboring agglomeration may adversely impact FDI by improving the desirability of neighboring locations. However, once we condition on these state-level attributes, the return to own and neighboring agglomeration, $\rho_{1}$ and $\rho_{2}$, respectively, are constant. While not testable, this seems plausible.

Continuing, we parameterize $S_{\varepsilon}\left(z_{i t}\right)$ and $S_{r}\left(z_{i t}\right)$ as

$$
\begin{aligned}
& S_{\varepsilon}\left(z_{i t}\right)=\sqrt{\exp \left(z_{\varepsilon i t} \theta_{\varepsilon}\right)} \\
& S_{r}\left(z_{i t}\right)=\sqrt{\exp \left(z_{r i t} \theta_{r}\right)}, \quad r=1,2
\end{aligned}
$$

where $z_{1}\left(z_{2}\right)$ includes own (spatially lagged) land prices, total road mileage, and market proximity (as in the Lewbel (2010) approach). Using the Breusch-Pagan test for heteroskedasticity to identify variables likely to be related to the structural error variance in the FDI equations, we include average production worker wages, population, and market proximity in $z_{\varepsilon}$ when examining FDI in the chemical sector; market proximity only is included when examining total manufacturing FDI. ${ }^{6}$

With this setup, (6) may be rewritten as

$$
\ln \left(F D I_{i t}\right)=X_{i t} \Pi+\beta \ln \left(R A C_{i t}\right)+\delta \ln \left(\sum_{j \in \Omega} \omega_{i j t} R A C_{j t}\right)+\rho_{1} \frac{S_{\varepsilon}\left(z_{i t}\right)}{S_{1}\left(z_{i t}\right)} \zeta_{1 i t}+\rho_{2} \frac{S_{\varepsilon}\left(z_{i t}\right)}{S_{2}\left(z_{i t}\right)} \zeta_{2 i t}+\widetilde{\widetilde{\varepsilon}}_{i t}
$$

where $\rho_{1} \frac{S_{\varepsilon}\left(z_{i t}\right)}{S_{1}\left(z_{i t}\right)} \zeta_{1 i t}+\rho_{2} \frac{S_{\varepsilon}\left(z_{i t}\right)}{S_{2}\left(z_{i t}\right)} \zeta_{2 i t}$ is a control function and $\widetilde{\widetilde{\varepsilon}}_{i t}$ is a well-behaved error term. Given the functional form assumptions in (15) and (16), (17) can be estimated by nonlinear least squares (NLS) in a number of ways. Standard errors are obtained via bootstrap. See Appendix B for further estimation details.

Results The results are presented in Tables 4 and 5 under the column labelled 'CF'. In Table 4 (chemical sector), the point estimates are fairly stable across the four specifications, particularly in Panel A (PP\&E) and especially when one considers the size of the standard errors. ${ }^{7}$ Moreover, while the coefficients on own environmental regulation are roughly similar to those obtained using the Lewbel (2010) approach, they are never statistically significant at the $p<0.10$ confidence level due to the relatively large standard errors. Neighboring environmental regulation is also never statistically significant (although the estimates

\footnotetext{
${ }^{6}$ Average production wages and population are excluded when examining total manufacturing FDI due to problems with convergence.

${ }^{7}$ Standard errors are obtaining using 1000 bootstrap repititions.
} 
are even more imprecise) and inclusion of the spatial effects has little influence on the estimated marginal effects of own environmental regulation.

In terms of total manufacturing (Table 5), the results are consistent with the OLS and Lewbel (2010) approaches, particularly when considering the size of the standard errors. Thus, there is no statistically meaningful evidence of a negative impact of own environmental regulation, or of neighboring environmental regulation, on FDI inflows across the manufacturing sector as a whole.

In sum, the three identification strategies provide a consistent picture: own environmental regulation has an economically significant effect on the spatial distribution of FDI inflows in pollution-intensive sectors across U.S. states. However, there is little impact of environmental regulation on the location choice of manufacturing FDI as a whole. The estimates are statistically meaningful when using the Lewbel (2010) or Pitt and Rosenzweig (1990) approach. Moreover, controlling for endogeneity, although not spatial effects, is crucial in empirical analyses of the PHH. All three estimators indicate much larger (but less precisely estimated) effects on FDI inflows in pollution-intensive sectors than suggested by traditional panel data estimates. The downward (in absolute value) bias of OLS estimates may be attributable in part to measurement error and in part to unobservables positively correlated with both environmental regulation and FDI inflows. For instance, Becker (2011) finds that there is significant variation in environmental compliance costs across counties within states; roughly one-third of counties differ significantly from their state average. Thus, significant attenuation bias due to measurement error is clearly plausible. Similarly, a multitude of unobservables (such as investments in other public goods or agglomeration effects) as well as omitted within-state variation in the observables included in the analysis, can explain the bias in estimates obtained under the assumption of strict exogeneity.

\subsection{Monte Carlo Study}

Prior to concluding, we undertake two small-scale Monte Carlo experiments for two reasons. First, given that the identification strategies utilized herein are somewhat unorthodox, it is worthwhile to illustrate their performance using simulated data. Second, as stated in the Introduction, existing analyses or applications of these methods focus nearly exclusively on the case of a single endogenous regressor; we verify that each method extends to the case of two endogenous variables. Note, however, due to the usual limitation of Monte Carlo evidence - the fact that results may be specific to the DGPs considered - our aim is not to set up a 'horse-race' between the different approaches. Rather, our aim is simply to verify the performance of each approach in a setting where the identifying assumptions hold. 
The first Monte Carlo design is based on the following data-generating process:

$$
\begin{aligned}
& \text { Outcomes: } \quad y^{p}=0.5+0.5 x_{1}+0.5 x_{2}-R_{1}+R_{2}+\varepsilon^{p} \\
& y^{n p}=0.25+0.5 x_{1}+0.5 x_{2}+\varepsilon^{n p} \\
& \text { First-Stage }: R_{1}=1+0.25 x_{1}-0.75 x_{2}+\zeta_{1} \\
& R_{2}=1-0.75 x_{1}+0.25 x_{2}+\zeta_{2} \\
& \text { Covariates }: x_{1}, x_{2} \stackrel{\text { iid }}{\sim} N(0,1) \\
& \text { Errors }: \varepsilon^{p}=S_{\varepsilon}(x) \varepsilon^{*} \\
& \zeta_{r}=S_{r}(x) \zeta_{r}^{*}, \quad r=1,2 \\
& S_{\varepsilon}(x)=\sqrt{\exp \left(0.8 x_{1}+0.8 x_{2}\right)} \\
& S_{1}(x)=\sqrt{\exp \left(-0.2 x_{1}-0.8 x_{2}\right)} \\
& S_{2}(x)=\sqrt{\exp \left(-0.8 x_{1}-0.2 x_{2}\right)} \\
& \varepsilon^{*}, \zeta_{1}^{*}, \zeta_{2}^{*}, \varepsilon^{n p} \sim N\left(0,\left[\begin{array}{cccc}
1 & 0.4 & -0.6 & 0 \\
& 1 & 0.2 & 0 \\
& & 1 & 0 \\
& & & 1
\end{array}\right]\right)
\end{aligned}
$$

where $R_{1}$ and $R_{2}$ are the two endogenous covariates, $y^{p}$ is the outcome used to assess the performance of the Lewbel (2010) and Klein and Vella (2009) approaches, and $y^{p}-y^{n p}$ is the differenced outcome used to assess the Pitt and Rosenzweig (1990) approach where the (correct) assumption that $x_{1}$ and $x_{2}$ have identical effects is used to identify the model. Thus, the true parameters of interest are -1 and 1 for all three estimators. Finally, note that $\left(x_{2}-\bar{x}_{2}\right) \zeta_{1}$ and $\left(x_{1}-\bar{x}_{1}\right) \zeta_{2}$ satisfy the requirements for valid instruments in the Lewbel (2010) approach, while the error structure also satisfies the setup in the Klein and Vella (2009) approach.

We perform this exercise twice; once using 1000 simulations of sample size 750 (roughly the size in our application) and once using 100 simulations of sample size 5,000. For comparison, we also simulate analogous data sets with traditional exclusion restrictions. In this case, the first-stage data-generating process becomes

$$
\begin{array}{cc}
\text { First-Stage }: & R_{1}=1+0.25 x_{1}-0.75 x_{2}+0.75 z_{1}+0.25 z_{2}+\zeta_{1} \\
& R_{2}=1-0.75 x_{1}+0.25 x_{2}+0.25 z_{1}+0.75 z_{2}+\zeta_{2}
\end{array}
$$

where $z_{1}, z_{2} \stackrel{\text { iid }}{\sim} N(0,1)$. The remainder of the data-generating process is unaltered. As in the Pitt and Rosenzweig (1990) and Lewbel (2010) approaches, we obtain the traditional IV results using LIML. 
The results are presented in Table 6; OLS results are also included for comparison. The simulations indicate that all three (non-OLS, non-traditional IV) estimators perform well overall and similarly to traditional IV. In the small sample, the Pitt and Rosenzweig (1990) and Lewbel (2010) approaches are superior in terms of bias (along with traditional IV); Lewbel (2010) yields the lowest mean absolute error (MAE) and root mean squared error (RMSE) followed closely by and Klein and Vella (2009) and traditional IV. Pitt and Rosenzweig (1990) has a MAE and RMSE substantially larger than the other three (nonOLS) estimators despite having an average bias near zero. In large samples, all four (non-OLS) estimators perform very well, with both the Lewbel (2010) and Klein and Vella (2009) approaches matching the performance of traditional IV.

The second Monte Carlo design is a so-called empirical Monte Carlo study, developed in Huber et al. (2010). The authors “... suggest a different approach of conducting simulations ... using the real data to simulate realistic 'placebo treatments' among the non-treated" (p. 3). In their application, since the focus is on the performance of several estimators of the effect of a binary regressor, the simulations entail restricting the sample to only those observations for whom their actual value of the regressor is zero, arbitrarily recoding the regressor to one for a subset of this sample, and then estimating the effect of the simulated binary regressor. In light of this setup, the 'true' effect of the simulated regressor is zero.

In our application, the process is a bit more complex for three reasons: (i) there are two variables of interest, (ii) the variables of interest are continuous, and (iii) our estimators require modeling the simulated variable in a particular way for identification. To proceed, we use the following algorithm:

1. For each observation $i, i=1, \ldots, N T$, in the real data, simulate a value for RAC by drawing a value from its empirical distribution. In practice, this entails drawing a random number, $s$, between 1 and $N T$ and defining the simulated value of RAC for observation $i$ as the value of RAC from observation $s$.

2. For each observation $i, i=1, \ldots, N T$, in the real data, simulate a value for neighboring $\mathrm{RAC}$ by drawing a value from its empirical distribution following the procedure in step 1.

3. Because we need the variables in $x_{2}$ to be correlated with own and neighboring RAC in the Pitt and Rosenzweig (1990) approach, as well as $z_{1}$ and $z_{2}$ to be associated with the variance of own and neighboring RAC in the Lewbel (2010) and Klein and Vella (2009) approaches, we also borrow the values of these variables from the observations chosen in steps 1 and $2 .^{8}$

\footnotetext{
${ }^{8}$ For example, in the Pitt and Rosenzweig (1990) approach, the instruments used in the differenced equation are market proximity, population, tax effort, and their corresponding spatial lags. Thus, as instruments in the differenced equation that now contains the simulated values of own and spatially lagged RAC we use the values of market proximity, population, tax
} 
4. After simulating the values of own and neighboring RAC (and the corresponding values in $x_{2}, z_{1}$, and $z_{2}$ ), we apply each estimator to the data and compare the resulting estimates to the 'true' values of zero.

OLS results are presented in Table 7, as well as for the Lewbel (2010) and Klein and Vella (2009) approaches. Note, now OLS is the preferred estimator since the DGP eliminates the endogeneity issue. Table 8 contains the Pitt and Rosenzweig (1990) approach results.

The results confirm the good performance of all four estimators in terms of bias. However, as in the first experimental design with entirely simulated data, the Pitt and Rosenzweig (1990) approach yields less precise estimates than the other three estimators. Between the Lewbel (2010) and Klein and Vella (2009) estimators, the Lewbel (2010) approach tends to outperform Klein and Vella (2009) approach in terms of precision. As expected, OLS outperforms the Lewbel (2010) approach, producing RMSEs about one-third to one-half the size.

In sum, both Monte Carlo experiments highlight the usefulness of all three identification strategies employed in the current application when the identifying assumptions hold, as well as show how these estimators can perform well even with multiple endogenous variables. Moreover, the simulations shed some light on how to carefully interpret the findings in the current application. First, the simulations point to the added variability of the estimates obtained using the Pitt and Rosenzweig (1990) approach in small samples, as well as the modest improvement in precision with the Lewbel (2010) approach relative to the Klein and Vella (2009) estimator in our data. That said, it is important to re-iterate that (i) our Monte Carlo study is limited to a specific simulated DGP as well as the data from our application and (ii) our implementation of Klein and Vella's (2009) estimator is based on a particular parametric implementation. Certainly more detailed comparisons are required before making general statements regarding the relative performance of the Lewbel (2010) and Klein and Vella (2009) approaches. Moreover, since each relies on a different set of identifying assumptions, 'ranking' the two approaches is not meaningful unless both sets of assumptions hold in a given data set. Nonetheless, the Monte Carlo results provide some additional context with which to interpret the magnitudes obtained using the Pitt and Rosenzweig (1990) approach in the current application, as well as the larger standard errors when using the Klein and Vella (2009) approach.

Second, the simulations in the empirical Monte Carlo study indicate that all three estimators yield much effort, and their corresponding spatial lags from the same observations used to obtain the simulated values of RAC and neighboring RAC in steps 1 and 2. If we did not do this, the estimator would perform extremely poorly because the true values of the instruments would fail to be correlated with the simulated endogenous regressors. Similar logic applies to the other two estimation approaches. 
more precise estimates of the effect of own environmental regulation relative to neighboring environmental regulation. This is especially true when using the Crone regional weighting scheme. Thus, some caution should be exhibited concluding that spatial effects are unimportant in empirical models of the PHH (as was already suggested by the large standard errors discussed previously).

\section{Conclusion}

The debate over the empirical validity of the $\mathrm{PHH}$ is heated and for good reason; the answer has far-reaching consequences at the local, national, and international levels. To date, however, empirical assessments of the PHH have been hampered by the lack of a credible identification strategy to overcome potential problems associated with measurement error and unobserved heterogeneity. In addition, the empirical literature on the PHH has yet to adequately incorporate lessons from the literature on so-called third-country effects. Here, we propose three novel identification strategies couched within a model that incorporates spatial effects. A traditional Monte Carlo design, as well as an empirical Monte Carlo experiment, give us confidence in these approaches in the current context, one that includes two endogenous covariates. Together, the three approaches shed new light on the role of environmental regulation in the determination of FDI location.

Specifically, using state-level panel data from 1977-1994 from the U.S., we consistently find (i) evidence of environmental regulation being endogenous when examining the pollution-intensive chemical sector, (ii) a negative and economically significant impact of own environmental stringency on inbound FDI in the chemical sector, particularly when measured by employment, and (iii) significantly larger effects of environmental regulation on the chemical sector once endogeneity is addressed. The upward bias in standard fixed effects estimates obtained under the assumption of strict exogeneity is consistent with attenuation bias due to measurement error, as well as important unobservables positively correlated with environmental regulation and FDI inflows (such as tax breaks, investments in other public goods, or agglomeration externalities).

While informative, continued research is warranted. First, the analysis here is at the regional level. Before reaching important policy conclusions regarding such issues as the WTO's justification to intervene in the domestic environmental policy arena or the sensibility of linking international environmental and trade agreements, further analysis is needed to determine the external validity of the findings obtained here. Does environmental regulation have similar effects at the country level? Despite this unknown, our results do firmly indicate that policymakers should worry about the incentives for local environmental standards to deviate from Pareto-efficient levels. Such fears are particularly worrisome since prior evidence 
suggests that domestic investment may be even more sensitive to spatial variation in environmental policy than foreign investment (e.g., List et al. 2004).

Second, the prior literature, while suffering from various deficiencies, has emphasized the heterogeneous effects of environmental regulation along numerous dimensions. For instance, Ederington et al. (2005) point to substantial heterogeneity across source country (of imports) and the pollution intensity and geographic mobility of the industrial sector. Dean et al. (2009) similarly document important heterogeneity by source country (of foreign investment). Henderson and Millimet (2007) and Millimet and List (2004) uncover heterogeneous effects utilizing nonparametric and semiparametric methods, respectively. Some of this heterogeneity is captured in this study; namely, differential effects by pollution intensity of the manufacturing sector as well as by measure of FDI (PP\&E versus employment). However, other dimensions of heterogeneity uncovered by the prior literature cannot be addressed given the data and identification strategies utilized here. Future research investigating whether the empirical evidence of heterogeneous effects continues to be present once measurement error, spatial effects, and unobserved heterogeneity are accounted for is needed for a deeper understanding of the linkages between environmental and trade policy. 


\section{References}

[1] Anderson, T.W. (1951), "Estimating Linear Restrictions on Regression Coefficients for Multivariate Normal Distributions," Annals of Mathematical Statistics, 22, 327-351.

[2] Anderson, T. W. and H. Rubin (1949), "Estimation of the Parameters of a Single Equation in a Complete System of Stochastic Equations," Annals of Mathematical Statistics, 20, 46-63.

[3] Anderson, T.W. and H. Rubin (1950), "The Asymptotic Properties of Estimates of the Parameters of a Single equation in a Complete System of Stochastic Equations," Annals of Mathematical Statistics, $21,570-582$.

[4] Arauzo-Carod, J.M., D. Liviano-Solis, and M. Manjón-Antolín (2010), "Empirical Studies in Industrial Location: An Assessment of Their Methods and Results," Journal of Regional Science, 50, 685-711.

[5] Baltagi, B.H., P. Egger, and M. Pfaffermayr (2007), "Estimating Model of Complex FDI: Are There Third-Country Effects?" Journal of Econometrics, 140, 260-281.

[6] Baltagi, B.H., P. Egger, and M. Pfaffermayr (2008), "Estimating Regional Trade Agreement Effects on FDI in an Interdependent World," Journal of Econometrics, 145, 194-208.

[7] Becker, R.A. (2011), "On Spatial Heterogeneity in Environmental Compliance Costs," Land Economics, 87, 28-44.

[8] Blonigen, B.A., R.B. Davies, G.R. Waddell, and H.T. Naughton (2007), "FDI in Space: Spatial Autoregressive Relationships in Foreign Direct Investment," European Economic Review, 51, 13031325.

[9] Blonigen, B.A., R.B. Davies, H.T. Naughton, and G.R. Waddell (2008), "Spacey Parents: Spatial Autoregressive Patterns in Inbound FDI," in S. Brakman and H. Garretsen (eds.) Foreign Direct Investment and the Multinational Enterprise, Cambridge, MA: The MIT Press, pp.173-198.

[10] Brunnermeier, S. and A. Levinson (2004), "Examining the Evidence on Environmental Regulations and Industry Location," Journal of Environment 69 Development, 13, 6-41.

[11] Cole, M.A. and R.J.R. Elliott (2003), "Do Environmental Regulations Influence Trade Patterns? Testing Old and New Trade Theories," World Economy, 26, 1163-1189.

[12] Cole, M.A. and R.J.R. Elliott (2005), "FDI and the Capital Intensity of 'Dirty' Sectors: A Missing Piece of the Pollution Haven Puzzle," Review of Development Economics, 9, 530-548. 
[13] Cole, M.A., R.J.R. Elliott, and K. Shimamoto (2005), "Why the Grass Is Not Always Greener: The Competing Effects of Environmental Regulations and Factor Intensities on US Specialization," Ecological Economics, 54, 95-109.

[14] Cole, M.A., R.J.R. Elliott, and P.G. Fredriksson (2006), "Endogenous Pollution Havens: Does FDI Influence Environmental Regulations?" Scandanavian Journal of Economics, 108, 157-178.

[15] Cole, M.A. and P.G. Fredriksson (2009), "Institutionalized Pollution Havens," Ecological Economics, $68,1239-1256$.

[16] Copeland, B. and M.S. Taylor (2004), "Trade, Growth, and the Environment," Journal of Economic Literature, 42, 7-71.

[17] Cragg, J.G. and S.G. Donald (1993), "Testing Identfiability and Specification in Instrumental Variables Models," Econometric Theory, 9, 222-240.

[18] Crone, T.M. (1998/1999), "Using State Indexes to Define Economic Regions in the U.S.," The Journal of Economic and Social Measurement, 25, 259-278.

[19] Dean, J.M., M.E. Lovely, and H. Wang (2009), "Are Foreign Investors Attracted to Weak Environmental Regulations? Evaluating the Evidence from China," Journal of Development Economics, 90, $1-13$.

[20] Ebbes, P., M. Wedel, and U. Böckenholt (2009), "Frugal IV Alternatives to Identify the Parameter for an Endogenous Regressor," Journal of Applied Econometrics, 24, 446-468.

[21] Ederington, J. and J. Minier (2003), "Is Environmental Policy a Secondary Trade Barrier? An Empirical Analysis," Canadian Journal of Economics, 36, 137-154.

[22] Ederington, J., A. Levinson, and J. Minier (2004), "Trade Liberalization and Pollution Havens," Advances in Economic Analysis and Policy, 4, Article 2.

[23] Ederington, J., A. Levinson, and J. Minier (2005), "Footloose and Pollution-Free," Review of Economics and Statistics, 87, 92-99.

[24] Ekholm, K., R. Forslid, and J.R. Markusen (2003), "Export-Platform Foreign Direct Investment," NBER WP No. 9517.

[25] Eliste, P. and P.G. Fredriksson (2004), "Does Trade Liberalization Cause a Race-to-the-bottom in Environmental Policies? A Spatial Econometric Analysis," in L. Anselin, R.J.G.M. Florax and S.J. Rey (eds.) Advances in Spatial Econometrics: Methodology, Tools, and Applications, Berlin: Springer. 
[26] Farré, L., R. Klein, and F. Vella (2010), "A Parametric Control Function Approach to Estimating the Returns to Schoolinh in the Absence of Exclusion Restrictions: An Application to the NLSY," Empirical Economics, forthcoming.

[27] Flores-Lagunes, A. (2007), "Finite Sample Evidence of IV Estimators Under Weak Instruments," Journal of Applied Econometrics, 22, 677-694.

[28] Fredriksson, P.G., J.A. List, and D.L. Millimet (2003), "Corruption, Environmental Policy, and FDI: Theory and Evidence from the United States," Journal of Public Economics, 87, 1407-1430.

[29] Fredriksson, P.G. and D.L. Millimet (2002), "Strategic Interaction and the Determination of Environmental Policy Across US States," Journal of Urban Economics, 51, 101-122.

[30] Glick, N.J. and D.P. Woodward (1987), Regional Patterns of Manufacturing Foreign Direct Investment in the United States, Special Report for U.S. Department of Commerce, Economic Development Administration.

[31] Grossman, G.M., E. Helpman, and A. Szeidl (2003), "Optimal Integration Strategies for the Multinational Firm," NBER WP No. 10189.

[32] Henderson, V. (1997), "The Impact of Air Quality Regulation on Industrial Location," Annales d'Économie et de Statistique, 45, 123-137.

[33] Henderson, D.J. and D.L. Millimet (2007), "Pollution Abatement Costs and Foreign Direct Investment Inflows to U.S. States: A Nonparametric Reassessment," Review of Economics and Statistics, 89, 178183.

[34] Huber, M., M. Lechner, and C. Wunsch (2010), "How to Control for Many Covariates? Reliable Estimators Based on the Propensity Score," IZA DP No. 5268.

[35] Jaffe, A.B., S.R. Peterson, P.R. Portney, and R.N. Stavins (1995), "Environmental Regulations and the Competitiveness of U.S. Manufacturing: What does the Evidence Tell Us?" Journal of Economic Literature, 33, 132-163.

[36] Jug, J. and D. Mirza (2005), "Environmental Regulations in Gravity Equations: Evidence from Europe," World Economy, 28, 1591-1615.

[37] Kellenberg, D.K. (2009), "An Empirical Investigation of the Pollution Haven Effect with Strategic Environment and Trade Policy," Journal of International Economics, 78, 242-255. 
[38] Keller, W. and A. Levinson (2002), "Pollution Abatement Costs and Foreign Direct Investment Inflows to U.S. States," Review of Economics and Statistics, 84, 691-703.

[39] Kleibergen, F. and R. Paap (2006), "Generalized Reduced Rank Tests Using the Singular Value Decomposition," Journal of Econometrics, Vol. 133, 97-126.

[40] Klein, R. and F. Vella (2009), "Estimating the Return to Endogenous Schooling Decisions via Conditional Second Moments," Journal of Human Resources, 44, 1047-1065.

[41] Klein, R. and F. Vella (2010), "Estimating a Class of Triangular Simultaneous Equations Models Without Exclusion Restrictions," Journal of Econometrics, 154, 154-164.

[42] Levinson, A. (1997), "A Note on Environmental Federalism: Interpreting Some Contradictory Results," Journal of Environmental Economics and Management, 33, 359-366.

[43] Levinson, A. (2001), "An Industry-Adjusted Index of State Environmental Compliance Costs," in C. Carraro and G.E. Metcalf (eds.) Behavioral and Distributional Effects of Environmental Policy, Chicago: University of Chicago Press.

[44] Levinson, A. (2003), "Environmental Regulatory Competition: A Status Report and Some New Evidence," National Tax Journal, 56, 91-106.

[45] Levinson, A. (2008), "Pollution Haven Hypothesis," New Palgrave Dictionary of Economics, 2nd Edition.

[46] Levinson, A. (2010), "Offshoring Pollution: Is the United States Increasingly Importing Polluting Goods," Review of Environmental Economics and Policy, 4, 62-83.

[47] Lewbel, A. (1997), "Constructing Instruments for Regressions With Measurement Error When No Additional Data are Available, with An Application to Patents and R\&D," Econometrica, 65, 12011213.

[48] Lewbel, A. (2010), "Using Heteroskedasticity to Identify and Estimate Mismeasured and Endogenous Variables," Journal of Business and Economic Statistics, forthcoming.

[49] List, J.A., D.L. Millimet, P.G. Fredriksson, and W.W. McHone (2003), "Effects of Environmental Regulations on Manufacturing Plant Births: Evidence from a Propensity Score Matching Estimator," Review of Economics and Statistics, 85, 944-952. 
[50] List, J.A., W.W. McHone, and D.L. Millimet (2004), "Effects of Environmental Regulation on Foreign and Domestic Plant Births: Is There a Home Field Advantage?," Journal of Urban Economics, 56, 303-326.

[51] Millimet, D.L. and J.A. List (2004), "The Case of the Missing Pollution Haven Hypothesis," Journal of Regulatory Economics, 26, 239-262.

[52] Mulatu, A., R. Gerlagh, and D. Rigby (2010), "Environmental Regulation and Industry Location in Europe," Environmental and Resource Economics, 45, 459-479.

[53] Pitt, M.M. and M.R. Rosenzweig (1990), "Estimating the Intrahousehold Incidence of Illness: Child Health and Gender-Inequality in the Allocation of Time," International Economic Review, 31, 969-989.

[54] Rigobon, R. (2003), "Identification Through Heteroskedasticity," Review of Economics and Statistics, $85,777-792$.

[55] Shadbegian, R. and A. Wolverton (2010), "Location Decisions of U.S. Polluting Plants: Theory, Empirical Evidence, and Consequences," International Review of Environmental and Resource Economics, $1,1-49$.

[56] Stock, J.H., J.H. Wright, and M. Yogo (2002), "A Survey of Weak Instruments and Weak Identification in Generalized Method of Moments," Journal of Business and Economic Statistics, 20, 518-529.

[57] Vella, F. and M. Verbeek (1997), "Using Rank Order as an Instrumental Variable: An Application to the Return to Schooling," CES Discussion Paper 97.10, K.U. Leuven.

[58] Wagner, U.J. and C.D. Timmins (2009), "Agglomeration Effects in Foreign Direct Investment and the Pollution Haven Hypothesis," Environmental and Resource Economics, 43, 231-256.

[59] Wilson, J.D. (1999), "Theories of Tax Competition,” National Tax Journal, 52, 269-304.

[60] Xing, Y. and C.D. Kolstad (2002), "Do Lax Environmental Regulations Attract Foreign Investment?" Environmental and Resource Economics, 21, 1-22.

[61] Yeaple, S.R. (2003), "The Complex Integration Strategies of Multinational Firms and Cross-Country Dependencies in the Structure of Foreign Direct Investment," Journal of International Economics, 60, 293-314.

[62] UNCTAD (2010), World Investment Report 2010, United Nations: New York and Geneva. 


\section{A Data Appendix}

The BEA regional classification is as follows.

1. New England: Maine, New Hampshire, Vermont, Massachusetts, Rhode Island, Connecticut

2. Mideast: New York, New Jersey, Pennsylvania, Delaware, Maryland

3. Great Lakes: Ohio, Indiana, Illinois, Michigan, Wisconsin

4. Plains: Minnesota, Iowa, Missouri, North Dakota, South Dakota, Nebraska, Kansas

5. Southeast: Georgia, Florida, Virginia, West Virginia, North Carolina, South Carolina, Kentucky, Tennessee, Alabama, Mississippi, Arkansas, Louisiana

6. Southwest: Oklahoma, Texas, Arizona, New Mexico

7. Rocky Mountain: Montana, Idaho, Wyoming, Colorado, Utah

8. Far West: Washington, Oregon, California, Nevada

The Crone (1998/1999) regions - based on a cluster analysis of similar economic activity - are as follows.

1. Maine, New Hampshire, Massachusetts, Arizona, Utah, Montana

2. Ohio, Indiana, Illinois, Michigan, Iowa, Delaware

3. Georgia, Florida, Virginia, North Carolina, South Carolina, Missouri, Kentucky, Tennessee, Alabama, Mississippi, Arkansas, Oklahoma, Rhode Island

4. New York, New Jersey, Pennsylvania, Maryland, Connecticut, West Virginia, Vermont

5. Washington, Oregon, California, Nevada, Idaho, Nebraska, Texas, Wyoming, Minnesota, Louisiana, Kansas

6. North Dakota, South Dakota, Colorado, New Mexico, Wisconsin 


\begin{tabular}{|c|c|c|c|c|c|c|c|c|c|}
\hline \multirow[b]{2}{*}{ Variable } & \multicolumn{3}{|c|}{ Full Sample } & \multicolumn{3}{|c|}{$\mathbf{R A C} \leq 1$} & \multicolumn{3}{|c|}{$\mathbf{R A C}>\mathbf{1}$} \\
\hline & $\mathbf{N}$ & Mean & SD & $\mathbf{N}$ & Mean & SD & $\mathbf{N}$ & Mean & SD \\
\hline Total Manufacturing FDI (PP\&E) & 811 & 2859.31 & 3919.40 & 449 & 2796.21 & 3610.31 & 362 & 2937.57 & 4275.67 \\
\hline Chemical Sector FDI (PP\&E) & 563 & 1016.94 & 1732.51 & 323 & 812.53 & 1117.36 & 240 & 1292.04 & 2289.90 \\
\hline Non-Chemical Sector FDI (PP\&E) & 563 & 1491.44 & 1923.02 & 323 & 1440.59 & 1703.17 & 240 & 1559.88 & 2186.17 \\
\hline Total Manufacturing FDI (Employment) & 814 & 32680.75 & 36602.64 & 452 & 37596.70 & 39038.80 & 362 & 26542.60 & 32329.69 \\
\hline Chemical Sector FDI (Employment) & 621 & 7691.73 & 9641.22 & 349 & 8760.95 & 10820.55 & 272 & 6319.83 & 7677.71 \\
\hline Non-Chemical Sector FDI (Employment) & 621 & 23377.44 & 26783.65 & 349 & 26047.92 & 26573.23 & 272 & 19950.99 & 26710.69 \\
\hline Relative Abatement Costs (RAC) & 816 & 1.02 & 0.37 & 452 & 0.76 & 0.16 & 364 & 1.34 & 0.31 \\
\hline Unemployment Rate & 816 & 6.61 & 2.09 & 452 & 6.14 & 1.87 & 364 & 7.20 & 2.21 \\
\hline Agricultural Land Values (\$/per acre) & 816 & 887.02 & 775.04 & 452 & 974.93 & 896.84 & 364 & 777.84 & 572.50 \\
\hline Energy Prices, Industrial Sector & 816 & 5.51 & 1.70 & 452 & 5.89 & 1.85 & 364 & 5.04 & 1.35 \\
\hline Highway Road Mileage & 816 & 80500.90 & 48367.55 & 452 & 82200.68 & 42205.87 & 364 & 78390.18 & 55056.13 \\
\hline Population (millions) & 816 & 4.94 & 5.13 & 452 & 5.45 & 5.43 & 364 & 4.30 & 4.67 \\
\hline Unionization Rate & 816 & 16.55 & 6.71 & 452 & 17.37 & 6.86 & 364 & 15.54 & 6.38 \\
\hline $\begin{array}{l}\text { Average Production Worker Wages, } \\
\text { Manufacturing Sector }(\$ / h r)\end{array}$ & 816 & 9.10 & 2.24 & 452 & 9.09 & 2.28 & 364 & 9.10 & 2.19 \\
\hline Tax Effort & 816 & 96.06 & 16.05 & 452 & 98.51 & 18.89 & 364 & 93.01 & 10.88 \\
\hline Market Proximity & 816 & 6630.94 & 8220.03 & 452 & 8218.10 & 9694.03 & 364 & 4660.08 & 5283.64 \\
\hline
\end{tabular}




\section{B Estimation Algorithms}

\section{B.1 Lewbel (2010) Approach}

Estimation of the empirical model

$$
\ln \left(F D I_{i t}\right)=X_{i t} \Pi+\beta \ln \left(R A C_{i t}\right)+\delta \ln \left(\sum_{j \in \Omega} \omega_{i j t} R A C_{j t}\right)+\varepsilon_{i t}
$$

proceeds as follows:

1. Regress $\ln \left(R A C_{i t}\right)$ on $X_{i t}$ and obtain $\widehat{\zeta}_{1 i t}$

2. Regress $\ln \left(\sum_{j \in \Omega} \omega_{i j t} R A C_{j t}\right)$ on $X_{i t}$ and obtain $\widehat{\zeta}_{2 i t}$

3. Form instruments $\widetilde{z}_{r i t} \equiv\left(z_{\text {rit }}-\bar{z}\right) \widehat{\zeta}_{\text {rit }}, r=1,2$

4. Estimate the structural model via Limited Information Maximum Likelihood using $\widetilde{z}_{\text {rit }}, r=1,2$, as instruments for $\ln \left(R A C_{i t}\right)$ and $\ln \left(\sum_{j \in \Omega} \omega_{i j t} R A C_{j t}\right)$.

\section{B.2 Klein \& Vella (2009) Approach}

Estimation of the empirical model

$$
\ln \left(F D I_{i t}\right)=X_{i t} \Pi+\beta \ln \left(R A C_{i t}\right)+\delta \ln \left(\sum_{j \in \Omega} \omega_{i j t} R A C_{j t}\right)+\rho_{1} \frac{S_{\varepsilon}\left(z_{i t}\right)}{S_{1}\left(z_{i t}\right)} \zeta_{1 i t}+\rho_{2} \frac{S_{\varepsilon}\left(z_{i t}\right)}{S_{2}\left(z_{i t}\right)} \zeta_{2 i t}+\widetilde{\widetilde{\varepsilon}}_{i t}
$$

proceeds as follows:

1. Regress $\ln \left(R A C_{i t}\right)$ on $X_{i t}$ and obtain $\widehat{\zeta}_{1 i t}$

2. Regress $\ln \left(\sum_{j \in \Omega} \omega_{i j t} R A C_{j t}\right)$ on $X_{i t}$ and obtain $\widehat{\zeta}_{2 i t}$

3. Estimate $\theta_{j}$ regressing $\ln \left(\widehat{\zeta}_{j i t}^{2}\right)$ on $z_{j i t} ;$ compute $\widehat{S}_{j i t}=\sqrt{\exp \left(z_{j i t} \widehat{\theta}_{j}\right)}, j=1,2$

4. Using $\widehat{\zeta}_{1 i t}, \widehat{\zeta}_{2 i t}, \widehat{S}_{1 i t}$, and $\widehat{S}_{2 i t}$, obtain consistent estimates via NLS:

$$
\min _{\Pi, \beta, \delta, \rho_{1}, \rho_{2}, \theta_{\varepsilon}} \sum_{i, t}\left[\begin{array}{c}
\ln \left(F D I_{i t}\right)-X_{i t} \Pi-\beta \ln \left(R A C_{i t}\right)-\delta \ln \left(\sum_{j \in \Omega} \omega_{i j t} R A C_{j t}\right) \\
-\rho_{1} \sqrt{\exp \left(z_{\varepsilon i t} \theta_{\varepsilon}\right)}\left(\frac{\widehat{\zeta}_{1 i t}}{\widehat{S}_{1 i t}}\right)-\rho_{2} \sqrt{\exp \left(z_{\varepsilon i t} \theta_{\varepsilon}\right)}\left(\frac{\widehat{\zeta}_{2 i t}}{\widehat{S}_{2 i t}}\right)
\end{array}\right]^{2}
$$

5. Estimate $\theta_{\varepsilon}$ (again) by regressing $\ln \left(\widehat{\varepsilon}_{i t}^{2}\right)$ on $z_{\varepsilon i t}$, where

$$
\widehat{\varepsilon}_{i t}=\ln \left(F D I_{i t}\right)-X_{i t} \widehat{\Pi}-\widehat{\beta} \ln \left(R A C_{i t}\right)-\widehat{\delta} \ln \left(\sum_{j \in \Omega} \omega_{i j t} R A C_{j t}\right),
$$

and compute $\widehat{S}_{\varepsilon i t}=\sqrt{\exp \left(z_{\varepsilon i t} \widehat{\theta}_{\varepsilon}\right)}$ 
6. Estimate via OLS:

$$
\ln \left(F D I_{i t}\right)=X_{i t} \Pi+\beta \ln \left(R A C_{i t}\right)+\delta \ln \left(\sum_{j \in \Omega} \omega_{i j t} R A C_{j t}\right)+\underbrace{\rho_{1}\left(\frac{\widehat{S}_{\varepsilon i t}}{\widehat{S}_{1 i t}} \widehat{\zeta}_{1 i t}\right)+\rho_{2}\left(\frac{\widehat{S}_{\varepsilon i t}}{\widehat{S}_{2 i t}} \widehat{\zeta}_{2 i t}\right)}_{\text {control function }}+\widetilde{\widetilde{\varepsilon}}_{i t} .
$$

7. Compute standard errors via bootstrap. 
Table 1. Select Review of the Pollution Haven Hypothesis Literature with Endogenous Environmental Regulation.

\begin{tabular}{|c|c|c|c|c|}
\hline Study & $\begin{array}{c}\text { Dependent } \\
\text { Variable }\end{array}$ & Data & $\begin{array}{c}\text { Primary Measure of } \\
\text { Environmental Regulation }\end{array}$ & Primary Instruments \\
\hline 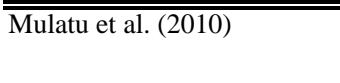 & I"Industry shares & $\begin{array}{l}13 \text { countries and 16 ISIC industries } \\
\text { averaged over 1990-1994 }\end{array}$ & $\begin{array}{l}\text { Environmental Sustainability Index in } \\
2001\end{array}$ & $\begin{array}{l}\text { Corruption in 1995; income in 1992; urbanization in 1997; } \\
\text { schooling in } 1990\end{array}$ \\
\hline Kellenberg (2009) & $\begin{array}{l}\text { Value added of majority owned U.S. } \\
\text { multinational affiliates }\end{array}$ & $\begin{array}{l}50 \text { countries and nine industries over } \\
1999-2003\end{array}$ & $\begin{array}{l}\text { Two survey-based responses from } \\
\text { executives concerning environmental } \\
\text { stringency and consistency of } \\
\text { enforcement }\end{array}$ & $\begin{array}{l}\text { Own country: arable land/agricultural worker; } \\
\text { tractors/agricultural worker. Spatial lag of other countries in } \\
\text { same region (weighted by GDP): land/agricultural worker; } \\
\text { tractors/agricultural worker; public schools; capital/labor } \\
\text { ratio; infrastructure; organized crime. }\end{array}$ \\
\hline Cole and Fredriksson (2009) & $\begin{array}{l}\text { Inbound FDI stocks and flows divided by } \\
\text { aggregate GDP }\end{array}$ & $\begin{array}{l}13 \text { OECD and } 20 \text { developing countries } \\
\text { over 1982-1992 }\end{array}$ & Lead content of gasoline & Total population \\
\hline
\end{tabular}

Levinson and Taylor (2008) $\quad$ U.S. net imports divided by the value of 132 3-digit manufacturing sectors from PAOC per unit of value added shipments $\quad$ Mexico and Canada over 1977-1986

Cole and Elliott (2005)

Cole et al. (2005)

Jug and Mirza (2005)

Ederington et al. (2004)

List et al. (2004)

List et al. (2003)

Fredriksson et al. (2003)
U.S. outbound FDI stocks in Brazil and Mexico divided by total U.S. stocks in each country

U.S. net exports as a share of value added 3-digit U.S. SIC industries over 19781992, except 1979 and 1987

Imports as a share of domestic sales

U.S. imports divided by the value of shipments

Number of manufacturing plant modifications and closures

Number of new manufacturing plants

U.S. state-level inbound FDI stocks across U.S. st states

countries from the EU15 and Central and

Eastern Europe over 1996-1999

Nine 2-digit ISIC industries; 12 importing Environmental expenditures for total countries from the EU15 and 19 exporting manufacturing

394 4-digit U.S. SIC industries fover 1978-1994 except 1979 and 1987

New York State county-level data over 1980-1990

New York State county-level data over Ozone attainment status 1980-1990
PAOC per unit of total materials costs

Ozone attainment status

Levinson (2001) index of state-level relative PAOC
Ederington and Minier (2003) U.S. net imports divided by the value of shipments
374 4-digit U.S. SIC industries over 1978- PAOC per unit of total materials costs 1992, except 1979 and 1987
The amount of a pollutant contributed by other sectors in the states in which the sector tends to locate (14 pollutants yields 14 instruments); weighted average of state per capita incomes

Lagged PAOC per unit of value added over 1973-1978; industry-level pollution intensity in 1987

Follow Levinson and Taylor (2008); six types of air pollution yields six instruments

Total public expenditure; lagged investment in environmental equipment; lagged wages

Similar to Levinson and Taylor (2008) based on geographic dispersion of industries

Proportion of all contiguous western neighbors that are out of attainment

Proportion of all contiguous western neighbors that are out of attainment

Per capita GSP and the share of legal services in GSP; nonmilitary government employment and the interaction between non-military government employment and share of legal services in GSP; corruption and its interaction with tax effort; corruption squared and its interaction with tax effort

Four-firm concentration ratio; number of firms; value of shipments; percentage of unionized workers; industry unemployment rates; lagged changes in import and export penetrations; recent industry growth; lagged total trade 
Table 1 (cont.). Select Review of the Pollution Haven Hypothesis Literature with Endogenous Environmental Regulation.

\begin{tabular}{|c|c|c|c|c|}
\hline Study & $\begin{array}{c}\text { Dependent } \\
\text { Variable }\end{array}$ & Data & $\begin{array}{c}\text { Primary Measure of } \\
\text { Environmental Regulation }\end{array}$ & Primary Instruments \\
\hline 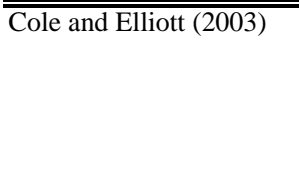 & Net exports & $\begin{array}{l}\text { Four manufacturing sectors in } 60 \\
\text { countries from } 1995\end{array}$ & $\begin{array}{l}\text { Index of environmental stringency from } \\
\text { Eliste and Fredriksson (2004); proxy } \\
\text { based on a change in energy intensity } \\
\text { over 1980-1985 and level of energy } \\
\text { intensity in } 1980\end{array}$ & Per capita income \\
\hline Xing and Kolstad (2002) & U.S. outbound FDI & $\begin{array}{l}\text { Six manfacturing sectors across } 22 \\
\text { countries from } 1985 \text { and 1990; data for } \\
\text { some countries for both time points, in } \\
\text { which case the average is used, and only } \\
\text { from one of the years for the remainder }\end{array}$ & $\mathrm{SO}_{2}$ emissions & Infant mortality rate; population density \\
\hline Henderson (1997) & $\begin{array}{l}\text { Binary variable indicating whether an } \\
\text { industry is located in a U.S. county or not }\end{array}$ & $\begin{array}{l}\text { Five 3-digit U.S. SIC industries over } 1978 \\
1987 \text { for } 742 \text { urban counties }\end{array}$ & Ozone attainment status & $\begin{array}{l}\text { State fuel prices over 1978-1987; metro area manufacturing } \\
\text { employment (except own industry) over 1978-1987; county } \\
\text { and metro area total employment (except own industry) over } \\
\text { 1978-1987 }\end{array}$ \\
\hline
\end{tabular}


Table 2. Determinants of Relative FDI: Pitt \& Rosenzweig (1990) Approach.

\begin{tabular}{|c|c|c|c|c|c|c|c|c|}
\hline & \multicolumn{2}{|c|}{ Spec (1) } & \multicolumn{2}{|c|}{ Spec (2) } & \multicolumn{2}{|c|}{ Spec (3) } & \multicolumn{2}{|c|}{ Spec (4) } \\
\hline & OLS & IV & OLS & IV & OLS & IV & OLS & IV \\
\hline \multicolumn{9}{|c|}{ Panel A. Plant, Property, and Equipment } \\
\hline \multirow[t]{2}{*}{$\ln (\mathrm{RAC})$} & $-0.789 *$ & $-4.720 *$ & $-0.724 *$ & $-4.657 *$ & $-0.802 *$ & $-3.437 *$ & $-0.657^{*}$ & $-3.535 *$ \\
\hline & $(0.155)$ & $(0.653)$ & $(0.146)$ & $(0.703)$ & $(0.142)$ & $(0.509)$ & $(0.151)$ & $(0.631)$ \\
\hline \multirow[t]{2}{*}{$\ln ($ spatial RAC) } & & & $-1.056^{*}$ & 0.930 & 0.596 & 0.977 & 0.148 & $7.210 \dagger$ \\
\hline & & & $(0.349)$ & (1.718) & $(0.498)$ & (1.958) & $(0.576)$ & (3.636) \\
\hline Underid Test & & 0.000 & & 0.000 & & 0.000 & & 0.000 \\
\hline F-stat & & 39.174 & & 8.674 & & 6.344 & & 9.340 \\
\hline Overid Test & & 0.040 & & 0.136 & & 0.074 & & 0.032 \\
\hline Endogeneity & & 0.000 & & 0.000 & & 0.000 & & 0.000 \\
\hline Joint Sign. Endog. & 0.000 & 0.000 & 0.000 & 0.000 & 0.000 & 0.000 & 0.000 & 0.000 \\
\hline $\mathrm{N}$ & 563 & 563 & 563 & 563 & 563 & 563 & 563 & 563 \\
\hline \multicolumn{9}{|c|}{ Panel B. Employment } \\
\hline \multirow[t]{2}{*}{$\ln (\mathrm{RAC})$} & $-0.498 *$ & $-2.205^{*}$ & $-0.447^{*}$ & $-2.399 *$ & $-0.494^{*}$ & $-1.463^{*}$ & $-0.584^{*}$ & $-2.212^{*}$ \\
\hline & $(0.096)$ & $(0.304)$ & $(0.096)$ & $(0.339)$ & $(0.099)$ & $(0.308)$ & $(0.101)$ & $(0.346)$ \\
\hline \multirow[t]{2}{*}{$\ln ($ spatial RAC) } & & & $-0.758 *$ & 1.052 & 0.096 & $1.984 \dagger$ & -0.546 & 2.421 \\
\hline & & & $(0.211)$ & $(0.869)$ & $(0.277)$ & $(0.929)$ & $(0.398)$ & (1.903) \\
\hline Underid Test & & 0.000 & & 0.000 & & 0.000 & & 0.000 \\
\hline F-stat & & 38.003 & & 13.256 & & 10.666 & & 10.037 \\
\hline Overid Test & & 0.834 & & 0.210 & & 0.172 & & 0.164 \\
\hline Endogeneity & & 0.000 & & 0.000 & & 0.000 & & 0.000 \\
\hline Joint Sign. Endog. & 0.000 & 0.000 & 0.000 & 0.000 & 0.000 & 0.000 & 0.000 & 0.000 \\
\hline $\mathrm{N}$ & 621 & 621 & 621 & 621 & 621 & 621 & 621 & 621 \\
\hline
\end{tabular}

Notes: $\ddagger \mathrm{p}<0.10, \dagger \mathrm{p}<0.05, * \mathrm{p}<0.01$. Standard errors are heteroskedasticity-robust. Dependent variable is chemical sector FDI minus all other manufacturing FDI. RAC is relative abatement costs. Other covariates included in Specification 1 include: average production-worker wages, land prices, energy prices, total road mileage, unemployment rate, unionization rate, region dummies, and year dummies. Specifications 2 - 4 also include spatial versions of these controls. Specification 2 uses contiguous weights; Specification 3 uses weights based on U.S. Census regions; Specification 4 uses weights based on Crone's (1998/1999) regions. Excluded instruments are market proximity, population, and tax effort (Specifications 1 4) and the spatial counterparts (Specifications 2 - 4). Underid reports the p-value of the Kleibergen-Paap (2006) rk statistic with rejection implying identification; Overid reports the p-value of Hansen J statistic with rejection casting doubt on instruments' validity; Endog reports the p-value of endogeneity test of the endogenous regressors; Joint Sign. reports the p-value of Anderson-Rubin (1949) chi-square test of significance of the endogenous regressors; F-stat reports the Kleibergen-Paap F statistic for weak identification. See text for further details. 
Table 3. Determinants of Relative FDI: Pitt \& Rosenzweig - Type Falsification Test.

\begin{tabular}{|c|c|c|c|c|c|c|c|c|}
\hline & \multicolumn{2}{|c|}{ Spec (1) } & \multicolumn{2}{|c|}{ Spec (2) } & \multicolumn{2}{|c|}{ Spec (3) } & \multicolumn{2}{|c|}{ Spec (4) } \\
\hline & OLS & IV & OLS & IV & OLS & IV & OLS & IV \\
\hline \multicolumn{9}{|c|}{ Panel A. Plant, Property, and Equipment } \\
\hline $\ln (\mathrm{RAC})$ & $\begin{array}{c}-0.509 * \\
(0.153)\end{array}$ & $\begin{array}{c}0.490 \\
(0.342)\end{array}$ & $\begin{array}{c}-0.346 \dagger \\
(0.151)\end{array}$ & $\begin{array}{c}-0.528 \\
(1.116)\end{array}$ & $\begin{array}{c}-0.294 \ddagger \\
(0.156)\end{array}$ & $\begin{array}{l}1.047^{*} \\
(0.348)\end{array}$ & $\begin{array}{l}-0.573 * \\
(0.166)\end{array}$ & $\begin{array}{c}0.654 \\
(0.455)\end{array}$ \\
\hline $\ln ($ spatial RAC) & & & $\begin{array}{c}0.296 \\
(0.325)\end{array}$ & $\begin{array}{c}6.287 \\
(5.431)\end{array}$ & $\begin{array}{c}0.708 \\
(0.452)\end{array}$ & $\begin{array}{c}1.933 \\
(1.814)\end{array}$ & $\begin{array}{l}-0.313 \\
(0.604)\end{array}$ & $\begin{array}{c}1.306 \\
(2.045)\end{array}$ \\
\hline Underid Test & & 0.000 & & 0.000 & & 0.003 & & 0.000 \\
\hline F-stat & & 34.698 & & 7.589 & & 4.103 & & 8.025 \\
\hline Overid Test & & 0.149 & & 0.000 & & 0.446 & & 0.116 \\
\hline Endogeneity & & 0.000 & & 0.094 & & 0.000 & & 0.011 \\
\hline Joint Sign. Endog. & 0.001 & 0.079 & 0.052 & 0.000 & 0.016 & 0.008 & 0.002 & 0.119 \\
\hline $\mathrm{N}$ & 469 & 469 & 469 & 469 & 469 & 469 & 469 & 469 \\
\hline \multicolumn{9}{|c|}{ Panel B. Employment } \\
\hline $\ln (\mathrm{RAC})$ & $\begin{array}{c}0.156 \\
(0.117)\end{array}$ & $\begin{array}{c}0.099 \\
(0.229)\end{array}$ & $\begin{array}{c}0.069 \\
(0.113)\end{array}$ & $\begin{array}{c}-0.472 \\
(2.228)\end{array}$ & $\begin{array}{c}0.257 \dagger \\
(0.116)\end{array}$ & $\begin{array}{l}0.642 \dagger \\
(0.283)\end{array}$ & $\begin{array}{c}0.190 \\
(0.130)\end{array}$ & $\begin{array}{c}0.254 \\
(0.262)\end{array}$ \\
\hline $\ln ($ spatial RAC) & & & $\begin{array}{l}0.921^{*} \\
(0.226)\end{array}$ & $\begin{array}{c}7.805 \\
(8.739)\end{array}$ & $\begin{array}{l}1.071^{*} \\
(0.310)\end{array}$ & $\begin{array}{l}2.023 \dagger \\
(0.980)\end{array}$ & $\begin{array}{c}0.752 \\
(0.475)\end{array}$ & $\begin{array}{c}2.050 \\
(1.350)\end{array}$ \\
\hline Underid Test & & 0.000 & & 0.000 & & 0.000 & & 0.000 \\
\hline F-stat & & 34.627 & & 10.226 & & 9.067 & & 10.627 \\
\hline Overid Test & & 0.525 & & 0.000 & & 0.000 & & 0.358 \\
\hline Endogeneity & & 0.735 & & 0.868 & & 0.052 & & 0.535 \\
\hline Joint Sign. Endog. & 0.184 & 0.701 & 0.000 & 0.000 & 0.001 & 0.000 & 0.206 & 0.271 \\
\hline $\mathrm{N}$ & 546 & 546 & 546 & 546 & 546 & 546 & 546 & 546 \\
\hline
\end{tabular}

Notes: $\ddagger \mathrm{p}<0.10, \dagger \mathrm{p}<0.05,{ }^{*} \mathrm{p}<0.01$. Dependent variable is FDI in the food and kindred products sector minus all other manufacturing FDI except the chemical sector. See Table 2 for further details. 
Table 4. Determinants of Chemical Sector FDI: OLS, Lewbel (2010), and Klein \& Vella (2009) Approaches.

\begin{tabular}{|c|c|c|c|c|c|c|c|c|c|c|c|c|}
\hline & \multicolumn{3}{|c|}{ Spec (1) } & \multicolumn{3}{|c|}{ Spec (2) } & \multicolumn{3}{|c|}{ Spec (3) } & \multicolumn{3}{|c|}{ Spec (4) } \\
\hline & OLS & IV & $\mathbf{C F}$ & OLS & IV & $\mathbf{C F}$ & OLS & IV & $\mathbf{C F}$ & OLS & IV & $\mathbf{C F}$ \\
\hline \multicolumn{13}{|c|}{ Panel A. Plant, Property, and Equipment } \\
\hline $\ln (\mathrm{RAC})$ & $\begin{array}{c}-0.198 \dagger \\
(0.092)\end{array}$ & $\begin{array}{c}-0.558 * \\
(0.195)\end{array}$ & $\begin{array}{c}-0.812 \\
(0.577)\end{array}$ & $\begin{array}{l}-0.199 \dagger \\
(0.092)\end{array}$ & $\begin{array}{c}-0.474 \dagger \\
(0.200)\end{array}$ & $\begin{array}{c}-0.946 \\
(0.586)\end{array}$ & $\begin{array}{c}-0.153 \\
(0.095)\end{array}$ & $\begin{array}{c}-0.544^{*} \\
(0.192)\end{array}$ & $\begin{array}{c}-0.826 \\
(0.639)\end{array}$ & $\begin{array}{c}-0.222 \dagger \\
(0.098)\end{array}$ & $\begin{array}{c}-0.477 \dagger \\
(0.235)\end{array}$ & $\begin{array}{c}-0.801 \\
(0.702)\end{array}$ \\
\hline $\ln ($ spatial RAC) & & & & $\begin{array}{c}-0.264 \\
(0.169)\end{array}$ & $\begin{array}{c}-1.100 \\
(0.755)\end{array}$ & $\begin{array}{c}1.482 \\
(1.379)\end{array}$ & $\begin{array}{c}-0.313 \\
(0.208)\end{array}$ & $\begin{array}{c}-1.178 * \\
(0.430)\end{array}$ & $\begin{array}{l}-2.383 \\
(1.702)\end{array}$ & $\begin{array}{c}0.323 \\
(0.310)\end{array}$ & $\begin{array}{c}0.235 \\
(1.174)\end{array}$ & $\begin{array}{c}0.366 \\
(1.383)\end{array}$ \\
\hline Underid Test & & 0.000 & & & 0.000 & & & 0.000 & & & 0.000 & \\
\hline F-stat & & 41.951 & & & 7.000 & & & 17.955 & & & 5.977 & \\
\hline Overid Test & & 0.814 & & & 0.000 & & & 0.550 & & & 0.236 & \\
\hline Endogeneity & & 0.036 & & & 0.332 & & & 0.027 & & & 0.389 & \\
\hline Joint Sign. Endog. & 0.033 & 0.030 & 0.159 & 0.023 & 0.000 & 0.376 & 0.128 & 0.022 & 0.198 & 0.018 & 0.056 & 0.149 \\
\hline $\mathrm{N}$ & 563 & 563 & 563 & 563 & 563 & 563 & 563 & 563 & 563 & 563 & 563 & 563 \\
\hline \multicolumn{13}{|c|}{ Panel B. Employment } \\
\hline $\ln (\mathrm{RAC})$ & $-0.397^{*}$ & $-0.802 *$ & -0.669 & $-0.386 *$ & $-0.719 *$ & -0.663 & $-0.291 *$ & $-0.687 *$ & -0.498 & $-0.379 *$ & $-0.886 *$ & -0.457 \\
\hline & $(0.072)$ & $(0.135)$ & $(0.588)$ & $(0.072)$ & $(0.133)$ & $(0.584)$ & $(0.071)$ & $(0.136)$ & $(0.595)$ & $(0.077)$ & $(0.168)$ & $(0.691)$ \\
\hline ln(spatial RAC) & & & & $-0.343 \dagger$ & $-0.645 \ddagger$ & -0.189 & $-0.273 \ddagger$ & $-0.824 *$ & -0.790 & 0.270 & -0.591 & -1.198 \\
\hline & & & & $(0.134)$ & $(0.343)$ & $(0.733)$ & $(0.153)$ & $(0.305)$ & $(0.705)$ & $(0.254)$ & $(0.783)$ & $(1.045)$ \\
\hline Underid Test & & 0.000 & & & 0.000 & & & 0.000 & & & 0.000 & \\
\hline F-stat & & 68.248 & & & 16.340 & & & 23.233 & & & 9.851 & \\
\hline Overid Test & & 0.137 & & & 0.001 & & & 0.138 & & & 0.710 & \\
\hline Endogeneity & & 0.000 & & & 0.020 & & & 0.003 & & & 0.001 & \\
\hline Joint Sign. Endog. & 0.000 & 0.000 & 0.255 & 0.000 & 0.000 & 0.209 & 0.000 & 0.000 & 0.415 & 0.000 & 0.000 & 0.566 \\
\hline $\mathrm{N}$ & 621 & 621 & 621 & 621 & 621 & 621 & 621 & 621 & 621 & 621 & 621 & 621 \\
\hline
\end{tabular}

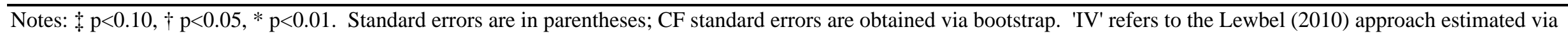

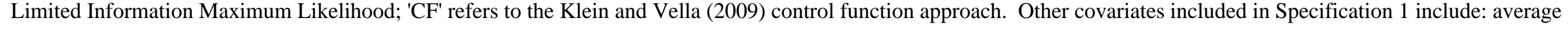

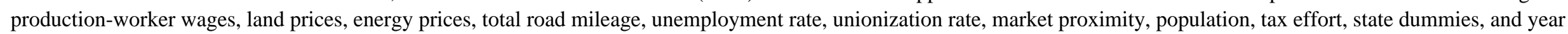

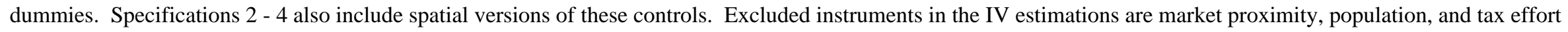

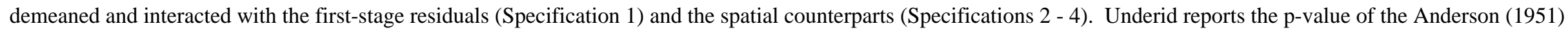

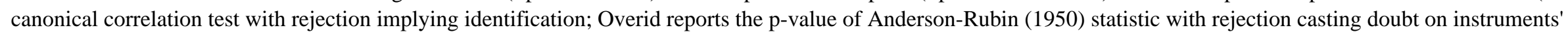

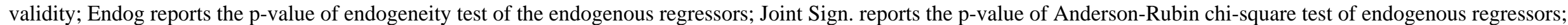
F-stat reports the Cragg and Donald (1993) F statistic for weak identification. See Table 2 for further details. 
Table 5. Determinants of Total Manufacturing FDI: OLS, Lewbel (2010), and Klein \& Vella (2009) Approaches.

\begin{tabular}{|c|c|c|c|c|c|c|c|c|c|c|c|c|}
\hline & \multicolumn{3}{|c|}{ Spec (1) } & \multicolumn{3}{|c|}{ Spec (2) } & \multicolumn{3}{|c|}{ Spec (3) } & \multicolumn{3}{|c|}{ Spec (4) } \\
\hline & OLS & IV & $\mathbf{C F}$ & OLS & IV & $\mathbf{C F}$ & OLS & IV & $\mathbf{C F}$ & OLS & IV & $\mathbf{C F}$ \\
\hline \multicolumn{13}{|c|}{ Panel A. Plant, Property, and Equipment } \\
\hline $\ln (\mathrm{RAC})$ & $\begin{array}{c}-0.079 \ddagger \\
(0.046)\end{array}$ & $\begin{array}{c}-0.155 \dagger \\
(0.073)\end{array}$ & $\begin{array}{c}-0.369 \\
(0.466)\end{array}$ & $\begin{array}{l}-0.082 \ddagger \\
(0.047)\end{array}$ & $\begin{array}{c}-0.285^{*} \\
(0.087)\end{array}$ & $\begin{array}{c}-0.472 \\
(0.356)\end{array}$ & $\begin{array}{c}-0.011 \\
(0.046)\end{array}$ & $\begin{array}{c}-0.021 \\
(0.074)\end{array}$ & $\begin{array}{l}-0.115 \\
(0.425)\end{array}$ & $\begin{array}{r}-0.086 \ddagger \\
(0.048)\end{array}$ & $\begin{array}{c}-0.110 \\
(0.083)\end{array}$ & $\begin{array}{c}-0.251 \\
(0.342)\end{array}$ \\
\hline $\ln ($ spatial RAC) & & & & $\begin{array}{l}-0.126 \\
(0.096)\end{array}$ & $\begin{array}{c}-1.166 * \\
(0.287)\end{array}$ & $\begin{array}{c}-0.902 \\
(1.021)\end{array}$ & $\begin{array}{c}-0.094 \\
(0.100)\end{array}$ & $\begin{array}{c}-0.198 \\
(0.201)\end{array}$ & $\begin{array}{c}0.577 \\
(0.548)\end{array}$ & $\begin{array}{c}0.181 \\
(0.159)\end{array}$ & $\begin{array}{c}0.690 \\
(0.471)\end{array}$ & $\begin{array}{c}-0.266 \\
(0.935)\end{array}$ \\
\hline Underid Test & & 0.000 & & & 0.000 & & & 0.000 & & & 0.000 & \\
\hline F-stat & & 137.812 & & & 15.194 & & & 34.614 & & & 14.245 & \\
\hline Overid Test & & 0.758 & & & 0.363 & & & 0.082 & & & 0.814 & \\
\hline Endogeneity & & 0.195 & & & 0.000 & & & 0.846 & & & 0.257 & \\
\hline Joint Sign. Endog. & 0.086 & 0.168 & 0.428 & 0.089 & 0.000 & 0.740 & 0.638 & 0.154 & 0.555 & 0.057 & 0.161 & 0.792 \\
\hline $\mathrm{N}$ & 811 & 811 & 811 & 811 & 811 & 811 & 811 & 811 & 811 & 811 & 811 & 811 \\
\hline \multicolumn{13}{|c|}{ Panel B. Employment } \\
\hline $\ln (\mathrm{RAC})$ & $\begin{array}{c}-0.013 \\
(0.041)\end{array}$ & $\begin{array}{c}0.042 \\
(0.065)\end{array}$ & $\begin{array}{c}0.042 \\
(0.411)\end{array}$ & $\begin{array}{l}-0.027 \\
(0.041)\end{array}$ & $\begin{array}{c}0.019 \\
(0.068)\end{array}$ & $\begin{array}{c}-0.034 \\
(0.553)\end{array}$ & $\begin{array}{c}0.053 \\
(0.040)\end{array}$ & $\begin{array}{c}0.167 * \\
(0.063)\end{array}$ & $\begin{array}{c}0.489 \\
(0.475)\end{array}$ & $\begin{array}{c}-0.042 \\
(0.043)\end{array}$ & $\begin{array}{c}-0.008 \\
(0.072)\end{array}$ & $\begin{array}{c}0.160 \\
(0.401)\end{array}$ \\
\hline $\ln$ (spatial RAC) & & & & $\begin{array}{c}0.039 \\
(0.086)\end{array}$ & $\begin{array}{c}-0.099 \\
(0.229)\end{array}$ & $\begin{array}{c}-0.310 \\
(0.475)\end{array}$ & $\begin{array}{c}-0.023 \\
(0.089)\end{array}$ & $\begin{array}{c}0.005 \\
(0.173)\end{array}$ & $\begin{array}{c}0.323 \\
(0.380)\end{array}$ & $\begin{array}{c}0.201 \\
(0.144)\end{array}$ & $\begin{array}{c}-0.027 \\
(0.418)\end{array}$ & $\begin{array}{c}-0.654 \\
(0.609)\end{array}$ \\
\hline Underid Test & & 0.000 & & & 0.000 & & & 0.000 & & & 0.000 & \\
\hline F-stat & & 147.699 & & & 17.159 & & & 37.330 & & & 14.560 & \\
\hline Overid Test & & 0.714 & & & 0.165 & & & 0.437 & & & 0.918 & \\
\hline Endogeneity & & 0.283 & & & 0.354 & & & 0.067 & & & 0.474 & \\
\hline Joint Sign. Endog. & 0.754 & 0.778 & 0.919 & 0.731 & 0.325 & 0.382 & 0.396 & 0.080 & 0.389 & 0.158 & 0.987 & 0.432 \\
\hline $\mathrm{N}$ & 814 & 814 & 814 & 814 & 814 & 814 & 814 & 814 & 814 & 814 & 814 & 814 \\
\hline
\end{tabular}

Notes: $\ddagger \mathrm{p}<0.10, \dagger \mathrm{p}<0.05, * \mathrm{p}<0.01$. See Table 4 for further details. 
Table 6. Monte Carlo Results.

\begin{tabular}{|c|c|c|c|c|c|c|c|c|c|c|}
\hline & \multicolumn{5}{|c|}{$\mathrm{N}=750$} & \multicolumn{5}{|c|}{$N=5000$} \\
\hline & OLS & PR - IV & Lewbel - IV & CF & $\begin{array}{c}\text { Traditional } \\
\text { IV }\end{array}$ & OLS & PR - IV & Lewbel - IV & $\mathbf{C F}$ & $\begin{array}{c}\text { Traditional } \\
\text { IV }\end{array}$ \\
\hline \multicolumn{11}{|l|}{ Coeff on Endogenous } \\
\hline \multicolumn{11}{|l|}{ Regressor \#1 } \\
\hline Bias & 0.394 & -0.008 & -0.003 & -0.025 & -0.002 & 0.396 & 0.007 & -0.003 & -0.006 & 0.007 \\
\hline Mean Absolute Error & 0.394 & 0.100 & 0.033 & 0.051 & 0.070 & 0.396 & 0.042 & 0.014 & 0.022 & 0.025 \\
\hline Root MSE & 0.396 & 0.125 & 0.043 & 0.067 & 0.089 & 0.396 & 0.053 & 0.017 & 0.027 & 0.030 \\
\hline \multicolumn{11}{|l|}{ Coeff on Endogenous } \\
\hline \multicolumn{11}{|l|}{ Regressor \#2 } \\
\hline Bias & -0.521 & -0.005 & 0.003 & 0.030 & -0.004 & -0.522 & 0.006 & 0.002 & 0.010 & -0.005 \\
\hline Mean Absolute Error & 0.521 & 0.099 & 0.035 & 0.058 & 0.070 & 0.522 & 0.042 & 0.013 & 0.024 & 0.028 \\
\hline Root MSE & 0.522 & 0.125 & 0.045 & 0.076 & 0.089 & 0.522 & 0.053 & 0.017 & 0.030 & 0.034 \\
\hline
\end{tabular}

" Notes: 1000 simulations used when N = 750; 100 simulations used when N = 5000. OLS = Ordinary Least Squares; PR-IV = Pitt and Rosenzweig (1990) IV estimator; Lewbel-IV = Lewbel (2010) IV estimator; CF = Klein and Vella (2009) control function estimator; Traditional-IV = IV estimator based on usual exclusion restrictions. MSE $=$ Mean Squared Error. See text for further details. 
Table 7. Empirical Monte Carlo Results: Lewbel (2010) and Klein \& Vella (2009) Approaches.

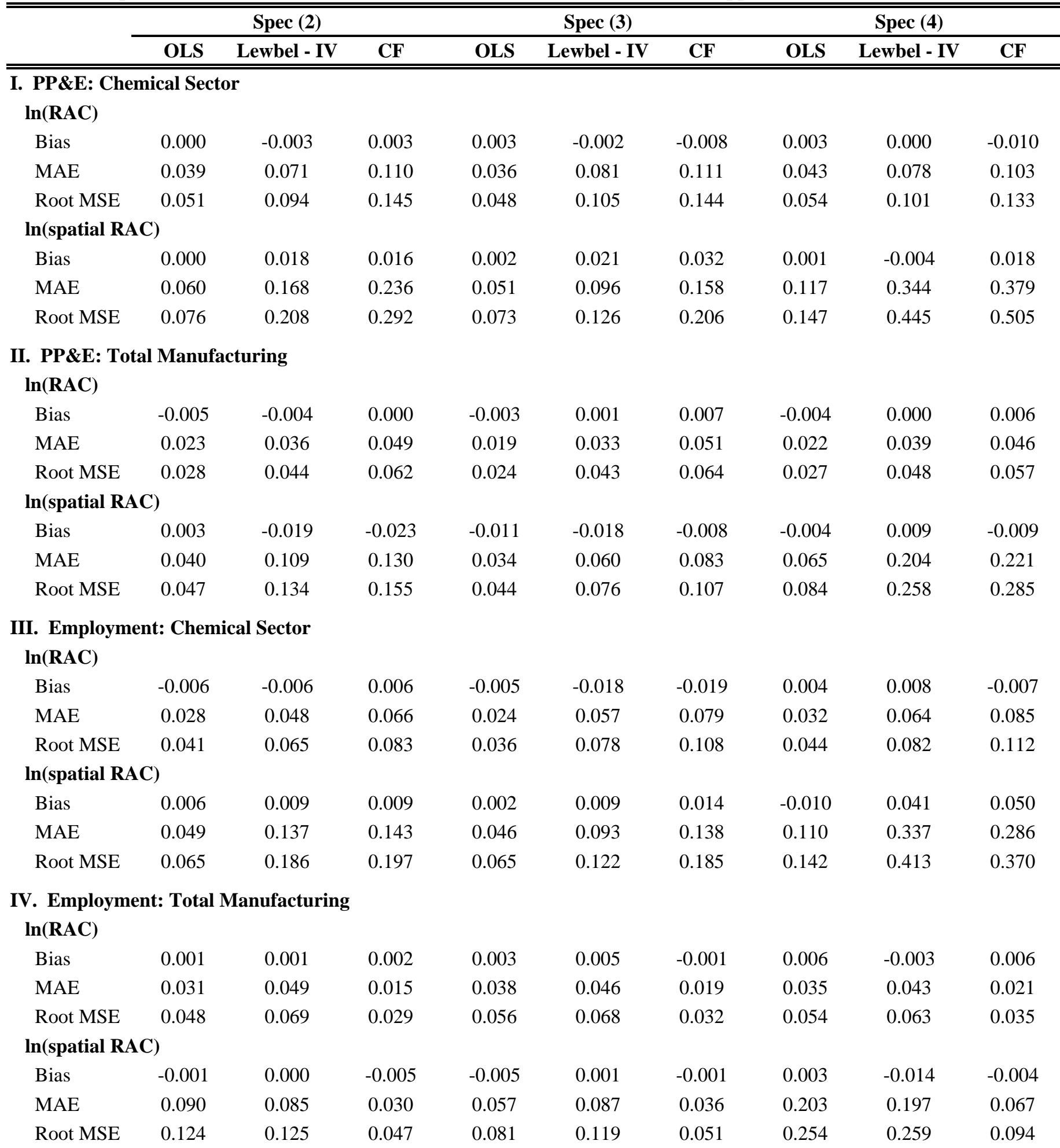

Notes: 100 simulations used, where $\ln (\mathrm{RAC})$ and $\ln ($ spatial RAC) are replaced by random draws from the empirical distribution of each variable. RAC is relative abatement costs. Specification 2 uses contiguous weights; Specification 3 uses weights based on U.S. Census regions; Specification 4 uses weights based on Crone's (1998/1999) regions. MAE = Mean Absolute Error; MSE = Mean Squared Error. See text and Table 6 for further details. 
Table 8. Empirical Monte Carlo Results: Pitt \& Rosenzweig (1990) Approach.

\begin{tabular}{|c|c|c|c|}
\hline & Spec (2) & Spec (3) & Spec (4) \\
\hline \multicolumn{4}{|l|}{ I. PP\&E } \\
\hline \multicolumn{4}{|l|}{$\ln (\mathrm{RAC})$} \\
\hline Bias & 0.054 & 0.019 & 0.007 \\
\hline MAE & 0.171 & 0.150 & 0.166 \\
\hline Root MSE & 0.211 & 0.184 & 0.201 \\
\hline \multicolumn{4}{|c|}{ In(spatial RAC) } \\
\hline Bias & 0.008 & -0.023 & 0.081 \\
\hline MAE & 0.139 & 0.199 & 0.503 \\
\hline Root MSE & 0.180 & 0.255 & 0.619 \\
\hline \multicolumn{4}{|c|}{ II. Employment } \\
\hline \multicolumn{4}{|l|}{$\ln (\mathrm{RAC})$} \\
\hline Bias & 0.000 & 0.011 & -0.004 \\
\hline MAE & 0.117 & 0.111 & 0.120 \\
\hline Root MSE & 0.158 & 0.145 & 0.159 \\
\hline \multicolumn{4}{|c|}{ In(spatial RAC) } \\
\hline Bias & 0.005 & -0.024 & 0.008 \\
\hline MAE & 0.120 & 0.135 & 0.447 \\
\hline Root MSE & 0.151 & 0.178 & 0.558 \\
\hline
\end{tabular}

Notes: 100 simulations used, where $\ln (\mathrm{RAC})$ and $\ln ($ spatial RAC) are replaced by random draws from the empirical distribution of each variable. Dependent variable is chemical sector FDI minus all other manufacturing FDI. MAE = Mean Absolute Error; MSE = Mean Squared Error. See text and Table 7 for further details. 


\title{
Three New Empirical Tests of the Pollution Haven Hypothesis When Environmental Regulation is Endogenous
}

\author{
Daniel L. Millimet* \\ Southern Methodist University \& IZA \\ Jayjit Roy \\ Appalachian State University
}

August 4, 2011

\begin{abstract}
The validity of existing empirical tests of the Pollution Haven Hypothesis (PHH) is constantly under scrutiny due to two shortcomings. First, the issues of unobserved heterogeneity and measurement error in environmental regulation are typically ignored due to the lack of a credible, traditional instrumental variable. Second, while the recent literature has emphasized the importance of geographic spillovers in determining the location choice of foreign investment, such spatial effects have yet to be adequately incorporated into empirical tests of the PHH. As a result, the impact of environmental regulations on trade patterns and the location decisions of multinational enterprises remains unclear. In this paper, we circumvent the lack of a traditional instrument within a model incorporating geographic spillovers utilizing three novel identification strategies. Using state-level panel data on inbound U.S. FDI, relative abatement costs, and other determinants of FDI, we consistently find (i) evidence of environmental regulation being endogenous, (ii) a negative impact of own environmental regulation on inbound FDI in pollution-intensive sectors, particularly when measured by employment, and (iii) larger effects of environmental regulation once endogeneity is addressed. Neighboring environmental regulation is not found to be an important determinant of FDI.
\end{abstract}

JEL: C31, F21, Q52

Keywords: Foreign Direct Investment, Environmental Regulation, Spillovers, Instrumental Variables, Control Function, Heteroskedasticity

${ }^{*}$ The authors are grateful to Arik Levinson for providing the data, and comments from Arik Levinson, Arthur Lewbel, Frank Vella, Per Fredriksson and seminar participants at SMU and Tulane University, and conference participants at Texas Camp Econometrics XVI, the 2010 Southern Economic Association Meetings, and the 2011 Western Economic Association Meetings. Corresponding author: Daniel Millimet, Department of Economics, Box 0496, Southern Methodist University, Dallas, TX 75275-0496. Tel: (214) 768-3269. Fax: (214) 768-1821. E-mail: millimet@smu.edu. 


\section{Introduction}

The precise relationship between environmental policy, the location of production, and subsequent trade flows remains an open and hot-button issue. Of particular concern is the so-called Pollution Haven Hypothesis $(\mathrm{PHH})$, whereby a reduction in trade barriers enables polluting multinational enterprises (MNEs) to outsource (at least some) production activities to areas with less stringent environmental regulation, thereby altering both the spatial distribution of economic activity and subsequent trade patterns through the creation of havens for polluting firms. Kellenberg (2009, p. 242) states that "the empirical validity of pollution haven effects continues to be one of the most contentious issues in the debate regarding international trade, foreign investment, and the environment." Brunnermeier and Levinson (2004, p. 6) characterize the debate as "particularly heated."

Proper examination of this relationship is crucial for several reasons. First, understanding determinants of trade patterns and the spatial distribution of MNE activity is imperative in the current economic climate. In particular, given the dramatic rise in foreign direct investment (FDI) relative to trade volumes over the past two decades, understanding the behavior of MNEs is critical. For example, global FDI inflows rose from less than $\$ 600$ billion in 2003 to roughly $\$ 2.1$ trillion in 2007 in nominal terms (UNCTAD 2010). Aggregate inbound FDI stocks rose from $\$ 2.1$ trillion in 1990 to nearly $\$ 18$ trillion in 2009 in nominal terms (UNCTAD 2010). Moreover, the U.S. is the largest recipient of global FDI flows, receiving $\$ 316$ billion in FDI inflows in 2008, roughly $\$ 100$ billion more than the next two largest hosts combined (Belgium and China).

Second, if countries are able to attract (or deter) FDI by manipulating environmental regulations, then international coordination may be necessary to avoid Pareto-inefficient levels of regulation due to transboundary pollutions or other spillovers (e.g., Levinson 1997, 2003). Third, if countries are able to influence the location of MNE activity and ultimately trade patterns through environmental regulation, then bringing environmental policies under the purview of trade agreements may be necessary to realize the intended effects of such agreements. Fourth, and related to this prior point, existing institutional structures such as the World Trade Organization (WTO) may be used to impede countries from choosing their desired environmental policies if such policies can be shown to impact trade flows between members. Finally, a detailed analysis of the PHH has broader implications for the general study of capital competition (e.g., Wilson 1999).

Despite the high stakes, the existing literature has been unable to convincingly assess the empirical validity of the PHH for three reasons. First, environmental regulation is complex and multidimensional, making any empirical measure fraught with measurement error. Shadbegian and Wolverton (2010, p. 13) 
state: "Measuring the level of environmental stringency in any meaningful way is quite difficult, whether at the national, state, or local level." The difficulty arises from the fact that different regulations typically cover different pollutants, regulations may exist at multiple levels (e.g., federal and local), and monitoring and enforcement are imperfect. Along these lines, Levinson (2008, p. 1) states: "The problem is not merely one of collecting the appropriate data; merely conceiving of data that would represent [environmental stringency] is difficult." Xing and Kolstad (2002, p. 3) refer to the measurement of environmental regulation as "no easy task" due to its "complexity." Moreover, depending on the empirical measure employed, the measurement error need not be classical and any bias may be accentuated by the reliance on fixed effects methods in the recent literature.

Second, even if an accurate measure of environmental regulation is available, it may be endogenous for other reasons (e.g., Levinson 2008; Levinson and Taylor 2008). For example, it may be correlated with unobserved determinants of location choice such as tax breaks or other firm-specific treatments, the provision of other public goods in addition to environmental quality (e.g., infrastructure), agglomeration, the stringency of other regulations such as occupational safety standards, corruption, local political activism, political institutions, etc. (see Arauzo-Carod et al. (2010) for a review). In addition, reverse causation may be an issue. For instance, anticipation of low FDI inflows may drive reductions in environmental stringency. Or, an increase in FDI may increase the efficacy of industrial lobby groups (e.g., Cole et al. 2006; Cole and Fredriksson 2009). Conversely, as Keller and Levinson (2002, p. 695) state: "Those states that do not attract a lot of polluting manufacturing probably do not enact stringent regulations - there simply is less need to worry about industrial pollution in states with less industrial activity, and those states that do attract polluting manufacturing may respond by enacting more stringent regulation." Levinson (2010, p. 63) summarizes these arguments succinctly: "International trade has environmental consequences, and environmental policy can have international trade consequences."

Third, existing studies of the PHH inadequately incorporate geographic spillovers. Recent theoretical models emphasize that the extent of MNE activity in one location depends not just on attributes of that location, but also on the attributes of other potential hosts. Moreover, the predicted direction of the crosseffects is not always in the opposite direction of the own-effects, a restriction that is implicit in discrete choice models (e.g., Yeaple 2003; Ekholm et al. 2003; Grossman et al. 2003; Baltagi et al. 2007, 2008; Blonigen et al. 2007, 2008; Arauzo-Carod et al. 2010). Failure to account for geographic spillovers in empirical analyses of PHH may lead to biased inference. This may be particularly problematic in the context of empirical analyses of inbound U.S. FDI since state-level environmental regulations have been shown to be strongly related to the regulatory stringency of neighboring states (Fredriksson and Millimet 2002). 
While these shortcomings, particularly the first and second, are well known, convincing solutions have proven elusive due to the difficulty of finding valid exclusion restrictions. In this paper, we simultaneously address these three shortcomings while examining the spatial distribution of inbound U.S. manufacturing FDI across the 48 contiguous states. Geographic spillovers are incorporated in an unrestricted manner by including a spatially lagged counterpart for each state-level attribute. Measurement error, unobserved heterogeneity, and reverse causation concerns are then addressed utilizing three novel identification strategies designed to circumvent the need to identify valid exclusion restrictions in the usual sense. As each does so under a different set of assumptions, utilizing all three strategies enables us to assess the robustness of the results to the identifying assumptions.

The first method generates instruments utilizing a differencing strategy based on Pitt and Rosenzweig (1990). The key identifying assumptions are that the marginal effects of certain covariates are identical across pollution-intensive and non-pollution-intensive sectors, and these covariates are significantly related to environmental stringency. The second and third methods are based on identification strategies that utilize higher moments of the data. Klein and Vella's (2009, 2010) and Lewbel's (2010) approaches each exploit conditional second moments to circumvent the need for traditional instruments. Identification is achieved in the Klein and Vella $(2009,2010)$ approach by assuming that while the errors are heteroskedastic, the conditional correlation between the errors is constant. In the Lewbel (2010) approach, identification is achieved through the presence of covariates related to the conditional variance of the first-stage errors, but not the conditional covariance between first- and second-stage errors.

In addition to the application, we also undertake a small-scale Monte Carlo study. While the performance of the estimators considered here have been evaluated previously using simulated data, to our knowledge these evaluations have been confined to the case of a single endogenous regressor. Here, we verify that each method extends to the case of multiple endogenous variables (as in our application). We also undertake a so-called empirical Monte Carlo design based on Huber et al. (2010) that simulates placebo values of the endogenous variables within the real data from our analysis.

The results are striking. In terms of the estimation approaches, we indeed verify that all three identification strategies perform well in settings with two endogenous variables. In addition, the performances of the Klein and Vella (2009) and Lewbel (2010) approaches are comparable to the performance of a traditional instrumental variable (IV) estimator when strong, valid exclusion restrictions are available.

In terms of the application, using state-level panel data, we consistently find (i) evidence of environmental regulation being endogenous when examining the behavior of pollution-intensive industries, (ii) a negative impact of own environmental stringency on inbound FDI in pollution-intensive sectors, particularly when measured by employment, and (iii) significantly larger effects of environmental regulation once 
endogeneity is addressed. Neighboring environmental regulation is not an important determinant of FDI (although the estimates are relatively imprecise in the analysis and the empirical Monte Carlo study). However, spillovers from other attributes are present (although not the focus of this study), indicating the importance of incorporating spatial effects more generally in models of FDI determination. Thus, while not homogeneous (as in Henderson and Millimet (2007) and Ederington et al. (2005)), environmental regulation is a significant determinant of location choice by some MNEs at least at the regional level. As such, policymakers should be concerned about the incentives for localities to set regulation at Pareto-inefficient levels and governments to influence trade patterns in highly pollution-intensive industries through the strategic manipulation of environmental policy.

The remainder of the paper is organized as follows. Section 2 presents a brief literature review, concentrating on prior studies attempting to address endogeneity concerns. Section 3 describes the empirical methods, the data, and the results. Finally, Section 4 concludes.

\section{Literature Review}

The literature assessing the empirical validity of the PHH has yet to reach a consensus due to the numerous complexities confronted by researchers. ${ }^{1}$ Levinson (2008) effectively separates the literature into first and second generation studies. The first generation encompasses cross-sectional studies treating environmental regulation as exogenous. These studies typically found no statistically meaningful evidence in support of the PHH (and sometimes found counter-intuitive effects). The second generation predominantly encompasses panel data studies designed to remove unobserved heterogeneity invariant along some dimension (most often time, but occasionally across sectors differentiated by pollution intensity). Panel approaches, however, require environmental regulation to be strictly exogenous conditional on the (typically time invariant) unobserved heterogeneity (and other covariates). A few studies within this second generation have attempted to relax this assumption and utilize traditional IV approaches. These second generation studies typically find economically and statistically significant evidence in support of the PHH.

As mentioned, it is unlikely that existing panel studies are sufficient to yield unbiased estimates of the impact of environmental regulation on the location of economic activity and/or subsequent trade patterns. The omission of third-country effects, the omission of variables that vary over time or differentially affect pollution-intensive and non-pollution-intensive sectors such as tax breaks and agglomeration effects, measurement error in proxies for environmental regulation, and dependence between current environmental regulation and past (or current) shocks to economic activity point strongly to violations of strict exogeneity

\footnotetext{
${ }^{1}$ See Jaffe et al. (1995), Copeland and Taylor (2004), and Brunnermeier and Levinson (2004) for reviews of the literature.
} 
(e.g., Henderson 1997; List et al. 2003; Cole and Fredriksson 2009).

Recognizing this, several studies test the PHH utilizing traditional exclusion restrictions. These studies are summarized in Table 1. At the risk of over-simplifying the literature, the instruments used generally fall within three categories. The first set includes lagged environmental regulation or lags of other covariates (Cole and Elliott 2005; Jug and Mirza 2005; Ederington and Minier 2003). For such variables to represent valid instruments, the error term should not be serially correlated, which may be particularly unrealistic if measurement error is serially correlated or agglomeration effects are not accurately modeled. Both are distinct possibilities. Serial correlation in measurement error is likely due to the use of the same imperfect proxy over time. Agglomeration effects are not likely to be modeled perfectly given their complex nature due to multiple origins (e.g., domestic versus foreign and within and across industries) and non-linearities (Arauzo-Carod et al. 2010).

The second set includes instruments based on the geographic dispersion of industries (Levinson and Taylor 2008; Cole et al. 2005; Ederington et al. 2004; List et al. 2003). Specifically, the level of pollution emitted by other industries in the locations where a given industry tends to locate is used to generate instruments. For such variables to be valid instruments, the geographic distribution of industries must be exogenous. However, as with the first set of instruments, these instruments are likely to be correlated with the error term if agglomeration effects are not accurately modeled. In fact, the instruments fail the Sargan overidentification test at the $p<0.01$ confidence level in Levinson and Taylor (2008). Similar instruments do fare better in Cole et al. (2005).

The final set of instruments include a variety of contemporaneous, location-specific attributes that are hypothesized to impact environmental regulation but not directly impact firm location decisions or trade patterns. Examples range from economic variables such as attributes of the agricultural sector, per capita income, and public expenditures to demographic variables such as urbanization, infant mortality, population density, and schooling to political economy variables such as corruption, and proxies for industry lobby bargaining power. Kellenberg (2009) also utilizes some spatially lagged covariates as exclusion restrictions. Needless to say, one can plausibly argue in each case that such variables may also directly impact firm location or trade patterns, or be correlated with the error term due to non-classical measurement error or omitted geographic spillovers, agglomeration effects, or other sources of heterogeneity. Brunnermeier and Levinson (2004, p. 37), reviewing the literature at the time, state that "as is always true of instrumental variable analyses, the instruments are open to critique." That said, Kellenberg (2009) is noteworthy as the instruments fare well in terms of the usual specification tests.

Despite the suspect validity of the identification strategies employed in these prior studies, rigorous specification testing is noticeably absent in many. A few discuss the strength of the first-stage relationship 
and/or conduct Hausman-type tests for endogeneity, but most neglect to test or even discuss why the proposed instruments should be exogenous or excluded from the second-stage equation for location choice or trade patterns; Levinson and Taylor (2008) and Kellenberg (2009) are notable exceptions. Nonetheless, these studies nearly universally obtain a more detrimental effect of environmental regulation on the behavior of pollution intensive sectors once endogeneity is (attempted to be) addressed. Given this background, we now turn to our analysis.

\section{Empirical Analysis}

\subsection{Structural Model}

To fix ideas, a typical model used to assess determinants of (continuous) measures of FDI stocks or flows with panel data is a standard two-way fixed effects specification:

$$
\ln \left(F D I_{i t}\right)=\eta_{i}+\lambda_{t}+\sum_{k} \beta_{k} x_{i k t}+\varphi_{i t}
$$

where $F D I$ is some measure of MNE activity in location $i$ and time $t, x_{k}, k=1, \ldots, K$, are time-varying observable attributes of location $i, \eta_{i}$ and $\lambda_{t}$ are location and period fixed effects, respectively, and $\varphi_{i t}$ is the error term. A proxy for environmental regulation is one element in $x$. As is well known, consistent estimates of the parameters in (1) requires $x$ to be strictly exogenous.

As discussed previously, the model in (1) is potentially flawed due to the exclusion of geographic spillovers. The omission of spillovers is one reason why the strict exogeneity assumption may fail in practice. Thus, we begin by augmenting (1) to include spatially lagged counterparts for each covariate:

$$
\ln \left(F D I_{i t}\right)=\eta_{i}+\lambda_{t}+\sum_{k}\left[\beta_{k} x_{i k t}+\delta_{k} \sum_{j \in \Omega} \omega_{i j t} x_{j k t}\right]+\varepsilon_{i t}
$$

where $\varepsilon_{i t} \equiv \varphi_{i t}-\sum_{k} \delta_{k} \sum_{j \in \Omega} \omega_{i j t} x_{j k t}, \omega$ is the weight given by location $i$ to neighbor $j$ in period $t, \Omega$ includes the set of neighbors of location $i$, and $\varepsilon_{i t}$ is the new error term. Even if all elements in the regressors in the augmented model are strictly exogenous, estimation of (2) is nonstandard given the introduction of the weights, $\omega$. To proceed, the weights must be chosen a priori.

As is well known in these types of models, the choice of the weights is ad hoc; thus, the spatially lagged variables are potentially measured with error. Prior to discussing the weighting schemes utilized, two comments are warranted. First, if the weights are mis-specified, this would likely attenuate the estimates of $\delta_{k}$ to zero, as we are essentially looking for evidence of spillovers in the wrong place. Thus, the estimates should be interpreted as lower bounds (in absolute value). However, if we find evidence of geographic 
spillovers, then this is not particularly problematic. Second, as discussed below, since we are treating own and neighboring environmental regulation as endogenous, we are able to recover consistent estimates (under the assumptions of the estimators utilized) of neighboring environmental regulation as long as the signal-noise ratio is not negligible.

That said, we utilize three straightforward weighting schemes. First, we assign a weight of zero to non-contiguous neighbors and equal weights to all contiguous neighbors. In other words, $\sum_{j} \omega_{i j t} x_{j k t}$ simplifies to the mean of $x_{j k t}$ in neighboring states. Second, following Fredriksson and Millimet (2002), we adopt two regional breakdowns for the 48 mainland U.S. states (see Appendix A). The use of regional weights is also motivated by the evidence in Glick and Woodward (1987) that foreign-owned affiliates in manufacturing tend to serve regional markets. For each regional breakdown, $\sum_{j} \omega_{i j t} x_{j k t}$ simplifies to the mean of $x_{j k t}$ in all other neighbors within the same region (again, giving each regional neighbor equal weight). The two regional classifications come from the U.S. Bureau of Economic Analysis (BEA) and Crone (1998/1999). The BEA regional classification system was introduced in the 1950s and has never been amended. While this classification system is widely used by economists in studying regional economic activity, Crone (1998/1999) devised an alternative regional breakdown for U.S. states using cluster analysis to group states according to similarities in economic activity. We refer to these weighting schemes as BEA and Crone regional weights, respectively.

Even with specification of the weights, estimation of (2) is complicated by the fact that own and neighboring environmental regulation are likely correlated with the error term, $\varepsilon$, due to measurement error, spatial error correlation, unobserved heterogeneity, and/or reverse causation. Thus, traditional fixed effects estimates are not likely to yield consistent estimates of $\beta$ and $\delta$. Before discussing our approach to identification, we briefly discuss the structure of the data as this will make the empirical approaches easier to document. We then present each estimation method along with its results.

\subsection{Data}

The data come directly from Keller and Levinson (2002); thus, we provide only limited details. Summary statistics are provided in the Appendix. The data cover the 48 contiguous U.S. states from 1977 - 1994, omitting 1987 due to missing data on abatement costs. The measures of FDI include the value of gross property, plant, and equipment (PP\&E) of foreign-owned affiliates for all manufacturers, as well as just for the chemical sector (1992 - 1994 omitted), and employment at foreign-owned affiliates for all manufacturers, as well as just for the chemical sector $\left(1992-1994\right.$ omitted). ${ }^{2}$ The chemical sector (SIC 28) is

\footnotetext{
${ }^{2}$ For each dependent variable, the sample represents an unbalanced panel where the number of observations for total manufacturing PP\&E (employment) are 811 (814); for chemical sector PP\&E (employment), the sample size is 563 (621).
} 
analyzed in isolation given that FDI in these industries is most likely to be responsive to spatial variation in environmental stringency given the pollution-intensive nature of production (Ederington et al. 2005).

Consistent with figures reported elsewhere, inbound FDI stocks increased tremendously over the sample period. Aggregate manufacturing PP\&E increased over tenfold from 1977 to 1994, from roughly $\$ 20$ million to nearly $\$ 300$ million (in 1982 US\$). An increase of similar proportion occurred in the chemical sector from 1977 to 1991, from roughly $\$ 10$ million to $\$ 90$ million. Employment grew at a slower, but still substantial, rate, increasing from roughly 675,000 to almost 2.3 million in aggregate manufacturing; 190,000 to 500,000 in the chemical sector.

In the theoretical model of inbound FDI presented in Blonigen et al. (2008), determinants of FDI include trade costs, cost and demand shifters, and parent country attributes. Here, total road mileage and state effects capture time-varying and time invariant (e.g., distance to ports) differences in trade costs across states. Population and market proximity (a distance-weighted average of all other states' gross state products) reflect market size and demand shocks. Relative abatement costs (RAC), unemployment rate, unionization rate, average production-worker wages across the state, land prices, energy prices, and tax effort (actual tax revenues divided by those that would be collected by a model tax code, as calculated by the Advisory Commission on Intergovernmental Relations) capture variation in production costs and resource availability. RAC is the proxy for environmental regulation. This measure is attributable to Levinson (2001) and represents the ratio of actual state-level abatement costs to predicted state-level abatement costs, where the predicted value is based on the industrial composition of the state. Consequently, higher values indicate relatively more stringent environmental protection. The index varies over time and across states. Finally, since FDI is aggregated across all countries outside the U.S., time effects capture parent country attributes. All variables are expressed in logarithmic form with the exception of the unemployment and unionization rates. In addition, we form the spatially lagged variables first and then take logs, again with the exception of spatially lagged unemployment and unionization rates.

Prior to continuing, it is important to note that the Spearman rank correlation between RAC and total manufacturing FDI as measured by PP\&E is positive $(\rho=0.11, p=0.003)$; the correlation is even stronger when only considering the chemical sector $(\rho=0.13 ; p=0.001)$. Neither correlation is statistically significant using employment to measure FDI. Moreover, as shown in Keller and Levinson (2002), total manufacturing FDI as measured by employment (and PP\&E) increased by more over the sample period in the 20 states experiencing the largest increase in RAC than in the 20 states experiencing the largest decline in RAC. In addition, Table A1 in the Appendix shows that mean total manufacturing FDI as measured by PP\&E is higher when RAC exceeds one (indicating more stringent environmental regulation), as well as for the chemical and non-chemical sectors considered separately. However, mean total manufacturing 
employment, as well as in the chemical and non-chemical sectors, is lower in states with RAC greater than one. In any event, finding statistical evidence consistent with the PHH, particularly using data on PP\&E, would appear to require the existence of significant selection (on either observed or unobserved variables) into more stringent RAC.

\subsection{Estimation}

\subsubsection{Pitt \& Rosenzweig (1990) Approach}

Model The first identification strategy used to address the potential endogeneity of own and spatially lagged environmental regulation is based on the approach put forth in Pitt and Rosenzweig (1990). Pitt and Rosenzweig (1990) are concerned with the impact of an endogenous household-level variable on children differentiated by gender. Lacking a traditional exclusion restriction, the solution proposed entails examining the differential effect of the endogenous variable on sons versus daughters and generating exclusion restrictions by assuming that some exogenous household-level covariates have identical effects on boys and girls. In our application, we apply this logic to assess the differential effect of own and spatially lagged environmental regulation on two types of FDI: FDI in pollution-intensive and non-pollution-intensive sectors. Valid exclusion restrictions are generated by assuming that some exogenous state-level covariates have equal effects on FDI across these two sectors.

Formally, we re-write the structural model in $(2)$ separately for pollution-intensive $(P)$ manufacturing sectors and non-pollution-intensive $(N P)$ manufacturing sectors:

$$
\begin{array}{r}
\ln \left(F D I_{i t}^{p}\right)=\eta_{i}^{p}+\lambda_{t}^{p}+\sum_{k=1}^{K_{1}}\left[\beta_{1 k}^{p} x_{1 i k t}+\delta_{1 k}^{p} \sum_{j \in \Omega} \omega_{i j t} x_{1 j k t}\right] \\
+\sum_{k=1}^{K_{2}}\left[\beta_{2 k} x_{2 i k t}+\delta_{2 k} \sum_{j \in \Omega} \omega_{i j t} x_{2 j k t}\right]+\varepsilon_{i t}^{p} \\
\ln \left(F D I_{i t}^{n p}\right)=\eta_{i}^{n p}+\lambda_{t}^{n p}+\sum_{k=1}^{K_{1}}\left[\beta_{1 k}^{n p} x_{1 i k t}+\delta_{1 k}^{n p} \sum_{j \in \Omega} \omega_{i j t} x_{1 j k t}\right] \\
+\sum_{k=1}^{K_{2}}\left[\beta_{2 k} x_{2 i k t}+\delta_{2 k} \sum_{j \in \Omega} \omega_{i j t} x_{2 j k t}\right]+\varepsilon_{i t}^{n p}
\end{array}
$$

where $K_{1}+K_{2}=K$. Thus, $x_{1}$ includes a subset of $x$ for which the marginal effects on FDI are allowed to differ depending on the pollution intensity of the industry. The marginal effects of covariates included in $x_{2}$ are assumed to be constant across sectors (and thus lack a $p$ or $n p$ superscript). In the analysis, we take the chemical sector as the pollution-intensive sector and all other manufacturing sectors as the (relatively) non-pollution-intensive sector (e.g., Xing and Kolstad 2002; Wagner and Timmins 2009). While there are 
certainly other data partitions one may try (conditional on data availability), results based on treating only the chemical sector as pollution-intensive should yield evidence of the PHH if it exists.

Subtracting (4) from (3) in each time period yields

$$
\begin{aligned}
\Delta \ln \left(F D I_{i t}\right) & =\Delta \eta_{i}+\Delta \lambda_{t}+\sum_{k=1}^{K_{1}}\left[\Delta \beta_{1 k} x_{1 i k t}+\Delta \delta_{1 k} \sum_{j \in \Omega} \omega_{i j t} x_{1 j k t}\right]+\Delta \varepsilon_{i t} \\
& \equiv \widetilde{\eta}_{i}+\widetilde{\lambda}_{t}+\sum_{k=1}^{K_{1}}\left[\Delta \beta_{1 k} x_{1 i k t}+\Delta \delta_{1 k} \sum_{j \in \Omega} \omega_{i j t} x_{1 j k t}\right]+\Delta \varepsilon_{i t} .
\end{aligned}
$$

In (5) $x_{2 i k t}$ and $\sum_{j \in \Omega} \omega_{i j t} x_{2 j k t}, k=1, \ldots, K_{2}$, are available as exclusion restrictions. ${ }^{3}$

This identification strategy relies on choosing a set of exogenous controls, $x_{2}$, and imposing the restrictions that $\beta_{2}^{p}=\beta_{2}^{n p}=\beta_{2}$. If the restrictions imposed lead to an overidentified model (i.e., there are at least two variables in $x_{2}$ ), then the usual overidentification test constitutes a test of the restrictions imposed. To see this, note that if $\beta_{2 k}$ or $\delta_{2 k}$ does in fact differ across sectors differentiated by pollution intensity, then the error term in (5) will contain terms such as $\Delta \beta_{2 k} x_{2 i k t}$ or $\Delta \delta_{2 k} \sum_{j=1}^{48} \omega_{i j t} x_{2 j k t}$ and the resulting instruments will be correlated with the error.

While this approach aids in the generation of instruments for environmental regulation, it does so at a cost (even if the restrictions are valid). Specifically, the approach only provides consistent estimates of $\Delta \beta_{1}$ and $\Delta \delta_{1}$, not the individual, structural parameters from (4) and (3). Thus, ignoring the case where $\beta_{1}^{n p}$ and $\delta_{1}^{n p}$ equal zero, this approach only identifies the differential effects of the (own and spatially lagged) covariates in $x_{1}$ on inbound FDI in pollution-intensive relative to non-pollution-intensive sectors. While one might be tempted to assume that the parameters in $\beta_{1}^{n p}$ and $\delta_{1}^{n p}$ corresponding to own and spatially lagged environmental regulation are zero, this is unlikely to be the case. On the one hand, our definition of the non-pollution-intensive sector still includes some polluting industries since it aggregates all manufacturing sectors except the chemical sector. On the other hand, when treating environmental regulation as exogenous and ignoring geographic spillovers, Henderson and Millimet (2007) obtain some positive and statistically meaningful nonparametric regression estimates of the association between environmental regulation and inbound U.S. FDI. Similarly, Mulatu et al. (2010) obtain a statistically insignificant, but positive effect of environmental stringency on production shares in the least pollution-intensive sectors. Thus, the magnitudes and even the signs of $\beta_{1}^{n p}$ and $\delta_{1}^{n p}$ are unknown.

\footnotetext{
${ }^{3}$ Note, this approach is similar to the strategy employed in Wagner and Timmins (2009). However, in that study, the authors assume that environmental regulation is exogenous in their analog to the differenced equation given by (5). Thus, their identification strategy requires no location-specific unobservables be correlated with environmental regulation, but differentially associated with investment across sectors by pollution intensity. As shown below, this assumption is rejected in our data.
} 
Results The results are presented in Panels A (PP\&E) and B (employment) in Table 2. The specifications estimated correspond to (5) except that the differenced state fixed effects, $\widetilde{\eta}_{i}$, are replaced with region dummies. Thus, we are assuming that time invariant attributes that differentially affect sectors according to their pollution intensity are constant within regions. Estimation is performed using ordinary least squares (OLS) and limited information maximum likelihood (LIML) which has been shown to perform relatively well in small samples with weaker instruments (e.g., Stock et al. 2002; Flores-Lagunes 2007). The variables in $x_{2}$ include market proximity, population, and tax effort as such variables should be equally relevant to all manufacturing industries. Four specifications are estimated. Specification 1 omits all geographic spillovers. Specifications 2-4 include such spillovers, where Specification 2 uses the contiguous weighting scheme and Specifications 3 and 4 use the BEA and Crone regional weighting schemes, respectively. Finally, note that we only display the point estimates for own and neighboring environmental regulation to conserve space. Full estimation results are available upon request.

Turning to the results, four findings emerge. First, the OLS estimates are negative and statistically significant, as well as significantly larger in magnitude than the estimates reported in Keller and Levinson (2002). This difference follows from a change in the definition of the dependent variable, as well as the fact that the model in (5) eliminates time-varying unobservables that are correlated with both FDI and environmental regulation, but affect FDI equally across sectors (e.g., local macroeconomic shocks or political corruption). In addition, the OLS estimates are fairly stable across the four specifications; neighboring environmental regulation is statistically significant only in Specification 2.

Second, the identification strategy works well as determined by the usual IV specification tests, particularly when using employment to measure FDI. Specifically, we reject the null that the model is underidentified at the $p<0.01$ confidence level in every case using Kleibergen and Paap's (2006) rk statistic, and the Kleibergen and Paap (2006) F-statistic is reasonably large. In addition, we fail to reject the validity of the instruments using Hansen's overidentification test in all cases when using employment to measure FDI, and in Specifications 2 and 3 in Panel A at the $p<0.05$ confidence level. Thus, the Pitt and Rosenzweig (1990) approach fares well in the current application. Third, in both panels, we reject exogeneity of own environmental regulation in Specification 1 and own and neighboring environmental regulation in Specifications 2-4. Thus, strict exogeneity of own and spatially lagged environmental regulation is overwhelmingly rejected.

Finally, the LIML estimates are statistically significant at the $p<0.01$ confidence level using either the traditional approach or the Anderson and Rubin (1949) test robust to weak instruments. Moreover, the point estimates are considerably larger in magnitude than the OLS estimates in absolute value; however, the standard errors are also roughly four to five times larger. Neighboring environmental regulation is 
rarely statistically significant although the estimates are very imprecise.

While the point estimates for own environmental regulation are economically large, and we will return to the issue of precision later, it helps to put the magnitude in context since the dependent variable is now the log difference in pollution-intensive and non-pollution-intensive FDI. For example, consider the results in Panel B, Specification 1. Ohio in 1991 had 17,600 (104,900) workers in foreign-owned affiliates in the chemical sector (all other manufacturing sectors); thus, relative employment in the chemical sector was $16.8 \%$. The value of its RAC index was 0.86 , making it a fairly lax state according to the index. The ceteris paribus effect of Ohio increasing its RAC at the time to match California (1.00) would have been a decline in relative employment in the chemical sector to $10.8 \%$. In contrast, the OLS estimate implies a decline to only $15.4 \%$. What is not known is how much of this change is due to a relative decline in employment in the pollution-intensive sector and how much is due to a relative increase in employment in the non-pollution-intensive sector. As stated previously, Henderson and Millimet (2007) find heterogeneous, and often positive, associations between own environmental regulation and total manufacturing FDI when treating regulation as exogenous.

Before turning to the next identification strategy, we attempt a (partial) falsification test of the Pitt and Rosenzweig (1990) approach in the current context. Specifically, we exclude the food and kindred products industry (SIC 20) from our original definition of the non-pollution-intensive sector (all manufacturing except the chemical industry) and treat this as our pollution-intensive sector. Our new definition of the non-pollution-intensive sector is all manufacturing industries except the chemical sector and the food and kindred products sector. Thus, we are attempting to compare two relatively non-pollution-intensive sectors by (incorrectly) treating the food and kindred products sector as pollution-intensive. As a result, if the identification strategy is valid and food and kindred products really is no more pollution-intensive than the average (non-chemical) manufacturing industry, we would expect to find statistically insignificant effects of own and neighboring environmental regulation.

The results are presented in Table $3{ }^{4}$ Of the eight models estimated using LIML, the instruments pass the overidentification test in five. In these five models, only one of eight coefficient estimates related to own or neighboring environmental regulation is statistically significant at even the $p<0.10$ confidence level. This is only marginally greater than is to be expected by chance. Thus, we interpret this as evidence in favor of the identification strategy.

\footnotetext{
${ }^{4}$ Note, the number of observations differs from Table 2 due missing data on FDI in the food and kindred products sector.
} 


\subsubsection{Lewbel (2010) Approach}

Model The next two identification strategies used to address the potential endogeneity of own and neighboring environmental regulation exploit the conditional second moments of the endogenous variables. Lewbel (2010) complements earlier work by Vella and Verbeek (1997), Lewbel (1997), Rigobon (2003), and Ebbes et al. (2004) and, as in the Pitt and Rosenzweig (1990) approach, generates instruments that are valid under certain assumptions.

To proceed, we re-write the FDI equation given in (2) together with the first-stage specifications for own and neighboring environmental regulation to make matters explicit. The system of equations is

$$
\begin{aligned}
\ln \left(F D I_{i t}\right) & =X_{i t} \Pi+\beta \ln \left(R A C_{i t}\right)+\delta \ln \left(\sum_{j \in \Omega} \omega_{i j t} R A C_{j t}\right)+\varepsilon_{i t} \\
\ln \left(R A C_{i t}\right) & =X_{i t} \Pi_{1}+\zeta_{1 i t} \\
\ln \left(\sum_{j \in \Omega} \omega_{i j t} R A C_{j t}\right) & =X_{i t} \Pi_{2}+\zeta_{2 i t},
\end{aligned}
$$

where $R A C$ is the measure of relative abatement costs, $X$ includes all the other regressors from $x$ in $(2)$ except $R A C$ (i.e., including the spatial terms and the state and time fixed effects), and $\zeta_{1}$ and $\zeta_{2}$ are the error terms in the first-stage equations assumed to be correlated with $\varepsilon$. As stated, the model is not identified since there are no exclusion restrictions in (7) and (8). However, Lewbel (2010) shows that if $\zeta_{1}$ and $\zeta_{2}$ are heteroskedastic and at least a subset of the elements of $X$ are correlated with the error variances but not with the error covariances, then the model is identified.

Formally, the Lewbel (2010) approach entails choosing $z_{r} \subseteq X$ such that

$$
\begin{aligned}
\mathbb{E}\left[z_{r}^{\prime} \zeta_{r}^{2}\right] & \neq 0 \\
\mathbb{E}\left[z_{r}^{\prime} \varepsilon \zeta_{r}\right] & =0
\end{aligned}
$$

for $r=1,2$. If these assumptions are satisfied, then $\widetilde{z}_{r} \equiv\left(z_{r}-\bar{z}\right) \zeta_{r}, r=1,2$, are valid instruments. If the errors contain a common (homoskedastic) factor, along with heteroskedastic idiosyncratic components (where the heteroskedasticity of $\zeta_{r}$ depends on $z_{r}$ ), then these assumptions will be satisfied. Formally, if we can re-write the errors in $(6)-(8)$ as

$$
\begin{aligned}
\varepsilon_{i t} & \equiv \kappa_{i t}+\widetilde{\varepsilon}_{i t} \\
\zeta_{\text {rit }} & \equiv \kappa_{i t}+\widetilde{\zeta}_{\text {rit }}, \quad r=1,2,
\end{aligned}
$$

where $\kappa$ is homoskedastic, $\widetilde{\zeta}_{r}, \quad r=1,2$, is heteroskedastic (with variance depending on $z_{r}$ ), and $\widetilde{\zeta}_{r}$, $r=1,2$, and $\widetilde{\varepsilon}$ are independent of each other and $\kappa$, then (9) and (10) are satisfied. This data-generating 
process (DGP) is plausible if $\kappa$ represents homoskedastic measurement error in environmental stringency, or a composite index of unobserved variables impacting both environmental stringency and FDI (such as those discussed previously) is drawn from an identical distribution across observations. However, the idiosyncratic shocks to environmental stringency may be drawn from different distributions.

In the analysis, we use the Breusch-Pagan test for heteroskedasticity to identify variables significantly related to the first-stage error variances. We include land prices, total road mileage, and market proximity in $z_{1}$; the spatially-lagged counterparts are included in $z_{2}$. The instruments, $\widetilde{z}_{r}$, are then created by replacing $\zeta_{r}$ with its estimate obtained from (consistent) OLS estimates of the first-stage. See Appendix B for further estimation details.

Prior to continuing, it is interesting to note - with further examination - that land prices and total road mileage are associated with a lower variance of $\zeta_{1}$; neighboring land prices and total road mileage (market proximity) are associated with a lower (higher) variance of $\zeta_{2}$. In Keller and Levinson (2002), land prices and total road mileage are negatively associated with FDI inflows, whereas market proximity is positively related. Thus, the pattern of heteroskedasticity is consistent with the notion that states with less favorable attributes for attracting FDI minimize the volatility in another attribute, environmental stringency, that may adversely impact inbound FDI.

Results The results are presented in Tables 4 and 5, where the different panels and specifications are identical to Tables 2 and 3. Table 4 contains the results for the chemical sector only; Table 5 assesses total manufacturing. In the tables, the OLS estimates are presented for comparison, where the Specification 1 results are identical to Keller and Levinson (2002). The estimates obtained using the Lewbel (2010) approach are given under the column labelled 'IV'.

As with the Pitt and Rosenzweig (1990) approach, four salient findings emerge. First, the OLS estimates are negative and statistically significant in the vast majority of cases. The main exception is when examining FDI as measured by employment in total manufacturing (Panel B, Table 5). In addition, the OLS estimates are fairly stable across the four specifications; neighboring environmental regulation is statistically significant only in Specifications 2 and 3 when assessing employment in the chemical sector (Panel B, Table 4). Inclusion of the spatial effects has little effect on the estimated marginal effect of own environmental regulation.

Second, as with the Pitt and Rosenzweig (1990) approach, the Lewbel (2010) identification strategy works well as determined by the usual IV specification tests when geographic spillovers are omitted (Specification 1) as well as in the majority of cases when spatial effects are included (particularly when using 
the two regional weighting schemes in Specifications 3 and 4). ${ }^{5}$ Specifically, we reject the null that the model is underidentified at the $p<0.01$ confidence level in every case using Anderson's (1951) canonical correlation test, and the Cragg and Donald (1993) F-statistic is reasonably large. In addition, we fail to reject the validity of the instruments using Anderson and Rubin's (1950) overidentification test in all cases but one at the $p<0.10$ confidence level for Specifications 1, 3, and 4. In addition, Specification 2 fares well in terms of these tests when examining total manufacturing. Thus, the Lewbel (2010) approach performs well.

Third, when focusing on the cases that pass the specification tests, we reject exogeneity of own (and neighboring) environmental regulation in the majority of cases for the chemical sector. There is much less support for endogeneity when examining total manufacturing. Thus, there is only strong evidence of endogeneity when focusing on the most pollution-intensive sectors.

Finally, turning to the point estimates in the cases that pass the specification tests for the chemical sector (Table 4), the LIML estimates are statistically significant at at least the $p<0.10$ confidence level using either the traditional approach or the Anderson and Rubin (1949) test robust to weak instruments; often statistically significant at the $p<0.01$ confidence level. Moreover, as with the Pitt and Rosenzweig (1990) approach, the point estimates are larger in absolute value compared to OLS; however, the standard errors are also roughly two to three times larger. Neighboring environmental regulation is statistically significant in Specification 3, but not Specification 4. Thus, choice of weighting scheme does matter in meaningful ways.

To put the magnitude of the effects in context, we return to the previous thought experiment. Using the results in Panel B, Specification 4, if Ohio in 1991 had raised the value of its RAC index from 0.86 to match California (1.00), then employment in foreign-owned affiliates in the chemical sector would have been expected to decline from 17,600 to roughly 15,100 . In contrast, the OLS estimate implies a decline to only about 16,500 .

In terms of the total manufacturing results (Table 5), we often fail to reject exogeneity as noted previously. Moreover, adding the spatial effects has little influence on the estimates from Keller and Levinson (2002); Kellenberg (2009) obtains a similar finding. One noteworthy finding, however, occurs in Specification 3 when examining employment (Panel B). Here, we do reject exogeneity and the IV point estimate indicates a positive and statistically significant effect of own environmental regulation. While we are cautious about putting too much stock in any one estimate given the number of specifications estimated, this is consistent with the heterogeneous effects documented elsewhere in the prior literature

\footnotetext{
${ }^{5}$ Note, for computational reasons, we follow Keller and Levinson (2002) and do not present robust standard errors here; in several specifications, the robust estimate of the covariance matrix was not of full rank.
} 
(e.g., Henderson and Millimet 2007). In particular, this result and the prior results for the chemical sector only highlight the fact that the impact of environmental regulation (as well as its statistical properties) depends on the pollution intensity of the industry, consistent with existing studies (e.g., Ederington et al. 2005; Jug and Mirza 2005; Mulatu et al. 2010).

\subsubsection{Klein \& Vella (2009) Approach}

Model The final identification strategy is based on the parametric implementation of the estimator proposed in Klein and Vella $(2009,2010)$ and expanded upon in Farré et al. (2010). To proceed, consider the system of equations given in (6) - (8). In addition to being mean zero, the following assumptions are made concerning the errors:

$$
\begin{aligned}
& \varepsilon_{i t}=S_{\varepsilon}\left(z_{i t}\right) \varepsilon_{i t}^{*} \\
& \zeta_{r i t}=S_{r}\left(z_{i t}\right) \zeta_{r i t}^{*}, \quad r=1,2 \\
& S_{\varepsilon}\left(z_{i t}\right) / S_{r}\left(z_{i t}\right), \quad r=1,2, \text { varies across } i \\
& \mathbb{E}\left[\varepsilon_{i t}^{*} \zeta_{r i t}^{*}\right]=\rho_{r}, \quad r=1,2
\end{aligned}
$$

where $\varepsilon_{i t}^{*}$ and $\zeta_{r i t}^{*}$ are homoskedastic errors and $z \subseteq X$. Thus, at least some of the errors are required to be heteroskedastic in such a way that the ratio $S_{\varepsilon}\left(z_{i t}\right) / S_{r}\left(z_{i t}\right), r=1,2$, varies across observations. However, the conditional correlation, $\rho_{r}, r=1,2$, between the underlying homoskedastic portion of the errors must be fixed. Note, while the three heteroskedasticity terms $-S_{\varepsilon}\left(z_{i t}\right)$ and $S_{r}\left(z_{i t}\right), r=1,2$ - are written as a function of the same set of covariates, $z$, this need not be the case. There are no restrictions on which variables may enter each of these terms.

Klein and Vella (2010) give some examples of DGPs satisfying these assumptions. One such case arises if there exists a common factor, as in the Lewbel (2010) approach. However, here the common factor enters multiplicatively and may itself be heteroskedastic. Specifically, if we can write the errors as

$$
\begin{aligned}
& \varepsilon_{i t}=S_{\varepsilon}\left(z_{i t}\right) \kappa_{i t} \widetilde{\varepsilon}_{i t} \\
& \zeta_{r i t}=S_{r}\left(z_{i t}\right) \kappa_{i t} \widetilde{\zeta}_{r i t}, \quad r=1,2
\end{aligned}
$$

where $\widetilde{\varepsilon}$ and $\widetilde{\zeta}_{r}$ are mean-zero, independent of $X$ and $\kappa$, and have a constant correlation given by $\rho_{r}$, then (11) - (14) are satisfied.

Reverting back to (14), it is worth considering what this identification condition implies. One possible interpretation includes viewing $\varepsilon_{i t}^{*}$ and $\zeta_{r i t}^{*}, r=1,2$, as correlated measures of agglomeration. Agglomeration may affect environmental stringency due to the scale effect of pollution-generating activity. However, 
the impact may depend on state-level attributes, $z_{i t}$. For instance, states with attributes that are not conducive to attracting FDI may limit the impact of agglomeration on environmental stringency. Similarly, own agglomeration may impact FDI through economies of scale, but the effect may depend on state-level attributes as well. Neighboring agglomeration may adversely impact FDI by improving the desirability of neighboring locations. However, once we condition on these state-level attributes, the return to own and neighboring agglomeration, $\rho_{1}$ and $\rho_{2}$, respectively, are constant. While not testable, this seems plausible.

Continuing, we parameterize $S_{\varepsilon}\left(z_{i t}\right)$ and $S_{r}\left(z_{i t}\right)$ as

$$
\begin{aligned}
& S_{\varepsilon}\left(z_{i t}\right)=\sqrt{\exp \left(z_{\varepsilon i t} \theta_{\varepsilon}\right)} \\
& S_{r}\left(z_{i t}\right)=\sqrt{\exp \left(z_{r i t} \theta_{r}\right)}, \quad r=1,2
\end{aligned}
$$

where $z_{1}\left(z_{2}\right)$ includes own (spatially lagged) land prices, total road mileage, and market proximity (as in the Lewbel (2010) approach). Using the Breusch-Pagan test for heteroskedasticity to identify variables likely to be related to the structural error variance in the FDI equations, we include average production worker wages, population, and market proximity in $z_{\varepsilon}$ when examining FDI in the chemical sector; market proximity only is included when examining total manufacturing FDI. ${ }^{6}$

With this setup, (6) may be rewritten as

$$
\ln \left(F D I_{i t}\right)=X_{i t} \Pi+\beta \ln \left(R A C_{i t}\right)+\delta \ln \left(\sum_{j \in \Omega} \omega_{i j t} R A C_{j t}\right)+\rho_{1} \frac{S_{\varepsilon}\left(z_{i t}\right)}{S_{1}\left(z_{i t}\right)} \zeta_{1 i t}+\rho_{2} \frac{S_{\varepsilon}\left(z_{i t}\right)}{S_{2}\left(z_{i t}\right)} \zeta_{2 i t}+\widetilde{\widetilde{\varepsilon}}_{i t}
$$

where $\rho_{1} \frac{S_{\varepsilon}\left(z_{i t}\right)}{S_{1}\left(z_{i t}\right)} \zeta_{1 i t}+\rho_{2} \frac{S_{\varepsilon}\left(z_{i t}\right)}{S_{2}\left(z_{i t}\right)} \zeta_{2 i t}$ is a control function and $\widetilde{\widetilde{\varepsilon}}_{i t}$ is a well-behaved error term. Given the functional form assumptions in (15) and (16), (17) can be estimated by nonlinear least squares (NLS) in a number of ways. Standard errors are obtained via bootstrap. See Appendix B for further estimation details.

Results The results are presented in Tables 4 and 5 under the column labelled 'CF'. In Table 4 (chemical sector), the point estimates are fairly stable across the four specifications, particularly in Panel A (PP\&E) and especially when one considers the size of the standard errors. ${ }^{7}$ Moreover, while the coefficients on own environmental regulation are roughly similar to those obtained using the Lewbel (2010) approach, they are never statistically significant at the $p<0.10$ confidence level due to the relatively large standard errors. Neighboring environmental regulation is also never statistically significant (although the estimates

\footnotetext{
${ }^{6}$ Average production wages and population are excluded when examining total manufacturing FDI due to problems with convergence.

${ }^{7}$ Standard errors are obtaining using 1000 bootstrap repititions.
} 
are even more imprecise) and inclusion of the spatial effects has little influence on the estimated marginal effects of own environmental regulation.

In terms of total manufacturing (Table 5), the results are consistent with the OLS and Lewbel (2010) approaches, particularly when considering the size of the standard errors. Thus, there is no statistically meaningful evidence of a negative impact of own environmental regulation, or of neighboring environmental regulation, on FDI inflows across the manufacturing sector as a whole.

In sum, the three identification strategies provide a consistent picture: own environmental regulation has an economically significant effect on the spatial distribution of FDI inflows in pollution-intensive sectors across U.S. states. However, there is little impact of environmental regulation on the location choice of manufacturing FDI as a whole. The estimates are statistically meaningful when using the Lewbel (2010) or Pitt and Rosenzweig (1990) approach. Moreover, controlling for endogeneity, although not spatial effects, is crucial in empirical analyses of the PHH. All three estimators indicate much larger (but less precisely estimated) effects on FDI inflows in pollution-intensive sectors than suggested by traditional panel data estimates. The downward (in absolute value) bias of OLS estimates may be attributable in part to measurement error and in part to unobservables positively correlated with both environmental regulation and FDI inflows. For instance, Becker (2011) finds that there is significant variation in environmental compliance costs across counties within states; roughly one-third of counties differ significantly from their state average. Thus, significant attenuation bias due to measurement error is clearly plausible. Similarly, a multitude of unobservables (such as investments in other public goods or agglomeration effects) as well as omitted within-state variation in the observables included in the analysis, can explain the bias in estimates obtained under the assumption of strict exogeneity.

\subsection{Monte Carlo Study}

Prior to concluding, we undertake two small-scale Monte Carlo experiments for two reasons. First, given that the identification strategies utilized herein are somewhat unorthodox, it is worthwhile to illustrate their performance using simulated data. Second, as stated in the Introduction, existing analyses or applications of these methods focus nearly exclusively on the case of a single endogenous regressor; we verify that each method extends to the case of two endogenous variables. Note, however, due to the usual limitation of Monte Carlo evidence - the fact that results may be specific to the DGPs considered - our aim is not to set up a 'horse-race' between the different approaches. Rather, our aim is simply to verify the performance of each approach in a setting where the identifying assumptions hold. 
The first Monte Carlo design is based on the following data-generating process:

$$
\begin{aligned}
& \text { Outcomes: } \quad y^{p}=0.5+0.5 x_{1}+0.5 x_{2}-R_{1}+R_{2}+\varepsilon^{p} \\
& y^{n p}=0.25+0.5 x_{1}+0.5 x_{2}+\varepsilon^{n p} \\
& \text { First-Stage }: R_{1}=1+0.25 x_{1}-0.75 x_{2}+\zeta_{1} \\
& R_{2}=1-0.75 x_{1}+0.25 x_{2}+\zeta_{2} \\
& \text { Covariates }: x_{1}, x_{2} \stackrel{\text { iid }}{\sim} N(0,1) \\
& \text { Errors }: \varepsilon^{p}=S_{\varepsilon}(x) \varepsilon^{*} \\
& \zeta_{r}=S_{r}(x) \zeta_{r}^{*}, \quad r=1,2 \\
& S_{\varepsilon}(x)=\sqrt{\exp \left(0.8 x_{1}+0.8 x_{2}\right)} \\
& S_{1}(x)=\sqrt{\exp \left(-0.2 x_{1}-0.8 x_{2}\right)} \\
& S_{2}(x)=\sqrt{\exp \left(-0.8 x_{1}-0.2 x_{2}\right)} \\
& \varepsilon^{*}, \zeta_{1}^{*}, \zeta_{2}^{*}, \varepsilon^{n p} \sim N\left(0,\left[\begin{array}{cccc}
1 & 0.4 & -0.6 & 0 \\
& 1 & 0.2 & 0 \\
& & 1 & 0 \\
& & & 1
\end{array}\right]\right)
\end{aligned}
$$

where $R_{1}$ and $R_{2}$ are the two endogenous covariates, $y^{p}$ is the outcome used to assess the performance of the Lewbel (2010) and Klein and Vella (2009) approaches, and $y^{p}-y^{n p}$ is the differenced outcome used to assess the Pitt and Rosenzweig (1990) approach where the (correct) assumption that $x_{1}$ and $x_{2}$ have identical effects is used to identify the model. Thus, the true parameters of interest are -1 and 1 for all three estimators. Finally, note that $\left(x_{2}-\bar{x}_{2}\right) \zeta_{1}$ and $\left(x_{1}-\bar{x}_{1}\right) \zeta_{2}$ satisfy the requirements for valid instruments in the Lewbel (2010) approach, while the error structure also satisfies the setup in the Klein and Vella (2009) approach.

We perform this exercise twice; once using 1000 simulations of sample size 750 (roughly the size in our application) and once using 100 simulations of sample size 5,000. For comparison, we also simulate analogous data sets with traditional exclusion restrictions. In this case, the first-stage data-generating process becomes

$$
\begin{array}{cc}
\text { First-Stage }: & R_{1}=1+0.25 x_{1}-0.75 x_{2}+0.75 z_{1}+0.25 z_{2}+\zeta_{1} \\
& R_{2}=1-0.75 x_{1}+0.25 x_{2}+0.25 z_{1}+0.75 z_{2}+\zeta_{2}
\end{array}
$$

where $z_{1}, z_{2} \stackrel{\text { iid }}{\sim} N(0,1)$. The remainder of the data-generating process is unaltered. As in the Pitt and Rosenzweig (1990) and Lewbel (2010) approaches, we obtain the traditional IV results using LIML. 
The results are presented in Table 6; OLS results are also included for comparison. The simulations indicate that all three (non-OLS, non-traditional IV) estimators perform well overall and similarly to traditional IV. In the small sample, the Pitt and Rosenzweig (1990) and Lewbel (2010) approaches are superior in terms of bias (along with traditional IV); Lewbel (2010) yields the lowest mean absolute error (MAE) and root mean squared error (RMSE) followed closely by and Klein and Vella (2009) and traditional IV. Pitt and Rosenzweig (1990) has a MAE and RMSE substantially larger than the other three (nonOLS) estimators despite having an average bias near zero. In large samples, all four (non-OLS) estimators perform very well, with both the Lewbel (2010) and Klein and Vella (2009) approaches matching the performance of traditional IV.

The second Monte Carlo design is a so-called empirical Monte Carlo study, developed in Huber et al. (2010). The authors “... suggest a different approach of conducting simulations ... using the real data to simulate realistic 'placebo treatments' among the non-treated" (p. 3). In their application, since the focus is on the performance of several estimators of the effect of a binary regressor, the simulations entail restricting the sample to only those observations for whom their actual value of the regressor is zero, arbitrarily recoding the regressor to one for a subset of this sample, and then estimating the effect of the simulated binary regressor. In light of this setup, the 'true' effect of the simulated regressor is zero.

In our application, the process is a bit more complex for three reasons: (i) there are two variables of interest, (ii) the variables of interest are continuous, and (iii) our estimators require modeling the simulated variable in a particular way for identification. To proceed, we use the following algorithm:

1. For each observation $i, i=1, \ldots, N T$, in the real data, simulate a value for RAC by drawing a value from its empirical distribution. In practice, this entails drawing a random number, $s$, between 1 and $N T$ and defining the simulated value of RAC for observation $i$ as the value of RAC from observation $s$.

2. For each observation $i, i=1, \ldots, N T$, in the real data, simulate a value for neighboring $\mathrm{RAC}$ by drawing a value from its empirical distribution following the procedure in step 1.

3. Because we need the variables in $x_{2}$ to be correlated with own and neighboring RAC in the Pitt and Rosenzweig (1990) approach, as well as $z_{1}$ and $z_{2}$ to be associated with the variance of own and neighboring RAC in the Lewbel (2010) and Klein and Vella (2009) approaches, we also borrow the values of these variables from the observations chosen in steps 1 and $2 .^{8}$

\footnotetext{
${ }^{8}$ For example, in the Pitt and Rosenzweig (1990) approach, the instruments used in the differenced equation are market proximity, population, tax effort, and their corresponding spatial lags. Thus, as instruments in the differenced equation that now contains the simulated values of own and spatially lagged RAC we use the values of market proximity, population, tax
} 
4. After simulating the values of own and neighboring RAC (and the corresponding values in $x_{2}, z_{1}$, and $z_{2}$ ), we apply each estimator to the data and compare the resulting estimates to the 'true' values of zero.

OLS results are presented in Table 7, as well as for the Lewbel (2010) and Klein and Vella (2009) approaches. Note, now OLS is the preferred estimator since the DGP eliminates the endogeneity issue. Table 8 contains the Pitt and Rosenzweig (1990) approach results.

The results confirm the good performance of all four estimators in terms of bias. However, as in the first experimental design with entirely simulated data, the Pitt and Rosenzweig (1990) approach yields less precise estimates than the other three estimators. Between the Lewbel (2010) and Klein and Vella (2009) estimators, the Lewbel (2010) approach tends to outperform Klein and Vella (2009) approach in terms of precision. As expected, OLS outperforms the Lewbel (2010) approach, producing RMSEs about one-third to one-half the size.

In sum, both Monte Carlo experiments highlight the usefulness of all three identification strategies employed in the current application when the identifying assumptions hold, as well as show how these estimators can perform well even with multiple endogenous variables. Moreover, the simulations shed some light on how to carefully interpret the findings in the current application. First, the simulations point to the added variability of the estimates obtained using the Pitt and Rosenzweig (1990) approach in small samples, as well as the modest improvement in precision with the Lewbel (2010) approach relative to the Klein and Vella (2009) estimator in our data. That said, it is important to re-iterate that (i) our Monte Carlo study is limited to a specific simulated DGP as well as the data from our application and (ii) our implementation of Klein and Vella's (2009) estimator is based on a particular parametric implementation. Certainly more detailed comparisons are required before making general statements regarding the relative performance of the Lewbel (2010) and Klein and Vella (2009) approaches. Moreover, since each relies on a different set of identifying assumptions, 'ranking' the two approaches is not meaningful unless both sets of assumptions hold in a given data set. Nonetheless, the Monte Carlo results provide some additional context with which to interpret the magnitudes obtained using the Pitt and Rosenzweig (1990) approach in the current application, as well as the larger standard errors when using the Klein and Vella (2009) approach.

Second, the simulations in the empirical Monte Carlo study indicate that all three estimators yield much effort, and their corresponding spatial lags from the same observations used to obtain the simulated values of RAC and neighboring RAC in steps 1 and 2. If we did not do this, the estimator would perform extremely poorly because the true values of the instruments would fail to be correlated with the simulated endogenous regressors. Similar logic applies to the other two estimation approaches. 
more precise estimates of the effect of own environmental regulation relative to neighboring environmental regulation. This is especially true when using the Crone regional weighting scheme. Thus, some caution should be exhibited concluding that spatial effects are unimportant in empirical models of the PHH (as was already suggested by the large standard errors discussed previously).

\section{Conclusion}

The debate over the empirical validity of the $\mathrm{PHH}$ is heated and for good reason; the answer has far-reaching consequences at the local, national, and international levels. To date, however, empirical assessments of the PHH have been hampered by the lack of a credible identification strategy to overcome potential problems associated with measurement error and unobserved heterogeneity. In addition, the empirical literature on the PHH has yet to adequately incorporate lessons from the literature on so-called third-country effects. Here, we propose three novel identification strategies couched within a model that incorporates spatial effects. A traditional Monte Carlo design, as well as an empirical Monte Carlo experiment, give us confidence in these approaches in the current context, one that includes two endogenous covariates. Together, the three approaches shed new light on the role of environmental regulation in the determination of FDI location.

Specifically, using state-level panel data from 1977-1994 from the U.S., we consistently find (i) evidence of environmental regulation being endogenous when examining the pollution-intensive chemical sector, (ii) a negative and economically significant impact of own environmental stringency on inbound FDI in the chemical sector, particularly when measured by employment, and (iii) significantly larger effects of environmental regulation on the chemical sector once endogeneity is addressed. The upward bias in standard fixed effects estimates obtained under the assumption of strict exogeneity is consistent with attenuation bias due to measurement error, as well as important unobservables positively correlated with environmental regulation and FDI inflows (such as tax breaks, investments in other public goods, or agglomeration externalities).

While informative, continued research is warranted. First, the analysis here is at the regional level. Before reaching important policy conclusions regarding such issues as the WTO's justification to intervene in the domestic environmental policy arena or the sensibility of linking international environmental and trade agreements, further analysis is needed to determine the external validity of the findings obtained here. Does environmental regulation have similar effects at the country level? Despite this unknown, our results do firmly indicate that policymakers should worry about the incentives for local environmental standards to deviate from Pareto-efficient levels. Such fears are particularly worrisome since prior evidence 
suggests that domestic investment may be even more sensitive to spatial variation in environmental policy than foreign investment (e.g., List et al. 2004).

Second, the prior literature, while suffering from various deficiencies, has emphasized the heterogeneous effects of environmental regulation along numerous dimensions. For instance, Ederington et al. (2005) point to substantial heterogeneity across source country (of imports) and the pollution intensity and geographic mobility of the industrial sector. Dean et al. (2009) similarly document important heterogeneity by source country (of foreign investment). Henderson and Millimet (2007) and Millimet and List (2004) uncover heterogeneous effects utilizing nonparametric and semiparametric methods, respectively. Some of this heterogeneity is captured in this study; namely, differential effects by pollution intensity of the manufacturing sector as well as by measure of FDI (PP\&E versus employment). However, other dimensions of heterogeneity uncovered by the prior literature cannot be addressed given the data and identification strategies utilized here. Future research investigating whether the empirical evidence of heterogeneous effects continues to be present once measurement error, spatial effects, and unobserved heterogeneity are accounted for is needed for a deeper understanding of the linkages between environmental and trade policy. 


\section{References}

[1] Anderson, T.W. (1951), "Estimating Linear Restrictions on Regression Coefficients for Multivariate Normal Distributions," Annals of Mathematical Statistics, 22, 327-351.

[2] Anderson, T. W. and H. Rubin (1949), "Estimation of the Parameters of a Single Equation in a Complete System of Stochastic Equations," Annals of Mathematical Statistics, 20, 46-63.

[3] Anderson, T.W. and H. Rubin (1950), "The Asymptotic Properties of Estimates of the Parameters of a Single equation in a Complete System of Stochastic Equations," Annals of Mathematical Statistics, $21,570-582$.

[4] Arauzo-Carod, J.M., D. Liviano-Solis, and M. Manjón-Antolín (2010), "Empirical Studies in Industrial Location: An Assessment of Their Methods and Results," Journal of Regional Science, 50, 685-711.

[5] Baltagi, B.H., P. Egger, and M. Pfaffermayr (2007), "Estimating Model of Complex FDI: Are There Third-Country Effects?" Journal of Econometrics, 140, 260-281.

[6] Baltagi, B.H., P. Egger, and M. Pfaffermayr (2008), "Estimating Regional Trade Agreement Effects on FDI in an Interdependent World," Journal of Econometrics, 145, 194-208.

[7] Becker, R.A. (2011), "On Spatial Heterogeneity in Environmental Compliance Costs," Land Economics, 87, 28-44.

[8] Blonigen, B.A., R.B. Davies, G.R. Waddell, and H.T. Naughton (2007), "FDI in Space: Spatial Autoregressive Relationships in Foreign Direct Investment," European Economic Review, 51, 13031325.

[9] Blonigen, B.A., R.B. Davies, H.T. Naughton, and G.R. Waddell (2008), "Spacey Parents: Spatial Autoregressive Patterns in Inbound FDI," in S. Brakman and H. Garretsen (eds.) Foreign Direct Investment and the Multinational Enterprise, Cambridge, MA: The MIT Press, pp.173-198.

[10] Brunnermeier, S. and A. Levinson (2004), "Examining the Evidence on Environmental Regulations and Industry Location," Journal of Environment 69 Development, 13, 6-41.

[11] Cole, M.A. and R.J.R. Elliott (2003), "Do Environmental Regulations Influence Trade Patterns? Testing Old and New Trade Theories," World Economy, 26, 1163-1189.

[12] Cole, M.A. and R.J.R. Elliott (2005), "FDI and the Capital Intensity of 'Dirty' Sectors: A Missing Piece of the Pollution Haven Puzzle," Review of Development Economics, 9, 530-548. 
[13] Cole, M.A., R.J.R. Elliott, and K. Shimamoto (2005), "Why the Grass Is Not Always Greener: The Competing Effects of Environmental Regulations and Factor Intensities on US Specialization," Ecological Economics, 54, 95-109.

[14] Cole, M.A., R.J.R. Elliott, and P.G. Fredriksson (2006), "Endogenous Pollution Havens: Does FDI Influence Environmental Regulations?" Scandanavian Journal of Economics, 108, 157-178.

[15] Cole, M.A. and P.G. Fredriksson (2009), "Institutionalized Pollution Havens," Ecological Economics, $68,1239-1256$.

[16] Copeland, B. and M.S. Taylor (2004), "Trade, Growth, and the Environment," Journal of Economic Literature, 42, 7-71.

[17] Cragg, J.G. and S.G. Donald (1993), "Testing Identfiability and Specification in Instrumental Variables Models," Econometric Theory, 9, 222-240.

[18] Crone, T.M. (1998/1999), "Using State Indexes to Define Economic Regions in the U.S.," The Journal of Economic and Social Measurement, 25, 259-278.

[19] Dean, J.M., M.E. Lovely, and H. Wang (2009), "Are Foreign Investors Attracted to Weak Environmental Regulations? Evaluating the Evidence from China," Journal of Development Economics, 90, $1-13$.

[20] Ebbes, P., M. Wedel, and U. Böckenholt (2009), "Frugal IV Alternatives to Identify the Parameter for an Endogenous Regressor," Journal of Applied Econometrics, 24, 446-468.

[21] Ederington, J. and J. Minier (2003), "Is Environmental Policy a Secondary Trade Barrier? An Empirical Analysis," Canadian Journal of Economics, 36, 137-154.

[22] Ederington, J., A. Levinson, and J. Minier (2004), "Trade Liberalization and Pollution Havens," Advances in Economic Analysis and Policy, 4, Article 2.

[23] Ederington, J., A. Levinson, and J. Minier (2005), "Footloose and Pollution-Free," Review of Economics and Statistics, 87, 92-99.

[24] Ekholm, K., R. Forslid, and J.R. Markusen (2003), "Export-Platform Foreign Direct Investment," NBER WP No. 9517.

[25] Eliste, P. and P.G. Fredriksson (2004), "Does Trade Liberalization Cause a Race-to-the-bottom in Environmental Policies? A Spatial Econometric Analysis," in L. Anselin, R.J.G.M. Florax and S.J. Rey (eds.) Advances in Spatial Econometrics: Methodology, Tools, and Applications, Berlin: Springer. 
[26] Farré, L., R. Klein, and F. Vella (2010), "A Parametric Control Function Approach to Estimating the Returns to Schoolinh in the Absence of Exclusion Restrictions: An Application to the NLSY," Empirical Economics, forthcoming.

[27] Flores-Lagunes, A. (2007), "Finite Sample Evidence of IV Estimators Under Weak Instruments," Journal of Applied Econometrics, 22, 677-694.

[28] Fredriksson, P.G., J.A. List, and D.L. Millimet (2003), "Corruption, Environmental Policy, and FDI: Theory and Evidence from the United States," Journal of Public Economics, 87, 1407-1430.

[29] Fredriksson, P.G. and D.L. Millimet (2002), "Strategic Interaction and the Determination of Environmental Policy Across US States," Journal of Urban Economics, 51, 101-122.

[30] Glick, N.J. and D.P. Woodward (1987), Regional Patterns of Manufacturing Foreign Direct Investment in the United States, Special Report for U.S. Department of Commerce, Economic Development Administration.

[31] Grossman, G.M., E. Helpman, and A. Szeidl (2003), "Optimal Integration Strategies for the Multinational Firm," NBER WP No. 10189.

[32] Henderson, V. (1997), "The Impact of Air Quality Regulation on Industrial Location," Annales d'Économie et de Statistique, 45, 123-137.

[33] Henderson, D.J. and D.L. Millimet (2007), "Pollution Abatement Costs and Foreign Direct Investment Inflows to U.S. States: A Nonparametric Reassessment," Review of Economics and Statistics, 89, 178183.

[34] Huber, M., M. Lechner, and C. Wunsch (2010), "How to Control for Many Covariates? Reliable Estimators Based on the Propensity Score," IZA DP No. 5268.

[35] Jaffe, A.B., S.R. Peterson, P.R. Portney, and R.N. Stavins (1995), "Environmental Regulations and the Competitiveness of U.S. Manufacturing: What does the Evidence Tell Us?" Journal of Economic Literature, 33, 132-163.

[36] Jug, J. and D. Mirza (2005), "Environmental Regulations in Gravity Equations: Evidence from Europe," World Economy, 28, 1591-1615.

[37] Kellenberg, D.K. (2009), "An Empirical Investigation of the Pollution Haven Effect with Strategic Environment and Trade Policy," Journal of International Economics, 78, 242-255. 
[38] Keller, W. and A. Levinson (2002), "Pollution Abatement Costs and Foreign Direct Investment Inflows to U.S. States," Review of Economics and Statistics, 84, 691-703.

[39] Kleibergen, F. and R. Paap (2006), "Generalized Reduced Rank Tests Using the Singular Value Decomposition," Journal of Econometrics, Vol. 133, 97-126.

[40] Klein, R. and F. Vella (2009), "Estimating the Return to Endogenous Schooling Decisions via Conditional Second Moments," Journal of Human Resources, 44, 1047-1065.

[41] Klein, R. and F. Vella (2010), "Estimating a Class of Triangular Simultaneous Equations Models Without Exclusion Restrictions," Journal of Econometrics, 154, 154-164.

[42] Levinson, A. (1997), "A Note on Environmental Federalism: Interpreting Some Contradictory Results," Journal of Environmental Economics and Management, 33, 359-366.

[43] Levinson, A. (2001), "An Industry-Adjusted Index of State Environmental Compliance Costs," in C. Carraro and G.E. Metcalf (eds.) Behavioral and Distributional Effects of Environmental Policy, Chicago: University of Chicago Press.

[44] Levinson, A. (2003), "Environmental Regulatory Competition: A Status Report and Some New Evidence," National Tax Journal, 56, 91-106.

[45] Levinson, A. (2008), "Pollution Haven Hypothesis," New Palgrave Dictionary of Economics, 2nd Edition.

[46] Levinson, A. (2010), "Offshoring Pollution: Is the United States Increasingly Importing Polluting Goods," Review of Environmental Economics and Policy, 4, 62-83.

[47] Lewbel, A. (1997), "Constructing Instruments for Regressions With Measurement Error When No Additional Data are Available, with An Application to Patents and R\&D," Econometrica, 65, 12011213.

[48] Lewbel, A. (2010), "Using Heteroskedasticity to Identify and Estimate Mismeasured and Endogenous Variables," Journal of Business and Economic Statistics, forthcoming.

[49] List, J.A., D.L. Millimet, P.G. Fredriksson, and W.W. McHone (2003), "Effects of Environmental Regulations on Manufacturing Plant Births: Evidence from a Propensity Score Matching Estimator," Review of Economics and Statistics, 85, 944-952. 
[50] List, J.A., W.W. McHone, and D.L. Millimet (2004), "Effects of Environmental Regulation on Foreign and Domestic Plant Births: Is There a Home Field Advantage?," Journal of Urban Economics, 56, 303-326.

[51] Millimet, D.L. and J.A. List (2004), "The Case of the Missing Pollution Haven Hypothesis," Journal of Regulatory Economics, 26, 239-262.

[52] Mulatu, A., R. Gerlagh, D. Rigby, and A. Wossnik (2010), "Environmental Regulation and Industry Location in Europe," Environmental and Resource Economics, 45, 459-479.

[53] Pitt, M.M. and M.R. Rosenzweig (1990), "Estimating the Intrahousehold Incidence of Illness: Child Health and Gender-Inequality in the Allocation of Time," International Economic Review, 31, 969-989.

[54] Rigobon, R. (2003), "Identification Through Heteroskedasticity," Review of Economics and Statistics, $85,777-792$.

[55] Shadbegian, R. and A. Wolverton (2010), "Location Decisions of U.S. Polluting Plants: Theory, Empirical Evidence, and Consequences," International Review of Environmental and Resource Economics, $1,1-49$.

[56] Stock, J.H., J.H. Wright, and M. Yogo (2002), "A Survey of Weak Instruments and Weak Identification in Generalized Method of Moments," Journal of Business and Economic Statistics, 20, 518-529.

[57] Vella, F. and M. Verbeek (1997), "Using Rank Order as an Instrumental Variable: An Application to the Return to Schooling," CES Discussion Paper 97.10, K.U. Leuven.

[58] Wagner, U.J. and C.D. Timmins (2009), "Agglomeration Effects in Foreign Direct Investment and the Pollution Haven Hypothesis," Environmental and Resource Economics, 43, 231-256.

[59] Wilson, J.D. (1999), "Theories of Tax Competition," National Tax Journal, 52, 269-304.

[60] Xing, Y. and C.D. Kolstad (2002), "Do Lax Environmental Regulations Attract Foreign Investment?" Environmental and Resource Economics, 21, 1-22.

[61] Yeaple, S.R. (2003), "The Complex Integration Strategies of Multinational Firms and Cross-Country Dependencies in the Structure of Foreign Direct Investment," Journal of International Economics, 60, 293-314.

[62] UNCTAD (2010), World Investment Report 2010, United Nations: New York and Geneva. 


\section{A Data Appendix}

The BEA regional classification is as follows.

1. New England: Maine, New Hampshire, Vermont, Massachusetts, Rhode Island, Connecticut

2. Mideast: New York, New Jersey, Pennsylvania, Delaware, Maryland

3. Great Lakes: Ohio, Indiana, Illinois, Michigan, Wisconsin

4. Plains: Minnesota, Iowa, Missouri, North Dakota, South Dakota, Nebraska, Kansas

5. Southeast: Georgia, Florida, Virginia, West Virginia, North Carolina, South Carolina, Kentucky, Tennessee, Alabama, Mississippi, Arkansas, Louisiana

6. Southwest: Oklahoma, Texas, Arizona, New Mexico

7. Rocky Mountain: Montana, Idaho, Wyoming, Colorado, Utah

8. Far West: Washington, Oregon, California, Nevada

The Crone (1998/1999) regions - based on a cluster analysis of similar economic activity - are as follows.

1. Maine, New Hampshire, Massachusetts, Arizona, Utah, Montana

2. Ohio, Indiana, Illinois, Michigan, Iowa, Delaware

3. Georgia, Florida, Virginia, North Carolina, South Carolina, Missouri, Kentucky, Tennessee, Alabama, Mississippi, Arkansas, Oklahoma, Rhode Island

4. New York, New Jersey, Pennsylvania, Maryland, Connecticut, West Virginia, Vermont

5. Washington, Oregon, California, Nevada, Idaho, Nebraska, Texas, Wyoming, Minnesota, Louisiana, Kansas

6. North Dakota, South Dakota, Colorado, New Mexico, Wisconsin 


\begin{tabular}{|c|c|c|c|c|c|c|c|c|c|}
\hline \multirow[b]{2}{*}{ Variable } & \multicolumn{3}{|c|}{ Full Sample } & \multicolumn{3}{|c|}{$\mathbf{R A C} \leq 1$} & \multicolumn{3}{|c|}{$\mathbf{R A C}>\mathbf{1}$} \\
\hline & $\mathbf{N}$ & Mean & SD & $\mathbf{N}$ & Mean & SD & $\mathbf{N}$ & Mean & SD \\
\hline Total Manufacturing FDI (PP\&E) & 811 & 2859.31 & 3919.40 & 449 & 2796.21 & 3610.31 & 362 & 2937.57 & 4275.67 \\
\hline Chemical Sector FDI (PP\&E) & 563 & 1016.94 & 1732.51 & 323 & 812.53 & 1117.36 & 240 & 1292.04 & 2289.90 \\
\hline Non-Chemical Sector FDI (PP\&E) & 563 & 1491.44 & 1923.02 & 323 & 1440.59 & 1703.17 & 240 & 1559.88 & 2186.17 \\
\hline Total Manufacturing FDI (Employment) & 814 & 32680.75 & 36602.64 & 452 & 37596.70 & 39038.80 & 362 & 26542.60 & 32329.69 \\
\hline Chemical Sector FDI (Employment) & 621 & 7691.73 & 9641.22 & 349 & 8760.95 & 10820.55 & 272 & 6319.83 & 7677.71 \\
\hline Non-Chemical Sector FDI (Employment) & 621 & 23377.44 & 26783.65 & 349 & 26047.92 & 26573.23 & 272 & 19950.99 & 26710.69 \\
\hline Relative Abatement Costs (RAC) & 816 & 1.02 & 0.37 & 452 & 0.76 & 0.16 & 364 & 1.34 & 0.31 \\
\hline Unemployment Rate & 816 & 6.61 & 2.09 & 452 & 6.14 & 1.87 & 364 & 7.20 & 2.21 \\
\hline Agricultural Land Values (\$/per acre) & 816 & 887.02 & 775.04 & 452 & 974.93 & 896.84 & 364 & 777.84 & 572.50 \\
\hline Energy Prices, Industrial Sector & 816 & 5.51 & 1.70 & 452 & 5.89 & 1.85 & 364 & 5.04 & 1.35 \\
\hline Highway Road Mileage & 816 & 80500.90 & 48367.55 & 452 & 82200.68 & 42205.87 & 364 & 78390.18 & 55056.13 \\
\hline Population (millions) & 816 & 4.94 & 5.13 & 452 & 5.45 & 5.43 & 364 & 4.30 & 4.67 \\
\hline Unionization Rate & 816 & 16.55 & 6.71 & 452 & 17.37 & 6.86 & 364 & 15.54 & 6.38 \\
\hline $\begin{array}{l}\text { Average Production Worker Wages, } \\
\text { Manufacturing Sector }(\$ / h r)\end{array}$ & 816 & 9.10 & 2.24 & 452 & 9.09 & 2.28 & 364 & 9.10 & 2.19 \\
\hline Tax Effort & 816 & 96.06 & 16.05 & 452 & 98.51 & 18.89 & 364 & 93.01 & 10.88 \\
\hline Market Proximity & 816 & 6630.94 & 8220.03 & 452 & 8218.10 & 9694.03 & 364 & 4660.08 & 5283.64 \\
\hline
\end{tabular}




\section{B Estimation Algorithms}

\section{B.1 Lewbel (2010) Approach}

Estimation of the empirical model

$$
\ln \left(F D I_{i t}\right)=X_{i t} \Pi+\beta \ln \left(R A C_{i t}\right)+\delta \ln \left(\sum_{j \in \Omega} \omega_{i j t} R A C_{j t}\right)+\varepsilon_{i t}
$$

proceeds as follows:

1. Regress $\ln \left(R A C_{i t}\right)$ on $X_{i t}$ and obtain $\widehat{\zeta}_{1 i t}$

2. Regress $\ln \left(\sum_{j \in \Omega} \omega_{i j t} R A C_{j t}\right)$ on $X_{i t}$ and obtain $\widehat{\zeta}_{2 i t}$

3. Form instruments $\widetilde{z}_{r i t} \equiv\left(z_{\text {rit }}-\bar{z}\right) \widehat{\zeta}_{\text {rit }}, r=1,2$

4. Estimate the structural model via Limited Information Maximum Likelihood using $\widetilde{z}_{\text {rit }}, r=1,2$, as instruments for $\ln \left(R A C_{i t}\right)$ and $\ln \left(\sum_{j \in \Omega} \omega_{i j t} R A C_{j t}\right)$.

\section{B.2 Klein \& Vella (2009) Approach}

Estimation of the empirical model

$$
\ln \left(F D I_{i t}\right)=X_{i t} \Pi+\beta \ln \left(R A C_{i t}\right)+\delta \ln \left(\sum_{j \in \Omega} \omega_{i j t} R A C_{j t}\right)+\rho_{1} \frac{S_{\varepsilon}\left(z_{i t}\right)}{S_{1}\left(z_{i t}\right)} \zeta_{1 i t}+\rho_{2} \frac{S_{\varepsilon}\left(z_{i t}\right)}{S_{2}\left(z_{i t}\right)} \zeta_{2 i t}+\widetilde{\widetilde{\varepsilon}}_{i t}
$$

proceeds as follows:

1. Regress $\ln \left(R A C_{i t}\right)$ on $X_{i t}$ and obtain $\widehat{\zeta}_{1 i t}$

2. Regress $\ln \left(\sum_{j \in \Omega} \omega_{i j t} R A C_{j t}\right)$ on $X_{i t}$ and obtain $\widehat{\zeta}_{2 i t}$

3. Estimate $\theta_{j}$ regressing $\ln \left(\widehat{\zeta}_{j i t}^{2}\right)$ on $z_{j i t} ;$ compute $\widehat{S}_{j i t}=\sqrt{\exp \left(z_{j i t} \widehat{\theta}_{j}\right)}, j=1,2$

4. Using $\widehat{\zeta}_{1 i t}, \widehat{\zeta}_{2 i t}, \widehat{S}_{1 i t}$, and $\widehat{S}_{2 i t}$, obtain consistent estimates via NLS:

$$
\min _{\Pi, \beta, \delta, \rho_{1}, \rho_{2}, \theta_{\varepsilon}} \sum_{i, t}\left[\begin{array}{c}
\ln \left(F D I_{i t}\right)-X_{i t} \Pi-\beta \ln \left(R A C_{i t}\right)-\delta \ln \left(\sum_{j \in \Omega} \omega_{i j t} R A C_{j t}\right) \\
-\rho_{1} \sqrt{\exp \left(z_{\varepsilon i t} \theta_{\varepsilon}\right)}\left(\frac{\widehat{\zeta}_{1 i t}}{\widehat{S}_{1 i t}}\right)-\rho_{2} \sqrt{\exp \left(z_{\varepsilon i t} \theta_{\varepsilon}\right)}\left(\frac{\widehat{\zeta}_{2 i t}}{\widehat{S}_{2 i t}}\right)
\end{array}\right]^{2}
$$

5. Estimate $\theta_{\varepsilon}$ (again) by regressing $\ln \left(\widehat{\varepsilon}_{i t}^{2}\right)$ on $z_{\varepsilon i t}$, where

$$
\widehat{\varepsilon}_{i t}=\ln \left(F D I_{i t}\right)-X_{i t} \widehat{\Pi}-\widehat{\beta} \ln \left(R A C_{i t}\right)-\widehat{\delta} \ln \left(\sum_{j \in \Omega} \omega_{i j t} R A C_{j t}\right),
$$

and compute $\widehat{S}_{\varepsilon i t}=\sqrt{\exp \left(z_{\varepsilon i t} \widehat{\theta}_{\varepsilon}\right)}$ 
6. Estimate via OLS:

$$
\ln \left(F D I_{i t}\right)=X_{i t} \Pi+\beta \ln \left(R A C_{i t}\right)+\delta \ln \left(\sum_{j \in \Omega} \omega_{i j t} R A C_{j t}\right)+\underbrace{\rho_{1}\left(\frac{\widehat{S}_{\varepsilon i t}}{\widehat{S}_{1 i t}} \widehat{\zeta}_{1 i t}\right)+\rho_{2}\left(\frac{\widehat{S}_{\varepsilon i t}}{\widehat{S}_{2 i t}} \widehat{\zeta}_{2 i t}\right)}_{\text {control function }}+\widetilde{\widetilde{\varepsilon}}_{i t} .
$$

7. Compute standard errors via bootstrap. 
Table 1. Select Review of the Pollution Haven Hypothesis Literature with Endogenous Environmental Regulation.

\begin{tabular}{|c|c|c|c|c|}
\hline Study & $\begin{array}{c}\text { Dependent } \\
\text { Variable }\end{array}$ & Data & $\begin{array}{c}\text { Primary Measure of } \\
\text { Environmental Regulation }\end{array}$ & Primary Instruments \\
\hline 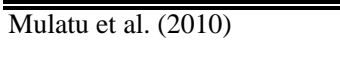 & I"Industry shares & $\begin{array}{l}13 \text { countries and 16 ISIC industries } \\
\text { averaged over 1990-1994 }\end{array}$ & $\begin{array}{l}\text { Environmental Sustainability Index in } \\
2001\end{array}$ & $\begin{array}{l}\text { Corruption in 1995; income in 1992; urbanization in 1997; } \\
\text { schooling in } 1990\end{array}$ \\
\hline Kellenberg (2009) & $\begin{array}{l}\text { Value added of majority owned U.S. } \\
\text { multinational affiliates }\end{array}$ & $\begin{array}{l}50 \text { countries and nine industries over } \\
1999-2003\end{array}$ & $\begin{array}{l}\text { Two survey-based responses from } \\
\text { executives concerning environmental } \\
\text { stringency and consistency of } \\
\text { enforcement }\end{array}$ & $\begin{array}{l}\text { Own country: arable land/agricultural worker; } \\
\text { tractors/agricultural worker. Spatial lag of other countries in } \\
\text { same region (weighted by GDP): land/agricultural worker; } \\
\text { tractors/agricultural worker; public schools; capital/labor } \\
\text { ratio; infrastructure; organized crime. }\end{array}$ \\
\hline Cole and Fredriksson (2009) & $\begin{array}{l}\text { Inbound FDI stocks and flows divided by } \\
\text { aggregate GDP }\end{array}$ & $\begin{array}{l}13 \text { OECD and } 20 \text { developing countries } \\
\text { over 1982-1992 }\end{array}$ & Lead content of gasoline & Total population \\
\hline
\end{tabular}

Levinson and Taylor (2008) $\quad$ U.S. net imports divided by the value of 132 3-digit manufacturing sectors from PAOC per unit of value added shipments $\quad$ Mexico and Canada over 1977-1986

Cole and Elliott (2005)

Cole et al. (2005)

Jug and Mirza (2005)

Ederington et al. (2004)

List et al. (2004)

List et al. (2003)

Fredriksson et al. (2003)
U.S. outbound FDI stocks in Brazil and Mexico divided by total U.S. stocks in each country

U.S. net exports as a share of value added 3-digit U.S. SIC industries over 19781992, except 1979 and 1987

Imports as a share of domestic sales

U.S. imports divided by the value of shipments

Number of manufacturing plant modifications and closures

Number of new manufacturing plants

U.S. state-level inbound FDI stocks across U.S. st states

countries from the EU15 and Central and

Eastern Europe over 1996-1999

Nine 2-digit ISIC industries; 12 importing Environmental expenditures for total countries from the EU15 and 19 exporting manufacturing

394 4-digit U.S. SIC industries fover 1978-1994 except 1979 and 1987

New York State county-level data over 1980-1990

New York State county-level data over Ozone attainment status 1980-1990
PAOC per unit of total materials costs

Ozone attainment status

Levinson (2001) index of state-level relative PAOC
Ederington and Minier (2003) U.S. net imports divided by the value of shipments
374 4-digit U.S. SIC industries over 1978- PAOC per unit of total materials costs 1992, except 1979 and 1987
The amount of a pollutant contributed by other sectors in the states in which the sector tends to locate (14 pollutants yields 14 instruments); weighted average of state per capita incomes

Lagged PAOC per unit of value added over 1973-1978; industry-level pollution intensity in 1987

Follow Levinson and Taylor (2008); six types of air pollution yields six instruments

Total public expenditure; lagged investment in environmental equipment; lagged wages

Similar to Levinson and Taylor (2008) based on geographic dispersion of industries

Proportion of all contiguous western neighbors that are out of attainment

Proportion of all contiguous western neighbors that are out of attainment

Per capita GSP and the share of legal services in GSP; nonmilitary government employment and the interaction between non-military government employment and share of legal services in GSP; corruption and its interaction with tax effort; corruption squared and its interaction with tax effort

Four-firm concentration ratio; number of firms; value of shipments; percentage of unionized workers; industry unemployment rates; lagged changes in import and export penetrations; recent industry growth; lagged total trade 
Table 1 (cont.). Select Review of the Pollution Haven Hypothesis Literature with Endogenous Environmental Regulation.

\begin{tabular}{|c|c|c|c|c|}
\hline Study & $\begin{array}{c}\text { Dependent } \\
\text { Variable }\end{array}$ & Data & $\begin{array}{c}\text { Primary Measure of } \\
\text { Environmental Regulation }\end{array}$ & Primary Instruments \\
\hline 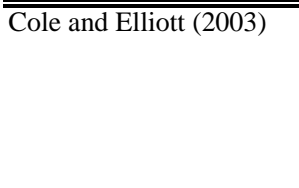 & Net exports & $\begin{array}{l}\text { Four manufacturing sectors in } 60 \\
\text { countries from } 1995\end{array}$ & $\begin{array}{l}\text { Index of environmental stringency from } \\
\text { Eliste and Fredriksson (2004); proxy } \\
\text { based on a change in energy intensity } \\
\text { over 1980-1985 and level of energy } \\
\text { intensity in } 1980\end{array}$ & Per capita income \\
\hline Xing and Kolstad (2002) & U.S. outbound FDI & $\begin{array}{l}\text { Six manfacturing sectors across } 22 \\
\text { countries from } 1985 \text { and 1990; data for } \\
\text { some countries for both time points, in } \\
\text { which case the average is used, and only } \\
\text { from one of the years for the remainder }\end{array}$ & $\mathrm{SO}_{2}$ emissions & Infant mortality rate; population density \\
\hline Henderson (1997) & $\begin{array}{l}\text { Binary variable indicating whether an } \\
\text { industry is located in a U.S. county or not }\end{array}$ & $\begin{array}{l}\text { Five 3-digit U.S. SIC industries over } 1978 \\
1987 \text { for } 742 \text { urban counties }\end{array}$ & Ozone attainment status & $\begin{array}{l}\text { State fuel prices over 1978-1987; metro area manufacturing } \\
\text { employment (except own industry) over 1978-1987; county } \\
\text { and metro area total employment (except own industry) over } \\
\text { 1978-1987 }\end{array}$ \\
\hline
\end{tabular}


Table 2. Determinants of Relative FDI: Pitt \& Rosenzweig (1990) Approach.

\begin{tabular}{|c|c|c|c|c|c|c|c|c|}
\hline & \multicolumn{2}{|c|}{ Spec (1) } & \multicolumn{2}{|c|}{ Spec (2) } & \multicolumn{2}{|c|}{ Spec (3) } & \multicolumn{2}{|c|}{ Spec (4) } \\
\hline & OLS & IV & OLS & IV & OLS & IV & OLS & IV \\
\hline \multicolumn{9}{|c|}{ Panel A. Plant, Property, and Equipment } \\
\hline \multirow[t]{2}{*}{$\ln (\mathrm{RAC})$} & $-0.789 *$ & $-4.720 *$ & $-0.724 *$ & $-4.657 *$ & $-0.802 *$ & $-3.437 *$ & $-0.657^{*}$ & $-3.535 *$ \\
\hline & $(0.155)$ & $(0.653)$ & $(0.146)$ & $(0.703)$ & $(0.142)$ & $(0.509)$ & $(0.151)$ & $(0.631)$ \\
\hline \multirow[t]{2}{*}{$\ln ($ spatial RAC) } & & & $-1.056^{*}$ & 0.930 & 0.596 & 0.977 & 0.148 & $7.210 \dagger$ \\
\hline & & & $(0.349)$ & (1.718) & $(0.498)$ & (1.958) & $(0.576)$ & (3.636) \\
\hline Underid Test & & 0.000 & & 0.000 & & 0.000 & & 0.000 \\
\hline F-stat & & 39.174 & & 8.674 & & 6.344 & & 9.340 \\
\hline Overid Test & & 0.040 & & 0.136 & & 0.074 & & 0.032 \\
\hline Endogeneity & & 0.000 & & 0.000 & & 0.000 & & 0.000 \\
\hline Joint Sign. Endog. & 0.000 & 0.000 & 0.000 & 0.000 & 0.000 & 0.000 & 0.000 & 0.000 \\
\hline $\mathrm{N}$ & 563 & 563 & 563 & 563 & 563 & 563 & 563 & 563 \\
\hline \multicolumn{9}{|c|}{ Panel B. Employment } \\
\hline \multirow[t]{2}{*}{$\ln (\mathrm{RAC})$} & $-0.498 *$ & $-2.205^{*}$ & $-0.447^{*}$ & $-2.399 *$ & $-0.494^{*}$ & $-1.463^{*}$ & $-0.584^{*}$ & $-2.212^{*}$ \\
\hline & $(0.096)$ & $(0.304)$ & $(0.096)$ & $(0.339)$ & $(0.099)$ & $(0.308)$ & $(0.101)$ & $(0.346)$ \\
\hline \multirow[t]{2}{*}{$\ln ($ spatial RAC) } & & & $-0.758 *$ & 1.052 & 0.096 & $1.984 \dagger$ & -0.546 & 2.421 \\
\hline & & & $(0.211)$ & $(0.869)$ & $(0.277)$ & $(0.929)$ & $(0.398)$ & (1.903) \\
\hline Underid Test & & 0.000 & & 0.000 & & 0.000 & & 0.000 \\
\hline F-stat & & 38.003 & & 13.256 & & 10.666 & & 10.037 \\
\hline Overid Test & & 0.834 & & 0.210 & & 0.172 & & 0.164 \\
\hline Endogeneity & & 0.000 & & 0.000 & & 0.000 & & 0.000 \\
\hline Joint Sign. Endog. & 0.000 & 0.000 & 0.000 & 0.000 & 0.000 & 0.000 & 0.000 & 0.000 \\
\hline $\mathrm{N}$ & 621 & 621 & 621 & 621 & 621 & 621 & 621 & 621 \\
\hline
\end{tabular}

Notes: $\ddagger \mathrm{p}<0.10, \dagger \mathrm{p}<0.05, * \mathrm{p}<0.01$. Standard errors are heteroskedasticity-robust. Dependent variable is chemical sector FDI minus all other manufacturing FDI. RAC is relative abatement costs. Other covariates included in Specification 1 include: average production-worker wages, land prices, energy prices, total road mileage, unemployment rate, unionization rate, region dummies, and year dummies. Specifications 2 - 4 also include spatial versions of these controls. Specification 2 uses contiguous weights; Specification 3 uses weights based on U.S. Census regions; Specification 4 uses weights based on Crone's (1998/1999) regions. Excluded instruments are market proximity, population, and tax effort (Specifications 1 4) and the spatial counterparts (Specifications 2 - 4). Underid reports the p-value of the Kleibergen-Paap (2006) rk statistic with rejection implying identification; Overid reports the p-value of Hansen J statistic with rejection casting doubt on instruments' validity; Endog reports the p-value of endogeneity test of the endogenous regressors; Joint Sign. reports the p-value of Anderson-Rubin (1949) chi-square test of significance of the endogenous regressors; F-stat reports the Kleibergen-Paap F statistic for weak identification. See text for further details. 
Table 3. Determinants of Relative FDI: Pitt \& Rosenzweig - Type Falsification Test.

\begin{tabular}{|c|c|c|c|c|c|c|c|c|}
\hline & \multicolumn{2}{|c|}{ Spec (1) } & \multicolumn{2}{|c|}{ Spec (2) } & \multicolumn{2}{|c|}{ Spec (3) } & \multicolumn{2}{|c|}{ Spec (4) } \\
\hline & OLS & IV & OLS & IV & OLS & IV & OLS & IV \\
\hline \multicolumn{9}{|c|}{ Panel A. Plant, Property, and Equipment } \\
\hline $\ln (\mathrm{RAC})$ & $\begin{array}{c}-0.509 * \\
(0.153)\end{array}$ & $\begin{array}{c}0.490 \\
(0.342)\end{array}$ & $\begin{array}{c}-0.346 \dagger \\
(0.151)\end{array}$ & $\begin{array}{c}-0.528 \\
(1.116)\end{array}$ & $\begin{array}{c}-0.294 \ddagger \\
(0.156)\end{array}$ & $\begin{array}{l}1.047^{*} \\
(0.348)\end{array}$ & $\begin{array}{l}-0.573 * \\
(0.166)\end{array}$ & $\begin{array}{c}0.654 \\
(0.455)\end{array}$ \\
\hline $\ln ($ spatial RAC) & & & $\begin{array}{c}0.296 \\
(0.325)\end{array}$ & $\begin{array}{c}6.287 \\
(5.431)\end{array}$ & $\begin{array}{c}0.708 \\
(0.452)\end{array}$ & $\begin{array}{c}1.933 \\
(1.814)\end{array}$ & $\begin{array}{l}-0.313 \\
(0.604)\end{array}$ & $\begin{array}{c}1.306 \\
(2.045)\end{array}$ \\
\hline Underid Test & & 0.000 & & 0.000 & & 0.003 & & 0.000 \\
\hline F-stat & & 34.698 & & 7.589 & & 4.103 & & 8.025 \\
\hline Overid Test & & 0.149 & & 0.000 & & 0.446 & & 0.116 \\
\hline Endogeneity & & 0.000 & & 0.094 & & 0.000 & & 0.011 \\
\hline Joint Sign. Endog. & 0.001 & 0.079 & 0.052 & 0.000 & 0.016 & 0.008 & 0.002 & 0.119 \\
\hline $\mathrm{N}$ & 469 & 469 & 469 & 469 & 469 & 469 & 469 & 469 \\
\hline \multicolumn{9}{|c|}{ Panel B. Employment } \\
\hline $\ln (\mathrm{RAC})$ & $\begin{array}{c}0.156 \\
(0.117)\end{array}$ & $\begin{array}{c}0.099 \\
(0.229)\end{array}$ & $\begin{array}{c}0.069 \\
(0.113)\end{array}$ & $\begin{array}{c}-0.472 \\
(2.228)\end{array}$ & $\begin{array}{c}0.257 \dagger \\
(0.116)\end{array}$ & $\begin{array}{l}0.642 \dagger \\
(0.283)\end{array}$ & $\begin{array}{c}0.190 \\
(0.130)\end{array}$ & $\begin{array}{c}0.254 \\
(0.262)\end{array}$ \\
\hline $\ln ($ spatial RAC) & & & $\begin{array}{l}0.921^{*} \\
(0.226)\end{array}$ & $\begin{array}{c}7.805 \\
(8.739)\end{array}$ & $\begin{array}{l}1.071^{*} \\
(0.310)\end{array}$ & $\begin{array}{l}2.023 \dagger \\
(0.980)\end{array}$ & $\begin{array}{c}0.752 \\
(0.475)\end{array}$ & $\begin{array}{c}2.050 \\
(1.350)\end{array}$ \\
\hline Underid Test & & 0.000 & & 0.000 & & 0.000 & & 0.000 \\
\hline F-stat & & 34.627 & & 10.226 & & 9.067 & & 10.627 \\
\hline Overid Test & & 0.525 & & 0.000 & & 0.000 & & 0.358 \\
\hline Endogeneity & & 0.735 & & 0.868 & & 0.052 & & 0.535 \\
\hline Joint Sign. Endog. & 0.184 & 0.701 & 0.000 & 0.000 & 0.001 & 0.000 & 0.206 & 0.271 \\
\hline $\mathrm{N}$ & 546 & 546 & 546 & 546 & 546 & 546 & 546 & 546 \\
\hline
\end{tabular}

Notes: $\ddagger \mathrm{p}<0.10, \dagger \mathrm{p}<0.05,{ }^{*} \mathrm{p}<0.01$. Dependent variable is FDI in the food and kindred products sector minus all other manufacturing FDI except the chemical sector. See Table 2 for further details. 
Table 4. Determinants of Chemical Sector FDI: OLS, Lewbel (2010), and Klein \& Vella (2009) Approaches.

\begin{tabular}{|c|c|c|c|c|c|c|c|c|c|c|c|c|}
\hline & \multicolumn{3}{|c|}{ Spec (1) } & \multicolumn{3}{|c|}{ Spec (2) } & \multicolumn{3}{|c|}{ Spec (3) } & \multicolumn{3}{|c|}{ Spec (4) } \\
\hline & OLS & IV & $\mathbf{C F}$ & OLS & IV & $\mathbf{C F}$ & OLS & IV & $\mathbf{C F}$ & OLS & IV & $\mathbf{C F}$ \\
\hline \multicolumn{13}{|c|}{ Panel A. Plant, Property, and Equipment } \\
\hline $\ln (\mathrm{RAC})$ & $\begin{array}{c}-0.198 \dagger \\
(0.092)\end{array}$ & $\begin{array}{c}-0.558 * \\
(0.195)\end{array}$ & $\begin{array}{c}-0.812 \\
(0.577)\end{array}$ & $\begin{array}{l}-0.199 \dagger \\
(0.092)\end{array}$ & $\begin{array}{c}-0.474 \dagger \\
(0.200)\end{array}$ & $\begin{array}{c}-0.946 \\
(0.586)\end{array}$ & $\begin{array}{c}-0.153 \\
(0.095)\end{array}$ & $\begin{array}{c}-0.544^{*} \\
(0.192)\end{array}$ & $\begin{array}{c}-0.826 \\
(0.639)\end{array}$ & $\begin{array}{c}-0.222 \dagger \\
(0.098)\end{array}$ & $\begin{array}{c}-0.477 \dagger \\
(0.235)\end{array}$ & $\begin{array}{c}-0.801 \\
(0.702)\end{array}$ \\
\hline $\ln ($ spatial RAC) & & & & $\begin{array}{c}-0.264 \\
(0.169)\end{array}$ & $\begin{array}{c}-1.100 \\
(0.755)\end{array}$ & $\begin{array}{c}1.482 \\
(1.379)\end{array}$ & $\begin{array}{c}-0.313 \\
(0.208)\end{array}$ & $\begin{array}{c}-1.178 * \\
(0.430)\end{array}$ & $\begin{array}{l}-2.383 \\
(1.702)\end{array}$ & $\begin{array}{c}0.323 \\
(0.310)\end{array}$ & $\begin{array}{c}0.235 \\
(1.174)\end{array}$ & $\begin{array}{c}0.366 \\
(1.383)\end{array}$ \\
\hline Underid Test & & 0.000 & & & 0.000 & & & 0.000 & & & 0.000 & \\
\hline F-stat & & 41.951 & & & 7.000 & & & 17.955 & & & 5.977 & \\
\hline Overid Test & & 0.814 & & & 0.000 & & & 0.550 & & & 0.236 & \\
\hline Endogeneity & & 0.036 & & & 0.332 & & & 0.027 & & & 0.389 & \\
\hline Joint Sign. Endog. & 0.033 & 0.030 & 0.159 & 0.023 & 0.000 & 0.376 & 0.128 & 0.022 & 0.198 & 0.018 & 0.056 & 0.149 \\
\hline $\mathrm{N}$ & 563 & 563 & 563 & 563 & 563 & 563 & 563 & 563 & 563 & 563 & 563 & 563 \\
\hline \multicolumn{13}{|c|}{ Panel B. Employment } \\
\hline $\ln (\mathrm{RAC})$ & $-0.397^{*}$ & $-0.802 *$ & -0.669 & $-0.386 *$ & $-0.719 *$ & -0.663 & $-0.291 *$ & $-0.687 *$ & -0.498 & $-0.379 *$ & $-0.886 *$ & -0.457 \\
\hline & $(0.072)$ & $(0.135)$ & $(0.588)$ & $(0.072)$ & $(0.133)$ & $(0.584)$ & $(0.071)$ & $(0.136)$ & $(0.595)$ & $(0.077)$ & $(0.168)$ & $(0.691)$ \\
\hline ln(spatial RAC) & & & & $-0.343 \dagger$ & $-0.645 \ddagger$ & -0.189 & $-0.273 \ddagger$ & $-0.824 *$ & -0.790 & 0.270 & -0.591 & -1.198 \\
\hline & & & & $(0.134)$ & $(0.343)$ & $(0.733)$ & $(0.153)$ & $(0.305)$ & $(0.705)$ & $(0.254)$ & $(0.783)$ & $(1.045)$ \\
\hline Underid Test & & 0.000 & & & 0.000 & & & 0.000 & & & 0.000 & \\
\hline F-stat & & 68.248 & & & 16.340 & & & 23.233 & & & 9.851 & \\
\hline Overid Test & & 0.137 & & & 0.001 & & & 0.138 & & & 0.710 & \\
\hline Endogeneity & & 0.000 & & & 0.020 & & & 0.003 & & & 0.001 & \\
\hline Joint Sign. Endog. & 0.000 & 0.000 & 0.255 & 0.000 & 0.000 & 0.209 & 0.000 & 0.000 & 0.415 & 0.000 & 0.000 & 0.566 \\
\hline $\mathrm{N}$ & 621 & 621 & 621 & 621 & 621 & 621 & 621 & 621 & 621 & 621 & 621 & 621 \\
\hline
\end{tabular}

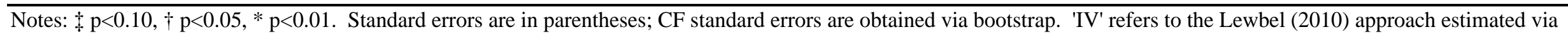

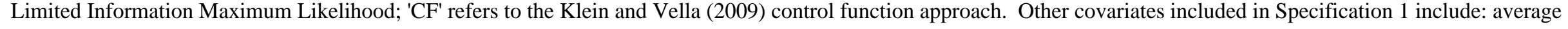

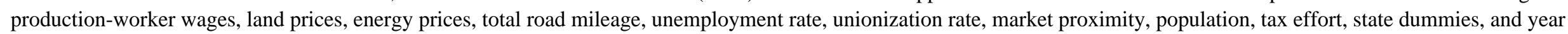

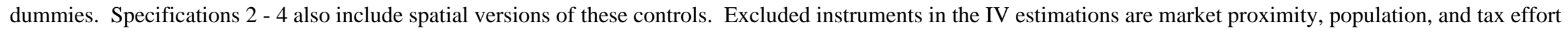

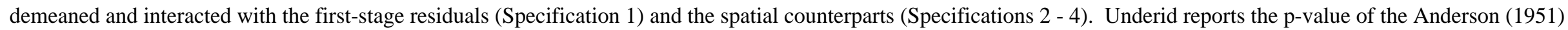

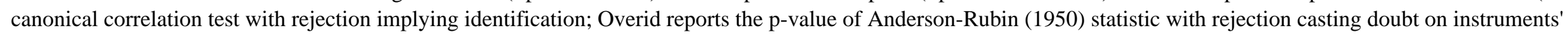

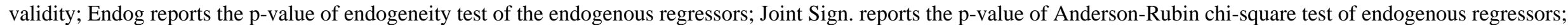
F-stat reports the Cragg and Donald (1993) F statistic for weak identification. See Table 2 for further details. 
Table 5. Determinants of Total Manufacturing FDI: OLS, Lewbel (2010), and Klein \& Vella (2009) Approaches.

\begin{tabular}{|c|c|c|c|c|c|c|c|c|c|c|c|c|}
\hline & \multicolumn{3}{|c|}{ Spec (1) } & \multicolumn{3}{|c|}{ Spec (2) } & \multicolumn{3}{|c|}{ Spec (3) } & \multicolumn{3}{|c|}{ Spec (4) } \\
\hline & OLS & IV & $\mathbf{C F}$ & OLS & IV & $\mathbf{C F}$ & OLS & IV & $\mathbf{C F}$ & OLS & IV & $\mathbf{C F}$ \\
\hline \multicolumn{13}{|c|}{ Panel A. Plant, Property, and Equipment } \\
\hline $\ln (\mathrm{RAC})$ & $\begin{array}{c}-0.079 \ddagger \\
(0.046)\end{array}$ & $\begin{array}{c}-0.155 \dagger \\
(0.073)\end{array}$ & $\begin{array}{c}-0.369 \\
(0.466)\end{array}$ & $\begin{array}{l}-0.082 \ddagger \\
(0.047)\end{array}$ & $\begin{array}{c}-0.285^{*} \\
(0.087)\end{array}$ & $\begin{array}{c}-0.472 \\
(0.356)\end{array}$ & $\begin{array}{c}-0.011 \\
(0.046)\end{array}$ & $\begin{array}{c}-0.021 \\
(0.074)\end{array}$ & $\begin{array}{l}-0.115 \\
(0.425)\end{array}$ & $\begin{array}{r}-0.086 \ddagger \\
(0.048)\end{array}$ & $\begin{array}{c}-0.110 \\
(0.083)\end{array}$ & $\begin{array}{c}-0.251 \\
(0.342)\end{array}$ \\
\hline $\ln ($ spatial RAC) & & & & $\begin{array}{l}-0.126 \\
(0.096)\end{array}$ & $\begin{array}{c}-1.166 * \\
(0.287)\end{array}$ & $\begin{array}{c}-0.902 \\
(1.021)\end{array}$ & $\begin{array}{c}-0.094 \\
(0.100)\end{array}$ & $\begin{array}{c}-0.198 \\
(0.201)\end{array}$ & $\begin{array}{c}0.577 \\
(0.548)\end{array}$ & $\begin{array}{c}0.181 \\
(0.159)\end{array}$ & $\begin{array}{c}0.690 \\
(0.471)\end{array}$ & $\begin{array}{c}-0.266 \\
(0.935)\end{array}$ \\
\hline Underid Test & & 0.000 & & & 0.000 & & & 0.000 & & & 0.000 & \\
\hline F-stat & & 137.812 & & & 15.194 & & & 34.614 & & & 14.245 & \\
\hline Overid Test & & 0.758 & & & 0.363 & & & 0.082 & & & 0.814 & \\
\hline Endogeneity & & 0.195 & & & 0.000 & & & 0.846 & & & 0.257 & \\
\hline Joint Sign. Endog. & 0.086 & 0.168 & 0.428 & 0.089 & 0.000 & 0.740 & 0.638 & 0.154 & 0.555 & 0.057 & 0.161 & 0.792 \\
\hline $\mathrm{N}$ & 811 & 811 & 811 & 811 & 811 & 811 & 811 & 811 & 811 & 811 & 811 & 811 \\
\hline \multicolumn{13}{|c|}{ Panel B. Employment } \\
\hline $\ln (\mathrm{RAC})$ & $\begin{array}{c}-0.013 \\
(0.041)\end{array}$ & $\begin{array}{c}0.042 \\
(0.065)\end{array}$ & $\begin{array}{c}0.042 \\
(0.411)\end{array}$ & $\begin{array}{l}-0.027 \\
(0.041)\end{array}$ & $\begin{array}{c}0.019 \\
(0.068)\end{array}$ & $\begin{array}{c}-0.034 \\
(0.553)\end{array}$ & $\begin{array}{c}0.053 \\
(0.040)\end{array}$ & $\begin{array}{c}0.167 * \\
(0.063)\end{array}$ & $\begin{array}{c}0.489 \\
(0.475)\end{array}$ & $\begin{array}{c}-0.042 \\
(0.043)\end{array}$ & $\begin{array}{c}-0.008 \\
(0.072)\end{array}$ & $\begin{array}{c}0.160 \\
(0.401)\end{array}$ \\
\hline $\ln$ (spatial RAC) & & & & $\begin{array}{c}0.039 \\
(0.086)\end{array}$ & $\begin{array}{c}-0.099 \\
(0.229)\end{array}$ & $\begin{array}{c}-0.310 \\
(0.475)\end{array}$ & $\begin{array}{c}-0.023 \\
(0.089)\end{array}$ & $\begin{array}{c}0.005 \\
(0.173)\end{array}$ & $\begin{array}{c}0.323 \\
(0.380)\end{array}$ & $\begin{array}{c}0.201 \\
(0.144)\end{array}$ & $\begin{array}{c}-0.027 \\
(0.418)\end{array}$ & $\begin{array}{c}-0.654 \\
(0.609)\end{array}$ \\
\hline Underid Test & & 0.000 & & & 0.000 & & & 0.000 & & & 0.000 & \\
\hline F-stat & & 147.699 & & & 17.159 & & & 37.330 & & & 14.560 & \\
\hline Overid Test & & 0.714 & & & 0.165 & & & 0.437 & & & 0.918 & \\
\hline Endogeneity & & 0.283 & & & 0.354 & & & 0.067 & & & 0.474 & \\
\hline Joint Sign. Endog. & 0.754 & 0.778 & 0.919 & 0.731 & 0.325 & 0.382 & 0.396 & 0.080 & 0.389 & 0.158 & 0.987 & 0.432 \\
\hline $\mathrm{N}$ & 814 & 814 & 814 & 814 & 814 & 814 & 814 & 814 & 814 & 814 & 814 & 814 \\
\hline
\end{tabular}

Notes: $\ddagger \mathrm{p}<0.10, \dagger \mathrm{p}<0.05, * \mathrm{p}<0.01$. See Table 4 for further details. 
Table 6. Monte Carlo Results.

\begin{tabular}{|c|c|c|c|c|c|c|c|c|c|c|}
\hline & \multicolumn{5}{|c|}{$\mathrm{N}=750$} & \multicolumn{5}{|c|}{$N=5000$} \\
\hline & OLS & PR - IV & Lewbel - IV & CF & $\begin{array}{c}\text { Traditional } \\
\text { IV }\end{array}$ & OLS & PR - IV & Lewbel - IV & $\mathbf{C F}$ & $\begin{array}{c}\text { Traditional } \\
\text { IV }\end{array}$ \\
\hline \multicolumn{11}{|l|}{ Coeff on Endogenous } \\
\hline \multicolumn{11}{|l|}{ Regressor \#1 } \\
\hline Bias & 0.394 & -0.008 & -0.003 & -0.025 & -0.002 & 0.396 & 0.007 & -0.003 & -0.006 & 0.007 \\
\hline Mean Absolute Error & 0.394 & 0.100 & 0.033 & 0.051 & 0.070 & 0.396 & 0.042 & 0.014 & 0.022 & 0.025 \\
\hline Root MSE & 0.396 & 0.125 & 0.043 & 0.067 & 0.089 & 0.396 & 0.053 & 0.017 & 0.027 & 0.030 \\
\hline \multicolumn{11}{|l|}{ Coeff on Endogenous } \\
\hline \multicolumn{11}{|l|}{ Regressor \#2 } \\
\hline Bias & -0.521 & -0.005 & 0.003 & 0.030 & -0.004 & -0.522 & 0.006 & 0.002 & 0.010 & -0.005 \\
\hline Mean Absolute Error & 0.521 & 0.099 & 0.035 & 0.058 & 0.070 & 0.522 & 0.042 & 0.013 & 0.024 & 0.028 \\
\hline Root MSE & 0.522 & 0.125 & 0.045 & 0.076 & 0.089 & 0.522 & 0.053 & 0.017 & 0.030 & 0.034 \\
\hline
\end{tabular}

" Notes: 1000 simulations used when N = 750; 100 simulations used when N = 5000. OLS = Ordinary Least Squares; PR-IV = Pitt and Rosenzweig (1990) IV estimator; Lewbel-IV = Lewbel (2010) IV estimator; CF = Klein and Vella (2009) control function estimator; Traditional-IV = IV estimator based on usual exclusion restrictions. MSE $=$ Mean Squared Error. See text for further details. 
Table 7. Empirical Monte Carlo Results: Lewbel (2010) and Klein \& Vella (2009) Approaches.

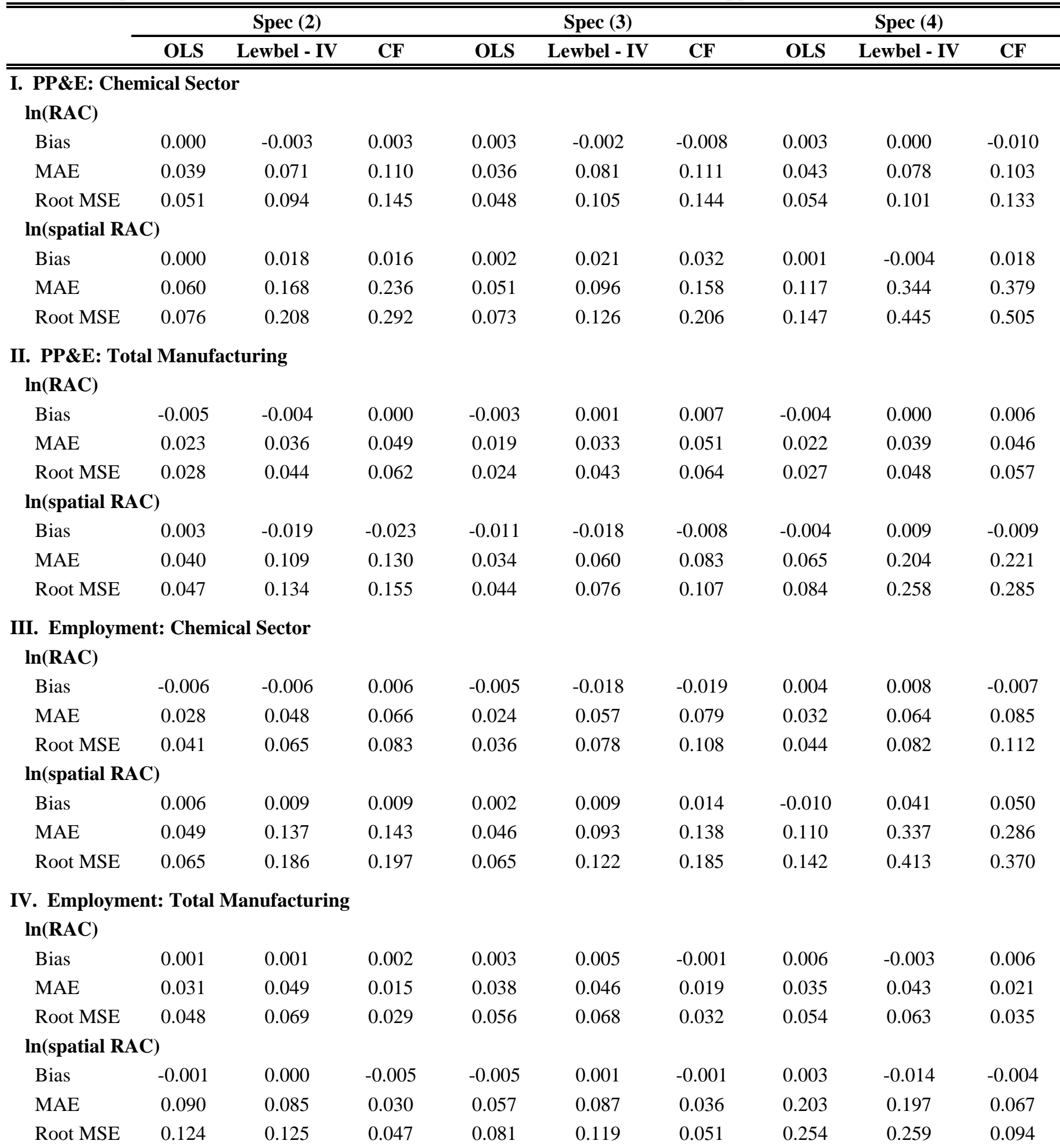

Notes: 100 simulations used, where $\ln (\mathrm{RAC})$ and $\ln ($ spatial RAC) are replaced by random draws from the empirical distribution of each variable. RAC is relative abatement costs. Specification 2 uses contiguous weights; Specification 3 uses weights based on U.S. Census regions; Specification 4 uses weights based on Crone's (1998/1999) regions. MAE = Mean Absolute Error; MSE = Mean Squared Error. See text and Table 6 for further details. 
Table 8. Empirical Monte Carlo Results: Pitt \& Rosenzweig (1990) Approach.

\begin{tabular}{|c|c|c|c|}
\hline & Spec (2) & Spec (3) & Spec (4) \\
\hline \multicolumn{4}{|l|}{ I. PP\&E } \\
\hline \multicolumn{4}{|l|}{$\ln (\mathrm{RAC})$} \\
\hline Bias & 0.054 & 0.019 & 0.007 \\
\hline MAE & 0.171 & 0.150 & 0.166 \\
\hline Root MSE & 0.211 & 0.184 & 0.201 \\
\hline \multicolumn{4}{|c|}{ In(spatial RAC) } \\
\hline Bias & 0.008 & -0.023 & 0.081 \\
\hline MAE & 0.139 & 0.199 & 0.503 \\
\hline Root MSE & 0.180 & 0.255 & 0.619 \\
\hline \multicolumn{4}{|c|}{ II. Employment } \\
\hline \multicolumn{4}{|l|}{$\ln (\mathrm{RAC})$} \\
\hline Bias & 0.000 & 0.011 & -0.004 \\
\hline MAE & 0.117 & 0.111 & 0.120 \\
\hline Root MSE & 0.158 & 0.145 & 0.159 \\
\hline \multicolumn{4}{|c|}{ In(spatial RAC) } \\
\hline Bias & 0.005 & -0.024 & 0.008 \\
\hline MAE & 0.120 & 0.135 & 0.447 \\
\hline Root MSE & 0.151 & 0.178 & 0.558 \\
\hline
\end{tabular}

Notes: 100 simulations used, where $\ln (\mathrm{RAC})$ and $\ln ($ spatial RAC) are replaced by random draws from the empirical distribution of each variable. Dependent variable is chemical sector FDI minus all other manufacturing FDI. MAE = Mean Absolute Error; MSE = Mean Squared Error. See text and Table 7 for further details. 